\title{
THE INFLUENCE OF THE EPIDERMAL GROWTH FACTOR RECEPTOR ON THE DNA DAMAGE RESPONSE AS EXAMINED THROUGH CLATHRIN AFFILIATED SIGNALLING COMPLEXES
}

\author{
By
}

\section{Ivan Boras}

BSc. Hon. Ryerson University 2017

\author{
A thesis presented to Ryerson University \\ in partial fulfillment of the \\ requirements for the degree of \\ Master of Science \\ in the program of \\ Molecular Science
}

Toronto, Ontario, Canada, 2019

C Ivan Boras, 2019 


\section{AUTHOUR'S DECLARATION}

I hereby declare that I am the sole author of this thesis. This is a true copy of the thesis, including any required final revisions, as accepted by my examiners.

I authorize Ryerson University to lend this thesis to other institutions or individuals for the purpose of scholarly research.

I further authorize Ryerson University to reproduce this thesis by photocopying or by other means, in total or in part, at the request of other institutions or individuals for the purpose of scholarly research.

I understand that my thesis may be made electronically available to the public. 
The influence of the epidermal growth factor receptor on the DNA damage response as examined through clathrin affiliated signalling complexes Master of Science 2019 Ivan Boras Ryerson University

\begin{abstract}
The EGFR is an oncogene that when dysregulated, can cause tumour progression. Upon binding ligand, EGFR triggers activation of many signalling pathways including PI3K/Akt, RasErk, STAT, and PLC $\gamma 1$. EGFR may also control DNA repair mechanism, although this remains poorly understood. Control of DNA repair by EGFR may be particularly relevant in the context of action and resistance of cancer drugs that cause DNA damage (eg. Cisplatin). I have examined how acute activation (10-30 minutes) of EGFR regulates DNA repair induced by cisplatin treatments and by examination of repair-markers such as $\gamma \mathrm{H} 2 \mathrm{AX}$. I observed that as little as 10 minutes of EGF stimulation is sufficient to elicit remodelling of $\gamma \mathrm{H} 2 \mathrm{AX}$ in chronic cisplatintreated cells. Using these methods, I dissected the EGFR signals and membrane traffic phenomena required for EGFR-dependent control of DNA repair. This work may reveal new ways to enhance the efficacy of existing chemotherapies, such as cisplatin, for cancer treatment.
\end{abstract}




\section{ACKNOWLEDGMENTS}

First and foremost I would like to thank Dr. Costin Antonescu, for his assistance in my completing this degree. For his kindness and willingness to help when things were rather trying during my master's and ability to give great amounts of advice, thank you! You have done an amazing job as a mentor, not only to myself, but to everyone in this lab. Thank you for giving me an opportunity to explore what it's like to be a scientist and examine a field that has always been of great interest to me.

To my lab mates, past and present. Thank you all for creating an environment where we can all get along in the pursuit of science and science related activities. To my mentor Stephen Bautista, thank you for always being available to answer my questions and taking time out of your day to help! To Stefanie Lucarelli, thank you for always making the extra effort to make sure that everything is taken care of in the lab, and thank you for crosswords. To Farnaz Fekri, thank you for being such an approachable person and always being willing to help others in the lab. Thank you, John Abousawan, for always providing valuable feedback and making the lab a fun place. To Sadia Rahmani, a lab mate and good friend since we began in this lab together 3 years ago, thank you for always being here for you fellow labmate and providing breaks from being stuck in the lab setting. To everyone else in the lab, Louis Lo, Michael Sugiyama, Karolina Zak, Nikol Uki, Laura Orafiamma, Dafne Vural, and the countless undergraduates, thank you!

To my friends, each and every one of you helped make this journey possible. To Brandon Foley, although most of the time we don't talk much about science I've always appreciated the chance to relax and do something to get off my mind everything for awhile, thank you for providing a break. To Melissa Iazzi, few people I know can be as committed to the work they do in the lab and caring about the people involved in their life, and you have excelled at both, thank you for 
being such an all around great human being and making everyone's lives better as a result. To Mackenzie Brauer, for all the perspective and feedback you have given, as well as all the efforts you have put in to improve the work of those around you and to never stop improving yourself, thank you for your service. To Sarah Birstonas, you are one of the strongest people I know, thank you for always taking time to be yourself, you have worked tremendously hard to get to where you are now and you should be proud of yourself for everything you have conquered to get here, thank you! To all the others not named here, but knowing who you are, thank you!

Mojoj obitelji hvala za sve. Ja znam da je bio vrlo tesko doci u Kanadu bez znanja jezika i kulture. Ja znam da ste vi ovo ucinili da mi mozemo imati bolji zivot. Hvala za sve! 
TABLE OF CONTENTS

AUTHOUR'S DECLARATION ii

ABSTRACT iii

ACKNOWLEDGEMENTS iv

LIST OF FIGURES viii

LIST OF ABBREVIATIONS ix

1.0 INTRODUCTION 1

1.1 The Epidermal Growth Factor Receptor 2

1.1.1 The Receptor Tyrosine Kinase 2

1.1.1.1 Mechanisms of Signalling Cascades 3

1.1.1.2 Overview of Cell Mechanisms Influenced 3 by RTK Activation

1.1.2 EGFR Activation and Signalling 4

1.1.2.1 Ligand and Trans-autophosphorylation 5 Induced Activation

1.1.2.2 Signalling Pathways $\quad 7$

a. PI3K-Akt Signalling Pathway 7

b. Ras-Raf-ERK Signalling Pathway 9

1.1.3 EGFR at the Plasma Membrane 10

$\begin{array}{ll}\text { 1.2 Cellular Compartments } & 11\end{array}$

1.2.1 Clathrin Mediated Endocytosis 11

1.2.1.1 Overview of CME

1.2.1.2 CME in Receptor Signalling 14

1.2.2 Regulation of receptor signalling by clathrin at 15

the plasma membrane

1.2.2.1 Clathrin-dependent interactions within 15

the plasma membrane regulate EGFR signalling

1.2.2.2 The Mammalian-Membrane Two-Hybrid Assay 17

1.3 DNA Damage and Repair $\quad 19$

1.3.1 Types of DNA Damage 20

1.3.2 DNA Repair 20

1.3.2.1 Repair of double strand breaks by Homologous 21

Recombination

1.3.2.2 Non-Homologous End Joining 22

1.3.3 Signalling Complexes in the DNA Damage Response 24

1.3.4 DNA Damage and Cancer 24

1.3.4.1 Accumulation of Mutations 25

1.3.4.2 DNA damage response proteins that function $\quad 26$

as tumor suppressors

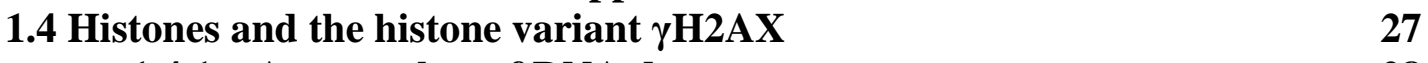

1.4.1 As a marker of DNA damage 28 
1.5 Cisplatin and other genotoxic chemotherapeutics 29

1.5.1 Use of cisplatin in cancer therapy 30

1.5.1.1 Mechanisms of action 30

1.6 Receptor signalling controlling DNA damage and repair 31

1.7 Rationale $\quad 32$

1.8 Hypothesis and Objectives $\quad 32$

1.9 Experimental Design 33

$\begin{array}{ll}\text { 2.0 RESULTS } & 35\end{array}$

3.0 DISCUSSION $\quad 55$

3.1 Acute EGF stimulation decreased $\gamma \mathrm{H} 2 \mathrm{AX}$ levels in $\quad 55$ cisplatin exposed cells

3.2 PI3K inhibition decreased $\gamma \mathrm{H} 2 \mathrm{AX}$ expression in cisplatin exposed cells

3.3 ERK inhibition antagonizes acute EHFR stimulations effect on $\gamma \mathrm{H} 2 \mathrm{AX}$ expression in cisplatin exposed cells

3.4 Protein-protein interactions can be examined by 64 the MaMTH assay in clathrin perturbed cells

$\begin{array}{ll}\text { REFERENCES } & 79\end{array}$ 


\section{LIST OF FIGURES}

Figure 1. Overview of EGFR in the monomer and homodimer form 6

Figure 2. The PI3K-AKT Signalling Pathway as regulated by EGFR 8

Figure 3. Ras-Raf-Erk Signalling Pathway 10

Figure 4. Clathrin Mediated Endocytosis 13

Figure 5. Homologous Recombination 2

Figure 6. Nonhomologous End Joining 23

Figure 7. EGFR mediated H2AX phosphorylation. 34

Figure 8. Acute stimulation with EGF decrease the detection of $\gamma \mathrm{H} 2 \mathrm{AX}$ in 35 cisplatin damaged MDA-MB-231 cells

Figure 9. PI3K pathway inhibition reverses the DNA damage response in cisplatin exposed cells 37

Figure 10. Variation in individual experiments alters the expression levels of $\gamma \mathrm{H} 2 \mathrm{AX}$ as seen by $\mathbf{4 0}$ the medians and standard error of the mean

Figure 11. PI3K pathway inhibition alters the distribution of the cells with $\gamma \mathrm{H} 2 \mathrm{AX}$ expression 4

Figure 12. Exposure to cisplatin induces an increase in the percentage of MDA-MB-231 cells 44 with DNA damage

Figure 13. ERK pathway inhibition reverses the DNA damage response in acutely EGF stimulated cisplatin damaged cells

Figure 14. Variation in individual experiments alters the expression levels of $\gamma \mathrm{H} 2 \mathrm{AX}$ as seen by the medians and standard error of the mean

Figure 15. ERK pathway inhibition reverses the DNA damage response in acutely EGF stimulated cisplatin damaged cells

Figure 16. Exposure to cisplatin induces an increase in the percentage of MDA-MB-231 cells with DNA damage

Figure 17. Examination of PitStop2 influence of protein-protein interactions in HEK 293 cells

Figure 18. EGFR mediates $\mathrm{H} 2 \mathrm{AX}$ phosphorylation through the Ras/Raf/Erk signalling pathway 


\section{LIST OF ABBREVIATIONS}

AP2 - Adaptor protein 2

ATM - Ataxia-telangiectasia mutated

BER- Base excision repair

BRCT - BRCA1 C-terminal

CCPs - Clathrin coated pits

CME - Clathrin mediated endocytosis

DAG - Diacylglycerol

dd $\mathrm{H}_{2} \mathrm{O}$ - Double-distilled $\mathrm{H}_{2} \mathrm{O}$

DMSO - Dimethyl sulfoxide

DSBs - Double stranded breaks

EGF - Epidermal growth factor

EGFR - Epidermal growth factor receptor

EREG - Epiregulin

FoxO - Forkhead Box O Family

GAB1 - GRB2 associated binder 1

GADD45 - growth arrest and DNA damage 45

GAK - G-associated kinase

GEF - Guanine nucleotide exchange factor

GG - Global genome

GPCRs - Guanine coupled protein receptors

H(D)R - Homolog recombination or homology-directed repair

HSC70 - Heat shock cognate 70

IP3 - Inositol-1,4,5-triphosphate

JAK-STAT - Janus kinase-signal transducer and activator of transcription

MaMTH - Mammalian-Membrane Two-Hybrid Assay

MDM2 - Mouse double minute homolog 2

MMR - Mismatch repair

MRN - Mre11-Rad50-Nbs1

mTORC - Mechanistic target of rapamycin complex

NER - Nucleotide excision repair

PARP - Protein poly-ADP-ribose-polymerase 
PDK1 - Phosphoinositide-dependent kinase 1

PH - Pleckstrin homology

PI3K - Phosphatidylinositol-3-kinase

PIKKs - Phosphoinositide-3-kinase-related protein kinases

PIP2 -Phosphatidylinositol-4,5-bisphosphate

PIP3 - Phosphatidylinositol-3,4,5-triphsophate

PLC - Phospholipase C

PNKP - Polynucleotide kinase-phosphatase

PTB- Phosphotyrosine binding

PTEN - Phosphatase and tensin homolog

ROS - Reactive oxidative species

RTK - Receptor tyrosine kinase

SH2 - Src homology 2

Sos - Son of sevenless

SSBs - Single stranded breaks

TC- Transcription coupled

TDP1 - Tyrosyl-DNA-phsophodiesterase 1

TGF $\alpha$ - Transforming growth factor- $\alpha$

TKD - Tyrosine kinase domain

TP53 - Tumour suppressor 53

TSC2 - Tuberous sclerosis complex 2

XRCC4 - X-ray repair complementing defective repair protein in Chinese hamster cells 4 


\subsection{INTRODUCTION}

Cells interact with their environment through molecules on their plasma membrane. Some these of interactions supply the cell with essential factors such as various nutrients and chemical cues from other cells, while others supply adhesion sites and many other factors. In addition to supplying these essential molecules and interactions, at various times the cellular environment may also result in exposure of cells to damaging molecules, such as agents that cause DNA damage. In this circumstance, the DNA damage response is engaged and regulates the ability of the cell to mediate cell survival and return to homeostasis and normal cell function (Jackson \& Bartek, 2009). Distinct regulation of the DNA damage response under various environmental contexts, such as in response to different chemical cues and intercellular signals, is essential. The epidermal growth factor (EGF) receptor (EGFR) regulates many cellular processes integral to cell physiology by activation of many intracellular signalling pathways that are pro-survival and mitogenic (Jackson \& Bartek, 2009; Lemmon \& Schlessinger, 2010; Zhang, Gureasko, Shen, Cole, \& Kuriyan, 2006). Importantly, disruption of the normal cellular regulation of EGFR occurs in some cancer cells and drives the progression and growth of certain types of tumors including triple-negative breast cancer and some lung cancers. Obtaining a better understanding of the regulation of EGFR, in particular how this receptor may impact the cellular response to DNA damage is thus important, in particular to devise better therapies to treat cancer patients. EGFR is predominantly located at the plasma

membrane, where clathrin mediated endocytosis (CME) regulates receptor internalization and recycling and alters the mosaic of proteins proximal to the cell surface (Garay et al., 2015; LeytonPuig et al., 2017). My thesis will examine how EGFR may regulate the DNA damage response and develop assays that may allow better understanding of the regulation of EGFR interactions at the plasma membrane. 


\subsection{The Epidermal Growth Factor Receptor}

EGFR is a member of the receptor tyrosine kinase (RTK) family, of which there are 58 members and 20 subfamilies in humans (Lemmon and Schlessinger, 2010). Ligand binding by EGFR activates the receptor, triggering a conformational change that results in activation of the receptor intrinsic kinase activity, in turn leading to receptor autophosphorylation on tyrosine residues and binding of adaptor (scaffolding) proteins (Freed et al., 2017; Lemmon and Schlessinger, 2010; Zhang et al., 2006). The proteins that make up the resulting signalling complexes that associate with EGFR influence the ability of the receptor to regulate proliferation, differentiation, and cell survival (Freed et al., 2017; Lemmon and Schlessinger, 2010; Oda et al., 2005; Zhang et al., 2006).

\subsubsection{The Receptor Tyrosine Kinase Family}

The RTK family of receptors is defined by the presence of an intrinsic intracellular protein tyrosine kinase domain (TKD) in receptors of this family (Lemmon and Schlessinger, 2010). In most cases (albeit with a few exceptions), ligand binding acts to trigger a conformational change that leads to kinase domain activation and tyrosine residue phosphorylation by the protein TKD (Lemmon and Schlessinger, 2010; Lucarelli et al., 2016a; Yao et al., 2017). The presence of these phosphorylated residues allows for the recruitment of scaffolding and adaptor proteins to the receptor, regulating the signalling complexes formed at the plasma membrane and the phosphorylation of proteins leading to activation of several specific signalling cascades (Lemmon and Schlessinger, 2010; Lucarelli et al., 2016a; Yao et al., 2017). 


\subsubsection{Mechanisms of Signalling Cascades}

Formation of these specific signalling complexes results from the binding of scaffolding or adaptor proteins to the phosphorylated tyrosine residues of RTKs (Schlessinger, 2000). These adaptor (scaffolding) proteins containing Src homology 2 (SH2) and/or phosphotyrosine binding (PTB) domains are recruited to the phosphorylated tyrosine residues and bind additional proteins (Schlessinger, 2000). The signalling complexes formed are supported by either protein-protein interactions or phospholipid binding modules (Lemmon and Schlessinger, 2010). These modular adaptor structures regulate signalling through a few proteins, but allow for diverse signalling to occur as a result of the number of permutations of modules that can be created (Lemmon and Schlessinger, 2010).

\subsubsection{Overview of Cell Mechanisms Influenced by RTK activation}

The RTK family of receptors regulates proliferation, differentiation, and cell survival (Oda et al., 2005). Signalling cascades that are dependent on the RTK family of receptors have an hourglass or bow-tie like schematic, in which a large number of inputs (extracellular ligands) make use of a small number of common intracellular signalling pathways to trigger a wide range of distinct and specific cellular outcomes (Kholodenko et al., 1999; Oda et al., 2005). In this context, many different ligands each lead to the recruitment of a few common adaptor proteins and signalling modules to their specific receptor, allowing for activation of a few key signalling cascades by RTKs (Kholodenko et al., 1999; Oda et al., 2005). Varying affinities of ligand-receptor binding can add robustness to a system as differential binding can influence the intensity and duration of the signal produced (Freed et al., 2017; Lemmon and Schlessinger, 2010; Zhang et al., 2006). Understanding the specific properties of activation of intracellular signalling by each 
receptor is thus essential to understanding how different receptors can use a common set of intracellular signalling pathways to elicit distinct cellular outcomes. To do so, I focus here on understanding the specific factors that control EGFR signalling.

\subsubsection{EGFR Activation and Signalling}

EGFR regulates processes that influence the early stages of embryotic development, as well as the central nervous system (Burgess, 2008). EGFR is expressed in many cells and tissues throughout the life cycle of the organisms it is found in, and knockout studies have shown that disruption of EGFR and other RTKs or their ligands can have a spectrum of effects on the physiology of the test subjects (Burgess, 2008). For example, EGFR knockout mice have impaired development of bones, as studied through embryonic development, as a result of delayed osteoclast recruitment and vascularization (Wang et al., 2004). Depending on whether EGFR is perturbed in the whole animal or in specific tissues, studies have shown that perturbation of EGFR can have varied effects ranging from changes in the phenotype of the mouse that is otherwise viable (some tissue-specific EGFR knockouts), to having the mice die early in the post-natal period due to complications from certain combinations of EGFR inhibition (whole-body knockout) (Burgess, 2008; Huang et al., 2012; Miettinen et al., 1995; Wang et al., 2004).

At the cellular and molecular level, EGFR is well characterized, and it is a member of the ErbB subfamily of RTK receptors (Lemmon and Schlessinger, 2010). Ligand induced binding is viewed as the primary mechanism of activation for EGFR (Lemmon and Schlessinger, 2010; Zhang et al., 2006). Some dimerization of receptors is ligand independent, but these dimers are transient and do not result in activation of the kinase domain. Ligand-binding induces a specific conformational change in the extracellular domain unique for the ErbB subfamily of RTK 
receptors that facilitates a specific type of receptor dimerization that leads to activation of the kinase domains (Lemmon and Schlessinger, 2010; Zhang et al., 2006). However, the composition of the dimer interface may depend on the EGFR ligand present, which may result in distinct signalling outcomes for each EGFR ligand (Freed et al., 2017). Dysregulation of the receptor can alter signal transduction from the cell surface (Hanahan and Weinberg, 2011).

\subsubsection{Ligand and Trans-autophosphorylation Induced Activation}

Activation of EGFR can occur by binding of ligands such as the epidermal growth factor (EGF), epiregulin (EREG), transforming growth factor- $\alpha$ (TGF $\alpha$ ) and other ligands (Freed et al., 2017). Ligand binding in EGFR is unique compared to many other RTKs, in that the ligand present does not bridge interaction between the two receptors that form a dimer at the surface, but instead results in an intra-receptor interaction between an individual receptor's extracellular domains (Zhang et al., 2006). The ligand binds to domains I and III of the extracellular region of EGFR, which are similar in structure to $\beta$-helix LRR solenoid domains (Lemmon and Schlessinger, 2010; Zhang et al., 2006). Ligand binding triggers a conformational change in the receptor, as a dimerization arm in domain II is no longer autoinhibited and is able to interact with domain II of another EGFR molecule, and this interaction underlies the formation of the stable, signallingactive receptor dimer (Lemmon and Schlessinger, 2010; Zhang et al., 2006). Once this activation occurs, the conformational changes initiated in the extracellular regions of EGFR trigger an additional set of conformational changes in the tyrosine kinase domain (TKD) as the C-terminus of the TKD of one EGFR interacts with the N-terminus of the other EGFR subunit (Huse and Kuriyan, 2002; Lemmon and Schlessinger, 2010; Zhang et al., 2006). In the inactive form the TKD leucine residues 834 and 837 are inhibited by binding to an $\alpha$-helix (Huse and Kuriyan, 2002; 
Lemmon and Schlessinger, 2010; Zhang et al., 2006). In the active conformation, leucine residues 834 and 837 are exposed and the ion-pair composed of lysine 721 and glutamate 738 (Huse and Kuriyan, 2002; Lemmon and Schlessinger, 2010; Zhang et al., 2006). The interaction between the $\mathrm{C}$ and $\mathrm{N}$-termini of the TKDs of the subunits within this dimer allows for the activation of the second receptor molecule without the need for activation loop phosphorylation (Lemmon and Schlessinger, 2010; Zhang et al., 2006). The active kinase domain of EGFR is then able to phosphorylate many tyrosine residues on the EGFR C-terminus. Additional scaffolding and adaptor proteins, as well as other modular cell signalling components, are then recruited to sites of tyrosine phosphorylation on the cytosolic tail of the receptor (Huse and Kuriyan, 2002; Lemmon and Schlessinger, 2010; Zhang et al., 2006). I next examine how specific signalling pathways are activated following this phenomenon.

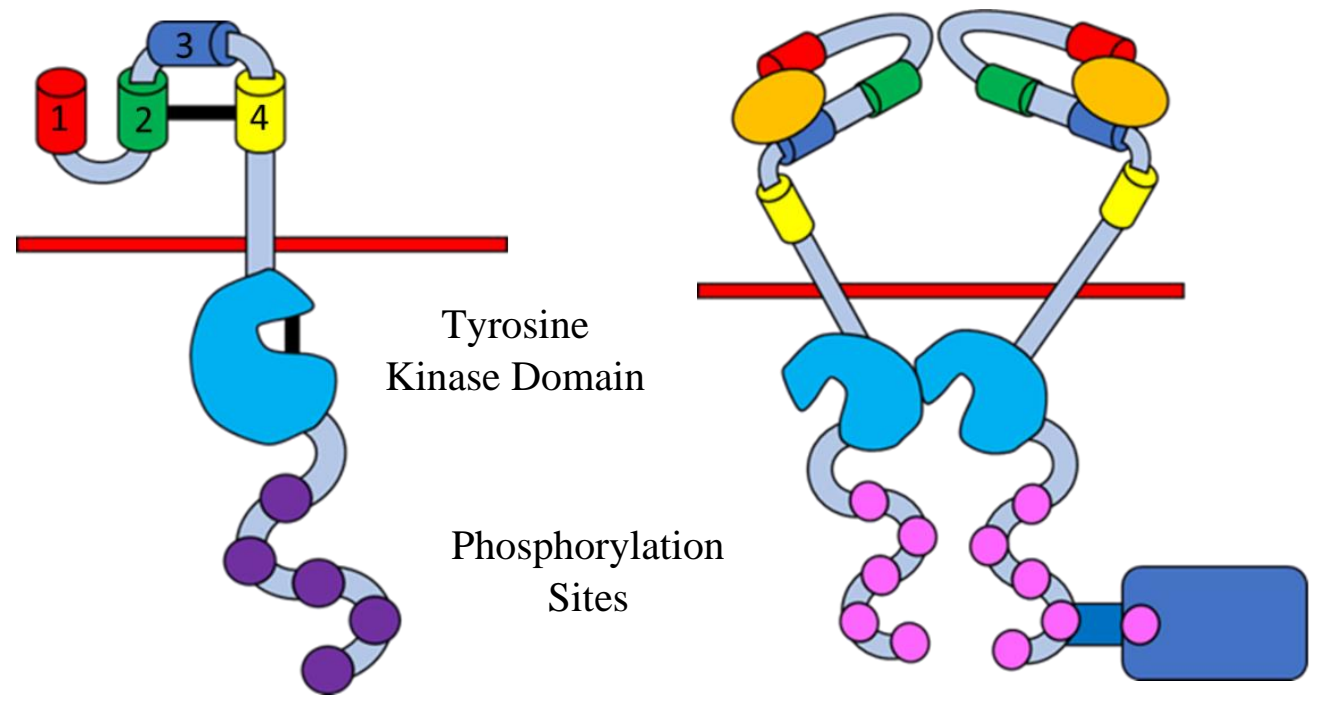

\section{Downstream Effector Protein}

Figure 1. Overview of EGFR in the monomer and homodimer form. In the monomer form, EGFR is unphosphorylated on the cytosolic tail and TKD has not yet had its activation loop altered, resulting in no interactions with additional EGFR proteins at the plasma membrane. After ligand binding, the EGFR monomer has undergone a conformational change, the ligand has bound so as to allow domains I and III of the extracellular receptor to interact, while the TKD has now had its activation loop phosphorylated and thus a conformational change allows the $\mathrm{C}$ terminus of one TKD to interact with the $\mathrm{N}$ terminus of another, tyrosine residues have become phosphorylated and scaffolding proteins are now able to bind the receptor (Schlessinger, 2000; Zhang et al., 2006). 


\subsubsection{Signalling Pathways}

Transduction of extracellular cues by receptors into intracellular signals is the basis of the regulation of cell function by these receptors (Funk, 2006; Hanahan and Weinberg, 2011; Oda et al., 2005). Elucidation of the signalling pathways and the key components associated with them allows for a better understanding of the control of outputs as a result of signal transduction. I next examine several key signaling pathways triggered by EGFR.

\section{a. PI3K-Akt Signalling Pathway}

The phosphatidylinositol-3-kinase (PI3K) Akt pathway regulates the proliferation and growth of cells (Er et al., 2013). PI3K has two subunits, a regulatory subunit and catalytic subunit (Scaltriti and Baselga, 2006). For example, the p85 regulatory subunit regulates binding to other proteins as well as the catalytic activity of the p110 subunit, while the p110 subunit harbors the kinase domain for PI3K activity (Scaltriti and Baselga, 2006). In general, ligand-activated RTKs can recruit PI3K directly through the $\mathrm{SH} 2$ domain of the $\mathrm{p} 85$ regulatory subunit, or indirectly by adaptor protein complexes such as Grb2 and Grb2 associated binder 1 (Gab1) (Liang and Slingerland, 2003; McCubrey et al., 2012; Mendoza et al., 2011). Recruitment of PI3K to a complex involving the cytosolic tail of the receptor allows for activation of the lipid kinase activity of PI3K, which results in phosphorylation of phosphoinositide phosphatidylinositol-4,5biphosphate (PIP2) at the D3 position, producing phosphatidylinositol-3,4,5-triphosphate (PIP3) (LoPiccolo et al., 2008). PIP3 is very scarce in the absence of receptor signalling, activation of receptors such as EGFR leads to a substantial production of PIP3, thus allowing downstream signalling events to become activated. 


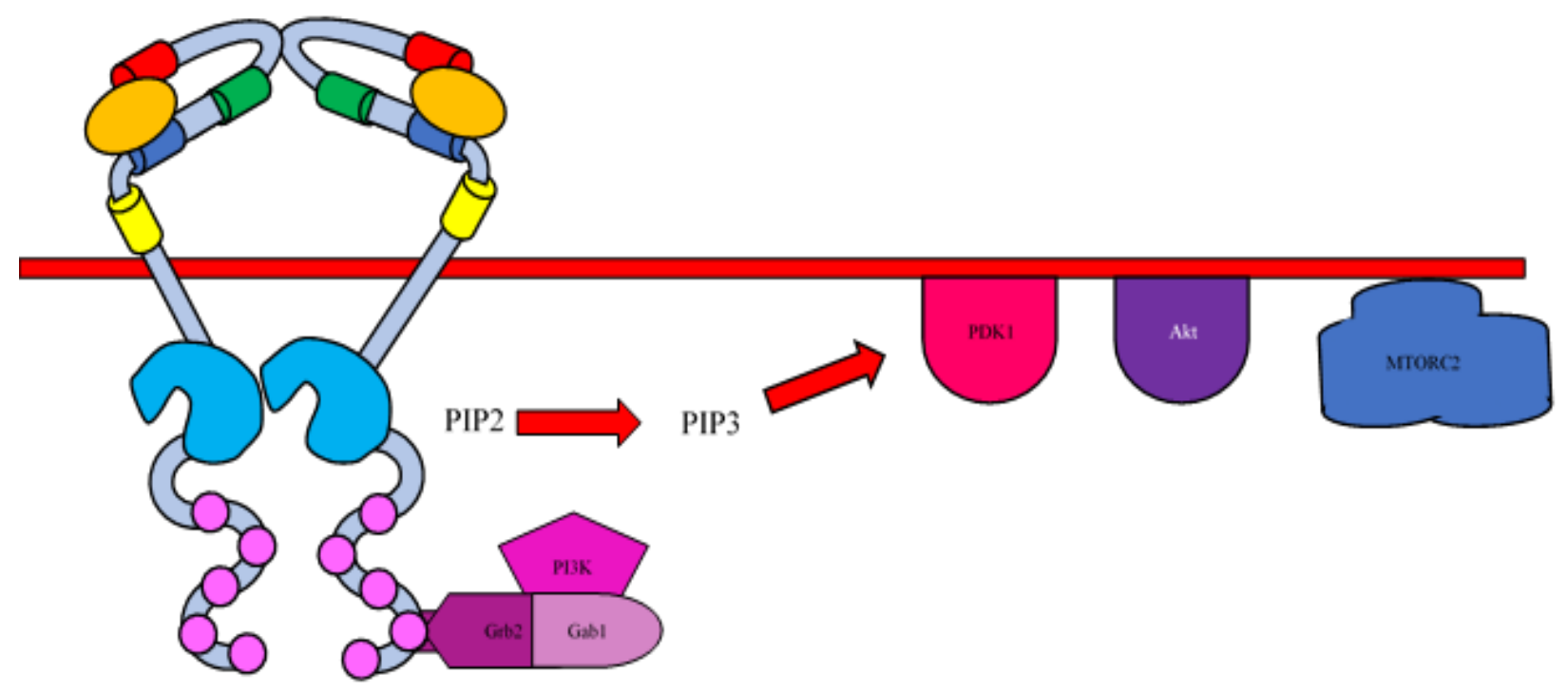

Figure 2. The PI3K-AKT Signalling Pathway as regulated by EGFR. When EGFR is activated the adaptor proteins Grb2 and Gab1 are able to bind to a phosphor-tyrosine site on the cytosolic tail of the receptor. PI3K is then able to bind to this scaffolding complex and convert PIP2 to PIP3 through phosphorylation of the D3 position. PIP3 recruits Akt to the plasma membrane through a PH domain. Akt is then activated through phosphorylation on residues T308 and S473, by PDK1 and mTORC2 respectfully (Ballou and Lin, 2008; Mattoon et al., 2004). Figure inspired by additional work from Antonescu, C.N.

For EGFR, PI3K activation does not occur by direct binding of PI3K to EGFR, but instead requires the adaptor proteins Grb2 and Gab1 (Mattoon et al., 2004). PIP3 acts as a membrane ligand to recruit several different signalling proteins. PIP3 recruits the kinase Akt to the plasma membrane through interactions mediated by the pleckstrin homology $(\mathrm{PH})$ domain of Akt (Liang and Slingerland, 2003; McCubrey et al., 2012; Mendoza et al., 2011). Following Akt binding to PIP3, phosphorylation of Akt at T308 and S473 by the phosphoinositide-dependent kinase 1 (PDK1) and mechanistic target of rapamycin complex 2 (mTORC2) are required for activation (Ballou and Lin, 2008). Once activated at the plasma membrane Akt has the capacity to phosphorylate downstream effectors on serine and threonine residues, influencing aspects of cell growth and metabolism, as seen through interactions with nutrients detectors such as mTORC1 (Mendoza et al., 2011; Porta et al., 2014). For example, signaling activated by Akt promotes mTORC1 recruitment to the lysosome, which results in regulation of various aspects of cell growth 
and biomass production, including control of protein synthesis (Sugiyama et al., 2019). Phosphatase and tensin homolog (PTEN) regulates the negative feedback loop responsible for Akt by dephosphorylating PIP3 preventing Akt recruitment to the plasma membrane (Sugiyama et al., 2019).

\section{b. Ras-Raf-ERK Signalling pathway}

Ligand-binding by EGFR leads to autophosphorylation on several residues, which in addition to activation of PI3K-Akt signalling also triggers activation of Ras-Raf-ERK signalling. To activate the latter, the adaptor protein Shc1 is recruited via its $\mathrm{SH} 2$ domain to a motif on EGFR that includes pY1173 (Batzer et al., 1994). This in turn allows recruitment of son of sevenless (Sos) to Shc1, which is enhanced by additional interactions with Grb2 bound to a motif spanning pY1068 on EGFR (McCubrey et al., 2012; Scaltriti and Baselga, 2006; Zheng et al., 2013). The Shc1-Gsb2-SOS complex thus bound to the cytosolic region of the receptor is then able to recruit Ras-GDP, which is activated by conversion to Ras-GTP mediated by Sos, a guanine nucleotide exchange factor (GEF) (McCubrey et al., 2007, 2012; Mendoza et al., 2011; Scaltriti and Baselga, 2006).

There are three well characterized isoforms of Ras, H, N, and K (Matallanas et al., 2003). The difference between the isoforms is in the $\mathrm{C}$ terminal hypervariable region; which includes the CAAX box, in which the cysteine is farnesylated (Matallanas et al., 2003). An additional modifications are required to recruit the Ras protein to the plasma membrane, such as the palmitoylation of C181 in N-Ras and C184 in H-Ras (Matallanas et al., 2003). The K-Ras isoform receives the secondary signal via a polybasic motif consisting of several lysine residues (Matallanas et al., 2003). Activated Ras then recruits the protein kinase Raf, and leads to the 
promotion of the ERK1/2 family kinases and the cascade of phosphorylation reactions leading to gene expression (Li et al., 2016).

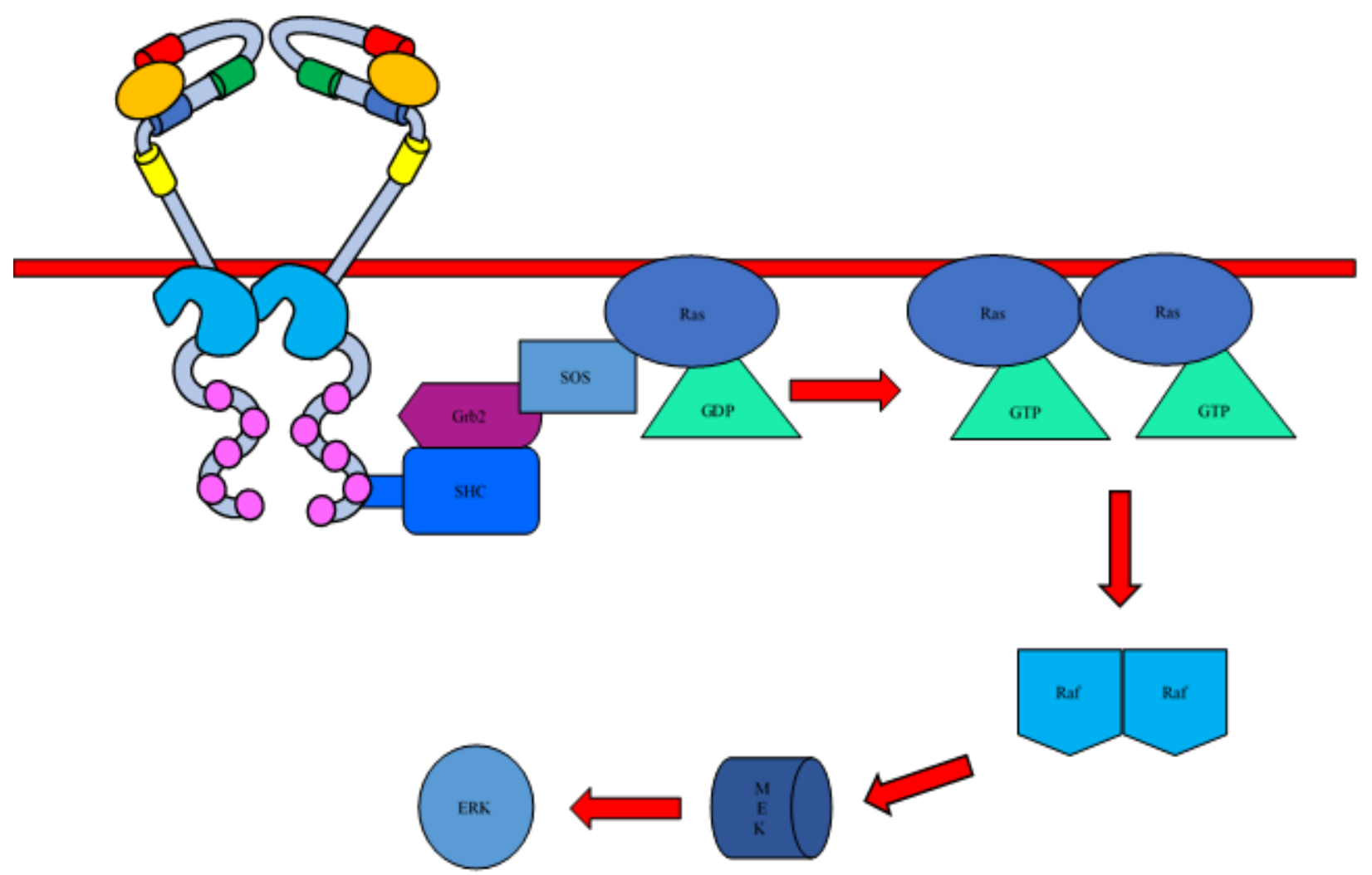

Figure 3. Ras-Raf-Erk Signalling Pathway. The initial step in this pathway involves the binding of SHC to bind through its SH2 domain to Y1173 allowing for recruitment of additional scaffolding proteins such as Grb2 and SOS. SOS is responsible for the conversion of Ras-GDP to Ras-GTP, allowing for Ras dimerization to occur, and the phosphorylation of Raf, which is then able to trigger a continuation of a signalling cascade that influences the expression of genes in the nucleus as regulated by Erk1/2 (Batzer et al., 1994; Li et al., 2016; Matallanas et al., 2003).

\subsubsection{EGFR at the Plasma Membrane}

Various protein-protein interactions involving EGFR regulate the transduction of signals from extracellular cues to intracellular results. For example, adaptor proteins Grb2, Gab1, and Shc interact with phosphorylated residues in EGFR to activate distinct signalling pathways. Notably, the activation of signalling pathways subsequently to engagement of adaptor proteins by EGFR may be complex and further regulated by a number of factors. Some of these regulatory factors 
that influence receptor signalling are found within distinct organelles, such as the plasma membrane and andosomes, or unique regions of the plasma membranes called membrane nanodomains (Delos Santos et al., 2015; Lu and Fairn, 2018). As such, the spatial and temporal arrangement of EGFR signalling molecules that are controlled by localization of the receptor to specific organelles or nanodomains (or "molecular neighborhoods") within the plasma membrane regulate the ability of receptors to influence the local environments and signal transduction.

\subsection{Cellular Compartments}

Clathrin mediated endocytosis (CME) is a transitionary step between cell signalling hubs at the plasma membrane and cytoplasm. Cells contain unique intracellular environments with different organelles, proteins, and functions. Compartmentalizing the different aspects of cellular functionality at different locations throughout the cell can occur through large-scale compartments such as the various organelles within a cell (Conner \& Schmid, 2003; Garay et al., 2015; Schmid \& McMahon, 2007). This can also occur by the generation of nanodomains that can be found on each membrane-bound organelle, a phenomenon which has been most studied at the plasma membrane. Communication between different membrane nanodomains can occur through the relocation of cellular signalling hub components as well as signal transduction (Conner \& Schmid, 2003; Garay et al., 2015; Schmid \& McMahon, 2007).

\subsubsection{Clathrin Mediated Endocytosis}

Clathrin mediated endocytosis (CME) regulates the presence of receptors and other cellular molecules at the surface of cells (Conner and Schmid, 2003). In addition to its role in triggering receptor internalization into vesicles, clathrin has intimate relationships with numerous receptors 
and influences the propagation of their signals by direct action at the plasma membrane (Garay et al., 2015), as I discuss below. Clathrin may this be able to facilitate unique protein-protein interaction hubs relevant for EGFR signaling, such as by introducing proteins to close proximity of one another in local nanoscale environments at the plasma membrane (Schmid \& McMahon, 2007).

\subsubsection{Overview of CME}

Clathrin coated pits (CCPs) are plasma membrane structures which assist in the vesicle budding process of CME. Clathrin subunits termed triskelia are composed of both light and heavy clathrin chains (McPherson et al., 2013). These clathrin subunits are recruited to the cytosolic side of the plasma membrane by adaptor protein 2 (AP2), which leads to the formation of clathrin lattices involving the self-assembly of clathrin (Conner and Schmid, 2003; McMahon and Boucrot, 2011; McPherson et al., 2013; Mettlen et al., 2018). The formation of CCPs can be described as occurring in various stages, each dependent on the presence and structural arrangement of clathrin, and these stages are defined by the presence of clathrin, adaptor proteins, and cargo (Conner and Schmid, 2003; McMahon and Boucrot, 2011; McPherson et al., 2013).

In the initial stage of $\mathrm{CCP}$ formation, the clathrin triskelions are recruited to the plasma membrane by AP2 (Conner and Schmid, 2003; McPherson et al., 2013). This adaptor protein directly binds to specific receptors destined for endocytosis, as well as phosphatidylinositol 4,5 bisphosphate (PIP2) (McMahon and Boucrot, 2011; Rosselli-Murai et al., 2018). This interaction between clathrin and AP2 promotes clathrin assembly into a lattice-like structure that eventually becomes a CCP (Conner and Schmid, 2003; McPherson et al., 2013). AP2 selects the cargo through either its $\mu 2$ and $\sigma 2$ subunits which are specific for the cytosolic tail of receptors, as well 
it has accessory appendage domains for binding additional adaptor proteins (McMahon and Boucrot, 2011). After the CCP has formed and the bud has become rounded, the clathrin coated structure is released through the scission of the pit through cellular scissors such as dynamin (Conner and Schmid, 2003; McPherson et al., 2013).

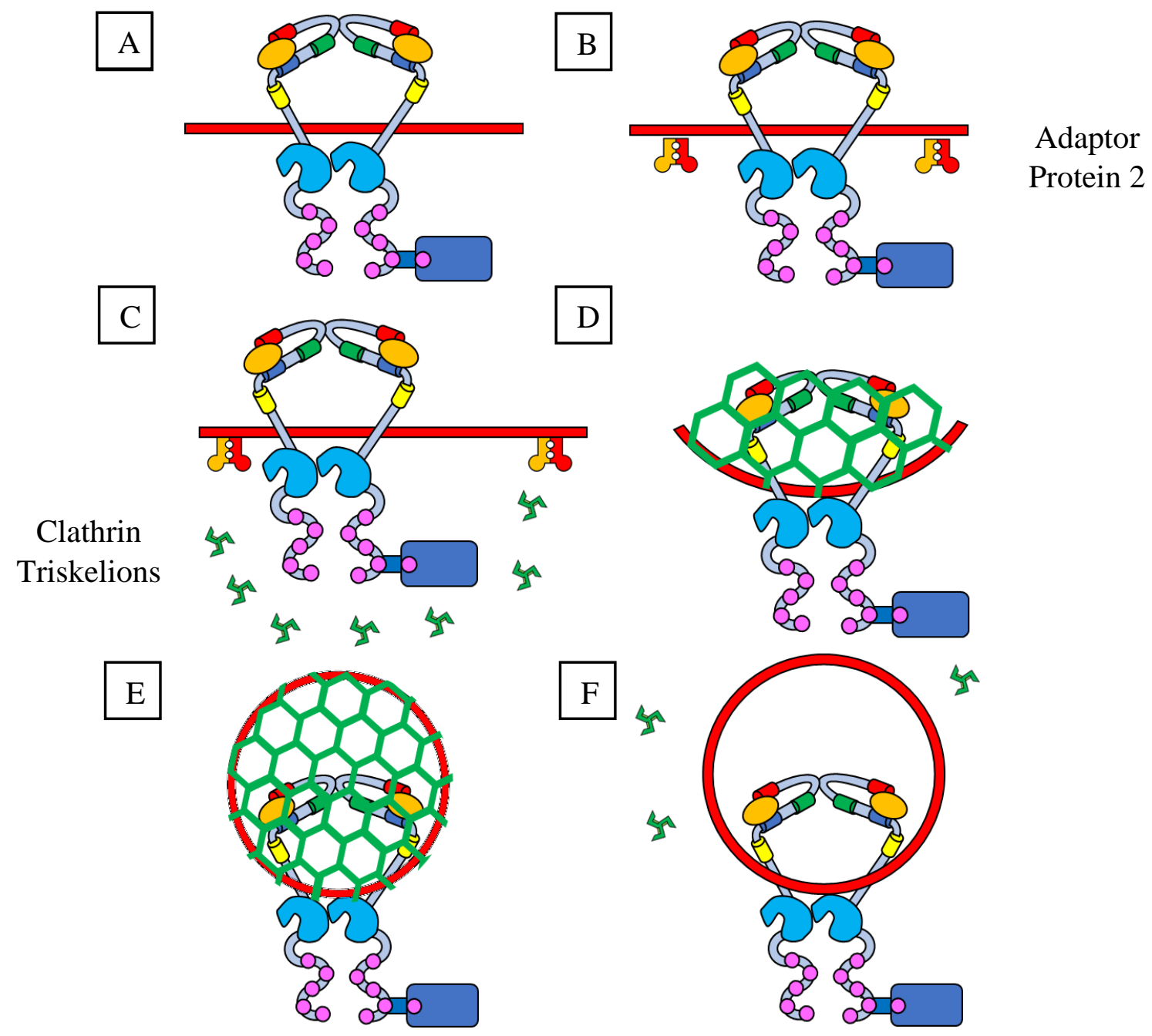

Figure 4. Clathrin Mediated Endocytosis. A). EGFR is ligand bound and could be transducing a signal that is nolonger required by the cell, it can now be selected for recycling B). AP2 is responsible for forming the initial structure at the plasma membrane which will C). recruit the clathrin triskelions to the cargo D). As more clathrin triskelions join to form the structure which will eventually be the CCP, a lattice structure is formed and the plasma membrane being to become invaginated. E). When the CCP is fully formed, dynamin releases the CCP from plasma membrane F). the clathrin structure is short lived, the multivesicular body is able to transverse the cell with its cargo, while the clathrin triskelions fall off and are ready to be recycled (Conner and Schmid, 2003; McMahon and Boucrot, 2011; McPherson et al., 2013). 
Dynamin is a GTPase that self assembles at the plasma membrane (Chappie et al., 2011; Ramachandran and Schmid, 2018). GTP hydrolysis is required for the mechanistic properties of dynamin to work, leading to constriction of CCPs, which in turn leads to severing of the lipid bilayers at the neck of the vesicle and their subsequent dissociation from the plasma membrane (Chappie et al., 2011; Ramachandran and Schmid, 2018). Following scission form the plasma membrane, the clathrin exostructure is disassembled and the individual clathrin triskelia subunits are recycled (Conner and Schmid, 2003; McPherson et al., 2013).

The heat shock cognate 70 (HSC70) and auxilin or cyclin G-associated kinase (GAK) are required for the removal of the clathrin triskelions from the vesicle (McMahon and Boucrot, 2011). Auxilin is responsible for recruitment of the ATPase HSC70 to the CCP at the site of attachment to the plasma membrane (McMahon and Boucrot, 2011). Recruitment of EGFR to CCPs depends on the presence of AP2 and binding to tyrosine-based motifs, as well as the ubiquitination of EGFR on its kinase domain or additional distal lysine residues (Goh et al., 2010)

\subsubsection{CME in Receptor Signalling}

One of the major class of cargo that undergoes internalization from the cell surface (via $\mathrm{CME}$ ) to intracellular membrane compartments is signalling receptors. As a result, the vesicular transport and resulting control of large-scale spatial organization of receptors within a cell by CME offers the potential for the regulation of receptor signalling in several ways. One way in which receptor internalization can regulate signalling is by triggering the initial stages that lead to receptor degradation in the lysosome (Goh and Sorkin, 2013; Sorkin and Goh, 2009). Acting as a mechanism of negative regulation of receptor signalling (Goh and Sorkin, 2013; Sorkin and Goh, 2009). As such, changes in the cells ability to recycle receptors from the cell surface alter signalling 
downstream of the receptor (Villaseñor et al., 2016). In addition, many studies have shown that signalling can continue from intracellular membrane compartments even as recycling of EGFR occurs (Di Fiore \& von Zastrow, 2014; Irannejad, Tsvetanova, Lobingier, \& von Zastrow, 2015; Miaczynska \& Bar-Sagi, 2010; Pálfy, Reményi, \& Korcsmáros, 2012; Platta \& Stenmark, 2011; Schmid, 2017). However, it seems that regulation of signalling through CCPs is not limited to EGFR; it has been found that regulation of G-protein coupled receptors can also occur through clathrin and $\beta$-arrestin (Eichel, Jullié, \& von Zastrow, 2016; Eichel et al., 2018; Leyton-Puig et al., 2017). Collectively, these studies have shown that the plasma membrane and various endosomal compartments represent different environments that each contain distinct upstream activators and substrates. As such, this large-scale organization of receptor signalling between distinct compartments represents an important mechanism of regulation of EGFR signalling. The compartmentalization of EGFR can influence signalling by Akt, as the endosome/lysosome environment can alter the duration of signals transduced through these organelles as well as the presence of phosphoinositides required for Akt signalling (Sugiyama et al., 2019).

\subsubsection{Regulation of receptor signalling by clathrin at the plasma membrane}

As discussed above, CME regulates the presence of molecular structures at the surface of the cell, and thus has the ability to regulate aspects of signalling related to these proteins. However, the formation of CCPs within the plasma membrane also creates unique structure or nanodomains within the plasma membrane that are able to regulate signalling prior to or separate from the regulation by formation of vesicles and transportation to specific compartments (Delos Santos et al., 2015). As such, CME and the formation of CCPs regulates some protein-protein interactions involved in the signalling complexes that influence the transduction of signals through EGFR. 
1.2.2.1 Clathrin-dependent interactions within the plasma membrane regulate EGFR signalling

EGFR is controlled by various interactions that are dependent on clathrin, which make CCPs important regulators of EGFR signalling. EGFR and the PIP3 phosphatase tensin homolog (PTEN) have been observed to both reside with short lived clathrin coated pits (CCPs) at the plasma membrane, suggesting that CCPs may be important for the regulation of EGFR signalling leading to PI3K-Akt activation (Rosselli-Murai et al., 2018). Importantly, inhibition of CCP formation by siRNA gene silencing or pharmacological inhibition of clathrin resulted in a decrease of Akt phosphorylation in the presence of EGF, suggesting the necessity of CCPs for signal transduction to occur (Garay et al., 2015; Rosselli-Murai et al., 2018). However, this requirement for clathrin is not due to a requirement for clathrin to form vesicles, as perturbations of dynamin that allow CCPs to form but block receptor internalization had no effect on EGFR signalling (Garay et al., 2015; Lucarelli, Delos Santos, \& Antonescu, 2017; Lucarelli, Pandey, Judge, \& Antonescu, 2016a). As well, our laboratory has shown that there is an enrichment of specific adaptor proteins such as Gab1 and phosphorylated Gab1 within CCPs in EGF-stimulated cells (Delos Santos et al., 2017; Lucarelli et al., 2016b). In addition, inhibition of clathrin results in loss of phosphorylation of Gab1 (Lucarelli et al., 2016b).

This suggests that clathrin may be acting as to form a larger-scale signalling complex or platform that assists in the phosphorylation of certain adaptor proteins as well as bringing key components of downstream signalling complexes within close proximity (Delos Santos et al., 2017; Garay et al., 2015; Lucarelli et al., 2016a; Rosselli-Murai et al., 2018). However, the molecular mechanism by which clathrin controls signalling remains to be elucidated. Given the role of clathrin as an important hub for protein-protein interactions (Schmid \& McMahon, 2007), it is thus very likely that residence of EGFR within CCPs alters the protein-protein interactions of 
EGFR and its receptor-proximal signalling proteins. However, how these protein-protein interactions of EGFR are controlled by recruitment of EGFR into clathrin signalling nanodomains at the cell surface remain unclear. Developing and adapting a method for elucidating proteinprotein interactions of EGFR that are controlled by clathrin will be one of the aims of this thesis.

The clathrin inhibitor PitStop2 has been used in previous studies to examine the prevalence of clathrin-dependent processes in cells (von Kleist et al., 2011). However, PitStop2 impairs the permeability of the nuclear pore complex and also has other off-target effects such as inhibition of clathrin-independent endocytosis (Dutta et al., 2012; Liashkovich et al., 2015; Willox et al., 2014). Hence, PitStop2 may be a useful to assess clathrin-dependent cell behaviours, but this approach requires 1) testing that PitStop2 does not have significant off-target action in the assay being tested and 2) subsequent confirmation of any phenotypes deemed to be clathrin-dependent by other more specific means of perturbing clathrin.

\subsubsection{The Mammalian-Membrane Two-Hybrid Assay}

Numerous methods can be utilized for the analysis of protein-protein interactions, such as co-immunoprecipitation, proximity biotinylation (e.g. BioID), and yeast two hybrid assays. I briefly describe each of these next. Co-immunoprecipitation works on the principle of two or more proteins interacting and remaining as a complex after cellular lysis. Following lysis, if the protein of interest is present, an antibody will be used to bind to this target protein, followed by isolation of said antibody-bound target protein by binding of the antibody to a large insoluble material such as beads, followed by purification of proteins that are specifically associated to the antibody-bead complex from other cellular components. Any proteins that co-purify with the target protein are strong candidates for protein-protein interactions with this protein (Sambrook and Russell, 2005). 
Alternative methods to detect protein-protein interactions, such as BioID and yeast two hybrid assays, work on principles distinct from co-immunoprecipitation in that these do not require cellular lysis. The yeast two hybrid assay requires the bait and prey proteins to come into close proximity of one another to allow for the detection of a reporter gene (Brückner, Polge, Lentze, Auerbach, \& Schlattner, 2009; Roux, Kim, \& Burke, 2013). The BioID assays have an engineered ligase fused to the target protein which is utilized for the detection of proteins in close proximity to the protein of interest (Brückner et al., 2009; Roux et al., 2013). This results in the biotinylation of proteins that are in close proximity to the ligase fused protein, which then allows the isolation and identification of biotinylated proteins (Brückner et al., 2009; Roux et al., 2013).

The Mammalian-Membrane Two-Hybrid (MaMTH) Assay is used to determine proteinprotein interactions that occur between a membrane bound protein and many other candidate proteins, including other membrane-bound proteins (Petschnigg et al., 2014). MaMTH is similar in some conceptual ways to the yeast two hybrid assay, in which the bait and prey will come together and indicate the presence of an interaction (Petschnigg et al., 2014; Saraon et al., 2017; Yao et al., 2017). This assay is based on previously developed split-ubiquitin systems (a form of biomolecular complementation), our collaborator, Igor Stagljar further developed the system to use in mammalian cells to determine protein-protein interactions (Petschnigg et al., 2014). Of note, if the two proteins do not interact, the two halves of the ubiquitin remain as separate, not functional parts of ubiquitin (Petschnigg et al., 2014). Interaction of the two proteins leads to close proximity of the ubiquitin halves, resulting in reformation of the full ubiquitin (Petschnigg et al., 2014; Saraon et al., 2017; Yao et al., 2017). In this system, the C terminal half of the ubiquitin is part of the bait and is fused to the EGFR cytosolic C-terminus along with the sequential fusion to a Gal4 transcription factor (Petschnigg et al., 2014; Saraon et al., 2017; Yao et al., 2017). 
In the absence of interaction or expression of the prey proteins, the Gal4 transcription factor is covalently anchored at the plasma membrane through fusion to the EGFR-ubiquitin-C-terminus chimeric protein, which results in no transcription of the reporter gene localized in the nucleus (Petschnigg et al., 2014; Saraon et al., 2017; Yao et al., 2017). The N terminus of ubiquitin is fused to the prey, the protein of interest (Petschnigg et al., 2014; Saraon et al., 2017; Yao et al., 2017). If the two halves come together (which can only occur if the two candidate proteins each fused to halves of uniquitin interact), the full ubiquitin is formed which in turn triggers cleavage of the ubiquitin moiety from EGFR and the bait by deubiquitinases, which then releases the Gal4 transcription factor from its membrane anchor. This in turn allows the Gal4 to translocate to the nucleus and initiate transcription of the reporter gene (Petschnigg et al., 2014; Saraon et al., 2017; Yao et al., 2017). Once in the nucleus of the cell, expression of the reporter, such as green fluorescent protein (GFP) or luciferase (an enzyme that produces a bioluminescent product) (Petschnigg et al., 2014; Saraon et al., 2017; Yao et al., 2017). The amount of expression can be quantified and compared with various conditions and controls, in order to determine the strength of the interaction (Petschnigg et al., 2014; Saraon et al., 2017; Yao et al., 2017).

\subsection{DNA Damage and Repair}

Cells are exposed to various environmental agents that can lead to various forms of DNA damage (Giglia-Mari et al., 2011; Sáez, 2018). As a result, over time, there is the potential to sustain DNA damage that will need to be repaired in order to ensure that these cells do not accumulate DNA damage or mutations that can be quite detrimental to the healthy function of each cell (Jackson and Bartek, 2009). Moreover, if this damage cannot be repaired, there is a need for signalling to trigger apoptosis that can limit the impact of cellular damage on tissue or organism 
function (Giglia-Mari et al., 2011; Jackson and Bartek, 2009; Sáez, 2018). Through a highly sophisticated DNA damage response and robust cell checkpoints, each cell is able to respond to many different types of DNA damage, repair many different forms of DNA damage, and in some cases trigger apoptosis if necessary (Funk, 2005; Giglia-Mari et al., 2011; Jackson and Bartek, 2009; Sáez, 2018) How this DNA damage response is regulated by EGFR and other forms of mitogenic signalling to allow a cell to coordinate the control of DNA stability and integrity with mitogenic and pro-survival signalling is poorly understood, which I examine in this thesis. In this portion of the introduction, I first examine the types of DNA damage and then subsequently the mechanisms that cells use to repair each.

\subsubsection{Types of DNA Damage}

DNA damage can occur at a level effecting individual bases in DNA, or extensively damage large portions of the DNA backbone, the former being repaired by processes such as nucleotide excision repair (NER) and the latter requiring more complex repair mechanisms (Table 1) considering the type and source of the damage. (Giglia-Mari et al., 2011; Jackson and Bartek, 2009).

Table.1 Types of DNA damage and their sources

\begin{tabular}{|c|c|c|}
\hline \multicolumn{1}{|c|}{$\begin{array}{c}\text { Type of Damage } \\
\text { Single Strand Breaks }\end{array}$} & $\begin{array}{c}\text { Source of Damage } \\
\text { Reactive Oxidative Species }\end{array}$ & $\begin{array}{c}\text { Reference } \\
\text { (Giglia-Mari, Zotter, and } \\
\text { Vermeulen 2011). }\end{array}$ \\
\hline Double Strand Breaks & $\begin{array}{l}\text { Ionizing Radiation } \\
\text { Chemotherapeutics }\end{array}$ & $\begin{array}{c}\text { (Borrego-Soto, Ortiz-López, } \\
\text { and Rojas-Martínez 2015). }\end{array}$ \\
\hline $\begin{array}{l}\text { Different sources of DNA damage can result in either single strand or double strand breaks. This can cause a myriad } \\
\text { of different forms of damage to accumulate in the cell and alter its ability to progress through the cell cycle. As a } \\
\text { result, cells require mechanisms by which they can repair DNA damage that has been accumulated. }\end{array}$
\end{tabular}




\subsubsection{DNA Repair}

Damaged DNA can be repaired by a number of damage specific mechanisms. Some methods of repair are selectively active during DNA replication stage, where molecular machines such as DNA polymerase 1 replace misplaced nucleotides before allowing for continuation in the replication process (McCulloch and Kunkel, 2008). Understanding how signalling from growth factor receptors such as EGFR may control the DNA damage response and/or DNA repair requires understanding the mechanisms that mediate DNA repair, which I examine next.

\subsubsection{Repair of double strand breaks by Homologous Recombination} Homologous recombination or homology-directed repair (HDR) is a process by which the DNA double-strand break is repaired through strand exchange with a homologous chromosome. HDR initiates when the DSB is bound by MRE11, RAD50, NBS1 these components assist in the 5' to 3' resection (Davis \& Chen, 2013; Wright et al., 2018; Jackson, 2002) After this has occurred the RAD51 complex binds to the sites of the double strand break in order to allow for the placement of other RAD components such as RAD51 and RAD 54 (Wright et al., 2018; Jackson, 2002). These RAD components assist with the insertion into a sister strand in order to copy the complimentary base pairs required in order for the damage to be repaired, creating a Holliday junction (Borrego-Soto, Ortiz-López, \& Rojas-Martínez, 2015; Wright et al., 2018; Jackson, 2002). DNA polymerase 1 is thyen recruited to the homologous DNA strand for the purpose of synthesizing the missing portion of DNA (Borrego-Soto et al., 2015; Wright et al., 2018; Jackson, 2002). Finally, the Holliday junction is resolved by the resolvase enzymes and DNA ligase 1 joins the DNA ends, finishing the repair of the double strand break (Borrego-Soto et al., 2015; Wright et al., 2018; Jackson, 2002). 


\section{IIIII $\overline{\underline{\mathrm{IIIIIIII}}}$}
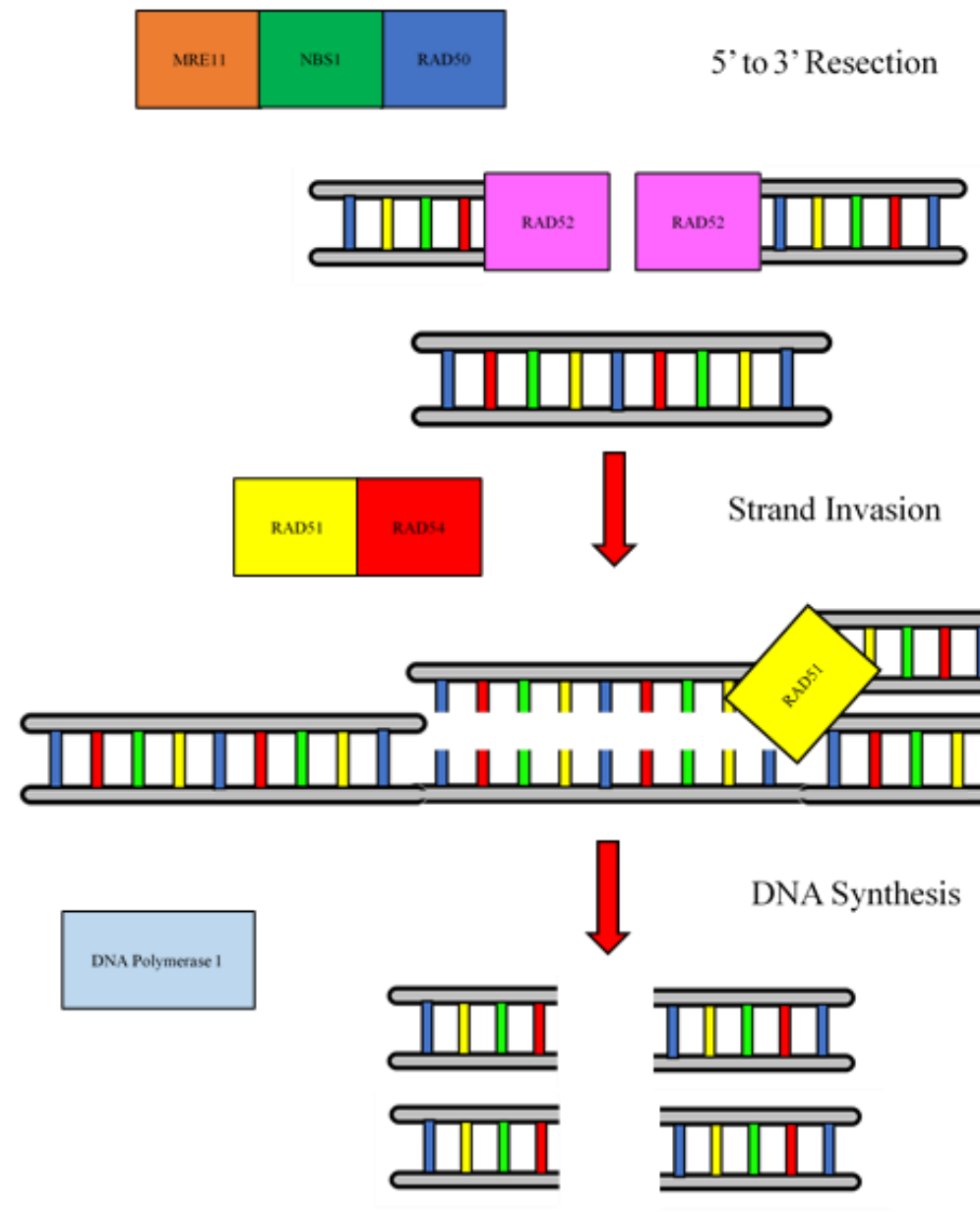

Figure 5. Homologous Recombination. In the first step, MRE11, RAD50, NBS1 are recruited to assist in the process of 5' to 3' resection, allowing for RAD51 to bind to end of the damaged DNA strands. RAD 51 recruits other RAD components to the ends of the DNA strands, and assist in the formation of the Holliday Junction. DNA polymerase 1 is then recruited to homologous strand, synthesizing the missing portion of DNA. The Holliday Junction is resolved and ligases complete the process by joining the damaged DNA strands together (Borrego-Soto et al., 2015; Wright et al., 2018; Jackson, 2002).

\subsubsection{Non-homologous End Joining}

Alternatively, non-homologous end-joining can be used to repair a double strand break throughout different phases of the cell cycle, while homologous recombination is limited to the G2 phase (Borrego-Soto et al., 2015). This process begins with the binding of the $\mathrm{Ku} 70 / 80$ 
heterodimer to the ends of the double stand break, preventing further degradation of the DNA strands (Borrego-Soto et al., 2015; Davis and Chen, 2013). The Ku 70/80 heterodimer acts as a scaffold for the DNA-PKcs (Borrego-Soto et al., 2015; Davis and Chen, 2013). X-ray repair complementing defective repair protein in Chinese hamster cells 4 (XRCC4) is then able to interact with the Ku 70/80 heterodimer and DNA-PKcs interfacing with enzymes at the site of the double stranded break (Borrego-Soto et al., 2015; Davis and Chen, 2013).

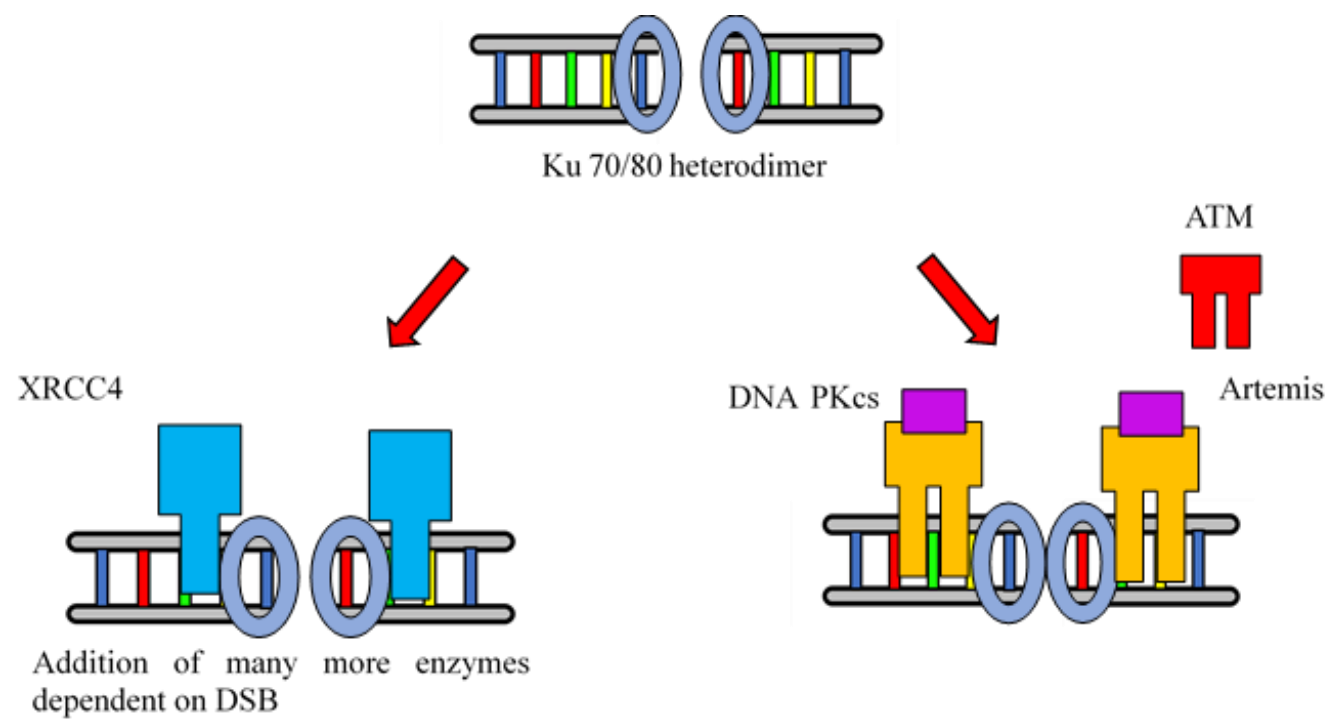

Figure 6. Nonhomologous End Joining. The initial step in the process of NHEJ is the binding of the Ku70/80 heterodimer at the damaged ends of the DNA. This allows for the recruitment of (left hand side) XRCC4, which can recruit additional enzymes dependent on the type of double stranded break that has occurred or (right hand side) DNA PKcs and their affiliated binding partners, Artemis, which allows for the activation of ATM and other signalling complexes associated with DSB repair (Borrego-Soto et al., 2015; Davis and Chen, 2013).

DNA ligase 4 is able to bind to the $\mathrm{Ku} 70 / 80$ heterodimer through the BRCA1 C-terminal (BRCT) domains (Borrego-Soto et al., 2015; Davis and Chen, 2013). PNKP (polynucleotide kinase-phosphatase) binds to the phosphorylated form of XRCC4 creating DNA stabilizing structures at the ends of the strands (Borrego-Soto et al., 2015; Davis and Chen, 2013). PKNP is a phosphatase that mediates the presence of phosphorylated groups on the 3' and 5' ends of the DNA 
strands (Borrego-Soto et al., 2015; Davis and Chen, 2013). Ligation of the DNA strands is completed by DNA ligase IV which is stimulated by XRCC4 (Borrego-Soto et al., 2015; Davis and Chen, 2013).

\subsubsection{Signalling Complexes in the DNA Damage Response}

The DNA damage response can be triggered by the phosphorylation of markers such as the histone $\mathrm{H} 2 \mathrm{AX}$ by phosphoinositide-3-kinase-related protein kinases (PIKKs), and the phosphorylated form of $\mathrm{H} 2 \mathrm{AX}$ is termed $\gamma \mathrm{H} 2 \mathrm{AX}$ (Borrego-Soto et al., 2015; Jackson, 2002). $\gamma \mathrm{H} 2 \mathrm{AX}$ initiates a signalling cascade that recruits proteins of the DNA damage response to the site of DNA damage (Jackson, 2002). ATM is an example of one kinases which is unique to the double strand break response, where phosphorylation will alter the ability of the cell to pass the G2/M cell cycle checkpoint, pausing the cell cycle and preventing the duplication of damaged DNA (Davis \& Chen, 2013; Wright et al., 2018; Jackson, 2002). H2AX is phosphorylated by ATM and the related kinase ATR, the influence of these kinases will be discussed in more detail later (BorregoSoto et al., 2015; Jackson, 2002).

\subsubsection{DNA Damage and Cancer}

Cancer can be defined as a family of diseases that result from various mutations leading to uncontrolled cell growth and proliferation, which results in the formation and growth of a tumour (Hanahan and Weinberg, 2011). DNA damage that can typically be resolved in healthy cells, either by repair or programmed cell death, can accumulate in cancer cells and result in cancer initiation or progression (Hanahan and Weinberg, 2011). Healthy cells have different systems to protect against the accumulation of such damage, but cancer cells also have means by which cell cycle 
arrest can be avoided and damage can go undetected (Funk, 2005). Furthermore, many chemotherapeutic agents that are used to treat cancer function by generating a large amount of DNA damage, while can selectively target the viability of rapidly-proliferating cells such as cancer cells (Hall et al., 2014; Wang \& Lippard, 2005). As such, understanding the factors that control the DNA damage response in cancer cells is important to develop better strategies to both limit tumor initiation and progression, as well as to enhance the efficacy of genotoxic chemotherapeutic agents.

\subsubsection{Accumulation of Mutations}

Mutations can accumulate over an extended period of time in the life of a cell. The majority of these will be repaired without any issue, as there are approximately 1 mutation for every 10,000 nucleotides over the course of a replication cycle (McCulloch and Kunkel, 2008). DNA damage can also result in the accumulation of mutations or resistance (Luria and Delbruck, 1943). This can be seen in the transfer of mutations over many generations, such as the early experiments completed by Lauria and Delbruck where it was observed that the presence of bacterial viruses can alter the mortality of bacterial samples based on the presence of resistance. Demonstrating not only the ability of organisms to develop resistance to sources of DNA damage, but also shows how certain mutations can be passed on generation to generation of cells and thus effect their ability to proliferate and function correctly (Hanahan and Weinberg, 2011; Luria and Delbruck, 1943). The accumulation of damage in mammalian cell lines can also be observed, these cells have mechanisms in order to limit the propagation of this damage to future generations of cells. Cancer, the uncontrolled growth of cells, can result from the accumulation of certain mutations in cells. The addition of mutations to mammalian cells can alter the expression levels of various proteins, 
and change the ability of the cell to interact with the local environment (Hanahan and Weinberg, 2011; Luria and Delbruck, 1943).

1.3.4.2 DNA damage response proteins that function as tumor suppressors

There are many genes that encode proteins that are central to the cellular response to DNA damage. One of the most important and well-studied such example is tumour suppressor 53 (TP53), which is referred to as the "Guardian of the Genome" due to its role in ensuring that cancer does not develop in the cell (Hanahan and Weinberg, 2011; Todd et al., 2002). TP53, and the protein it encodes, p53, is part of many different cell pathways that are involved in regulating cell growth (McCubrey et al., 2012). Indeed, p53 is mutated resulting in complete or partial loss of protein function in 38-50\% of cancers (Olivier et al., 2010) indicating the importance of disruption of DNA damage response in tumor growth and progression.

The mitogenic kinase, Akt (which was described earlier) is able to influence the activity of p53 as a result of a signalling pathway involving downstream effectors, which in turn prevents cell cycle arrest or apoptosis upon DNA damage (McCubrey et al., 2012; Xu, Li, Xiang, \& Sun, 2014). This can be seen through the expression of mouse double minute homolog 2 (MDM2) marking p53 for degradation by proteases, resulting in more invasive forms of cancers (McCubrey et al., 2012; Xu et al., 2014). If it is found that the DNA is damaged, p53 and other tumour suppressors, have means of shutting down the cell cycle to prevent the accumulation of DNA damage in future generations of cells and to allow repair to occur (Watcharasit et al., 2002).

Ataxia-telangiectasia mutated (ATM) protein is responsible for the phosphorylation of p53 when DNA damage has accumulated in the cell (Wang \& Lippard, 2005). The Mre11-Rad50-Nbs1 (MRN) complex recruits ATM to the site of the double stranded break, resulting in 
phosphorylation and kinase activation (Giglia-Mari et al., 2011). The phosphorylation of p53 in this manner leads to stabilization of p53 expression, allowing p53 to carry out a number of important cellular functions. This can lead to the activation of checkpoint kinases responsible for preventing cell cycle progression (Giglia-Mari et al., 2011). In addition, upon detection of DNA damage and stabilization of p53, $\mathrm{p} 21^{\mathrm{WAF} / \mathrm{CIP} 1}$ and GADD45 (growth arrest and DNA damage 45) can be expressed by the p53 transcription factor activity which can lead to DNA damage repair (Wang \& Lippard, 2005). These systems are in place to provide the cell an opportunity to correct DNA damage before progressing through the cell cycle, and if the damage is too severe, an opportunity to terminate the cell before proliferation occurs.

\subsection{Histones and the histone variant $\gamma \mathrm{H} 2 \mathrm{AX}$}

The core histones involved in creating the bundling structure are interconnected through dimerization and the formation of tetramers (Cutter and Hayes, 2015). This can be seen in the formation of an $\mathrm{H} 3: \mathrm{H} 4$ dimer that self-associates and then is able to connect to another dimer of the same composition to form a tetramer (Cutter and Hayes, 2015). On either end of this tetramer structure an H2A:H2B dimer is able to bind through the H3 interface (Cutter and Hayes, 2015). These form a ramp-like structure where the DNA strand is able to link (Cutter and Hayes, 2015). Different components of the histone octamer have different functions, and are manipulated at varying points in the cell cycle (Giglia-Mari et al., 2011; Jackson, 2002). This can be seen by the

phosphorylation of histone H2AX to trigger cell cycle arrest (Giglia-Mari et al., 2011; Jackson, 2002; Jackson \& Bartek, 2009; Sáez, 2018; Xu et al., 2016). 


\subsubsection{As a marker of DNA damage}

The H2AX variant of histones is found in approximately $5-25 \%$ of the octamers present in a cell (Giglia-Mari et al., 2011). The intimate relationship between histones and DNA allows for histones and phosphorylation patterns on key components to be useful indicators of DNA damage. Phosphorylation of $\mathrm{H} 2 \mathrm{AX}$ is used to indicate the efficacy of reagents and their ability to create double stranded breaks in the DNA (Giglia-Mari et al., 2011; Jackson, 2002; Jackson \& Bartek, 2009; Sáez, 2018; Xu et al., 2016).

1.4.1.1 Phosphorylated and Unphosphorylated forms

The phosphorylated form of $\mathrm{H} 2 \mathrm{AX}$ indicates that the DNA strand has been broken and that there are exposed ends (Giglia-Mari et al., 2011; Jackson, 2002; Jackson \& Bartek, 2009; Sáez, 2018; $\mathrm{Xu}$ et al., 2016). This signals for the DNA damage response to occur (Giglia-Mari et al., 2011; Jackson, 2002; Jackson \& Bartek, 2009). H2AX is phosphorylated by the kinase ATM, this triggers a signal cascade that involves several signalling pathways (Giglia-Mari et al., 2011; Jackson, 2002; Jackson \& Bartek, 2009). In the unphosphorylated form, H2AX acts as a stabilizer of homologous recombination during meiosis, as this provides genetic diversity in the gametes (Jackson \& Bartek, 2009).

\subsubsection{2 $\gamma \mathrm{H} 2 \mathrm{AX}$ associated proteins and pathways}

Though there remains much debate in the scientific community on full roles and functions of $\gamma \mathrm{H} 2 \mathrm{AX}$ and its influence in certain pathways, some aspects have been determined. The DNA damage response can be triggered by $\gamma \mathrm{H} 2 \mathrm{AX}$ (Jackson, 2002). This marker is responsible for influencing a signalling cascade which recruits kinases of the DNA damage response to the site of 
DNA damage (Borrego-Soto et al., 2015; Jackson, 2002). The additional kinases can act as mechanisms by which a more complex response is completed and can be unique based on the type of damage present. ATM is an example of one of these kinases which is unique to the double strand break response, where phosphorylation will alter the ability of the cell to surpass the G2/M cell cycle checkpoint, pausing the cell cycle and preventing the duplication of damaged DNA (Davis \& Chen, 2013; Wright et al., 2018; Jackson, 2002).

DNA damage can induce activation of ATM, ATR, and other PIKKs, effectively changing the outcome of the cell (Borrego-Soto et al., 2015; Davis and Chen, 2013). This can lead to cell cycle arrest, or apoptosis, ultimately preventing the propagation of DNA damage to daughter cells. Cisplatin, a chemotherapeutic is an effective therapeutic means of eliciting DNA damage, which if sufficient results in triggering apoptosis, a phenomenon that is the basis of cisplatin's action as a cancer chemotherapeutic agent (Hall et al., 2014). A strategy used in chemotherapeutics is to trigger the arrest of the cell cycle, or induce apoptosis, this can be completed by triggering excessive amount of DNA damage to the cell in order to activate the DNA damage response (Hall et al., 2014; Wang \& Lippard, 2005). Understanding the mechanism behind the damage induced signalling as a result of $\mathrm{H} 2 \mathrm{AX}$ phosphorylation provides a new insight into how cells respond to DNA damage, as cell fate after DNA damage is reliant on the signalling complexes responsible for $\mathrm{H} 2 \mathrm{AX}$ phosphorylation.

\subsection{Cisplatin and other genotoxic chemotherapies}

One of the major therapeutic strategies for cancer cells is the use of genotoxic or cytotoxic agents that trigger apoptosis in rapidly proliferating cells (Hall et al., 2014; Hanahan and Weinberg, 2011). Several chemotherapeutic agents are well known for their ability to elicit 
apoptosis in cancer cells (Wang \& Lippard, 2005). The mechanism of action of chemotherapeutic agents with apoptotic properties are of great interest of study in the field of cancer research in order to better understand how to utilize them.

\subsubsection{Use of cisplatin in cancer therapy}

Cisplatin triggers DNA double stranded breaks, usually triggering apoptosis (Hall et al., 2014). Cisplatin, alone or in combination with other chemotherapeutics, can be used to treat several forms of cancers including testicular, ovarian, and small cell lung carcinomas (Hall et al., 2014; Wang \& Lippard, 2005). In the case of testicular cancers it has a success rate of $90 \%$ with near perfect success when the cancer is caught early (Wang \& Lippard, 2005). Some ovarian cancers and carcinomas show signs of resistance as deficits and mutations of certain cisplatin adducts effect the efficacy of the drug (Wang \& Lippard, 2005). Examining the mechanism of action in cisplatin we can better understand the reasons behind resistance in some forms of cancers and not others. In particular, since EGFR is overexpressed in many cancers, it is possible that the control of DNA repair and response to DNA damage caused by cisplatin can influence the ability of cisplatin to elicit cell death in certain EGFR-expressing cancers (Hall et al., 2014; Hanahan \& Weinberg, 2011; Wang \& Lippard, 2005) By determining the influence of EGFR on the DNA damage response, we may thus be able to create better means by which cisplatin can be used in the clinic for the treatment of certain cancers.

\subsubsection{Mechanisms of action}

Cisplatin, in the clinic, is solubilized in a saline solution (Hall et al., 2014). In research of the drug, it can also be solubilized in double-distilled $\mathrm{H}_{2} \mathrm{O}$ or dimethyl sulfoxide (DMSO) (Hall et 
al., 2014). The solubilization reaction involves the displacement of a hydrogen ion on the drug, resulting in a hydrolyzed state (Dasari and Tchounwou, 2014). This allows for the cisplatin drug to act as an electrophile and displace a leaving group on a purine residue in the DNA double strand (Dasari and Tchounwou, 2014). Cisplatin forms a covalent bond at the N7 position of the 1,2 or 1,3 intra-strand position in DNA, displacing the major groove structure (Wang \& Lippard, 2005). When this occurs a double-strand break is created (Dasari and Tchounwou, 2014). The double strand breaks are triggered by the creation of cisplatin based DNA adducts, high motility group box proteins (HMGB) bind to these sites directly and trigger the activation of tumour suppressing proteins such as p53 (Wang \& Lippard, 2005). Dependent on the solubilizing agent there is much debate about the types of damage created by cisplatin, although it is commonly used as a reagent to trigger double strand breaks (Hall et al., 2014). This is believed to be done by the inter-strand breaks and intra-strand adducts created in the presence of cisplatin, which can lead to the accumulation of more substantial forms of DNA damage and eventual triggering of apoptosis in cancer cells (Dasari and Tchounwou, 2014).

\subsection{Receptor signalling controlling DNA damage and repair}

A review of the literature on the topic of EGFR and DNA damage and repair suggests some of the pathways regulated by EGFR activation can influence the phosphorylation of histones and thus possibly control DNA structure or damage response. EGFR phosphorylates the Y72 residue of Histone (H4), influencing the ability of DNA to undergo post-translational modifications, DNA synthesis, and influence the DNA damage response in the presence of DSBs (Chou et al., 2014). Additionally, oncogenic Ras mutants can alter the ability of cells to progress through the cell cycle and undergo apoptosis (Abulaiti et al., 2006). In cases where activated Ras is presented to cells, 
micronuclei were abundant suggesting chromosome inability (DNA damage present) however various markers of cell cycle progression such as phosphorylation of the $\mathrm{H} 3$ variant histone and MDM2 (Abulaiti et al., 2006). Since EGFR can trigger an activation of Ras, leading to downstream activation of the Erk pathway, a further examination of EGFR influence on the DNA damage response can elucidate the mechanisms by which histones can be modified through signal transduction and how this alters the ability of a cell to undergo apoptosis.

\subsection{Rationale}

The mechanisms by which the regulation of EGFR and its protein-protein interactions are controlled by clathrin nanodomains, and how this type of nanodomain influences the ability of EGFR to trigger signalling to control the DNA damage response remains unclear. The work completed in the Antonescu laboratory to date has revealed that there are clathrin dependent EGFR signalling pathways triggered at the cell surface, indicating that it is likely that clathrin influences EGFR protein-protein interactions important for signalling. Therefore, I hypothesize that there may be some signals that are triggered by EGFR, perhaps in the context of clathrin nanodomains, that lead to manipulation of the DNA damage response, but this has not yet been studied in great detail.

\subsection{Hypothesis and Objectives}

I hypothesize that upon ligand binding, EGFR will initiate a specific signalling pathway that will regulate the DNA damage response, either by modulating the efficiency of DNA repair or the extent to which DNA repair occurs. In addition, I hypothesize that clathrin inhibition will perturb specific protein-protein interactions of EGFR, which may be involved in control of DNA damage 
and repair. Therefore, to test these hypotheses, I aim to examine the influence of EGFR activation on the DNA damage response, particularly how signal transduction will either increase or decrease the presence of $\gamma \mathrm{H} 2 \mathrm{AX}$, a marker of DSBs, to determine how EGFR is regulating the DNA damage response. This will be done by dissecting the role(s) of EGFR-activated Akt and ERK signalling pathways on the DNA damage response. Then, I aim to probe if the MaMTH assay can be used to study clathrin-dependent protein-protein interactions of EGFR.

\subsection{Experimental Design}

In the first step of the experimental process we will use immunofluorescence microscopy to determine the presence of double stranded breaks as created by cisplatin. I do so using an antibody that detects the presence of levels of $\mathrm{H} 2 \mathrm{AX}$ phosphorylation, a marker of double stranded breaks, to compare the levels of DNA damage elicited by cisplatin and how this is regulated by treatment with EGF, an activating EGFR ligand. I will also use inhibitors of the Ras-Erk and PI3K-Akt pathways to probe how each of these signaling pathways may contribute to EGFR-dependent control of H2AX phosphorylation (Figure 7). Furthermore, in subsequent experiments, I will develop the use the MaMTH assay to study clathrin-dependent EGFR protein-protein interactions and how they are altered when clathrin is inhibited. 


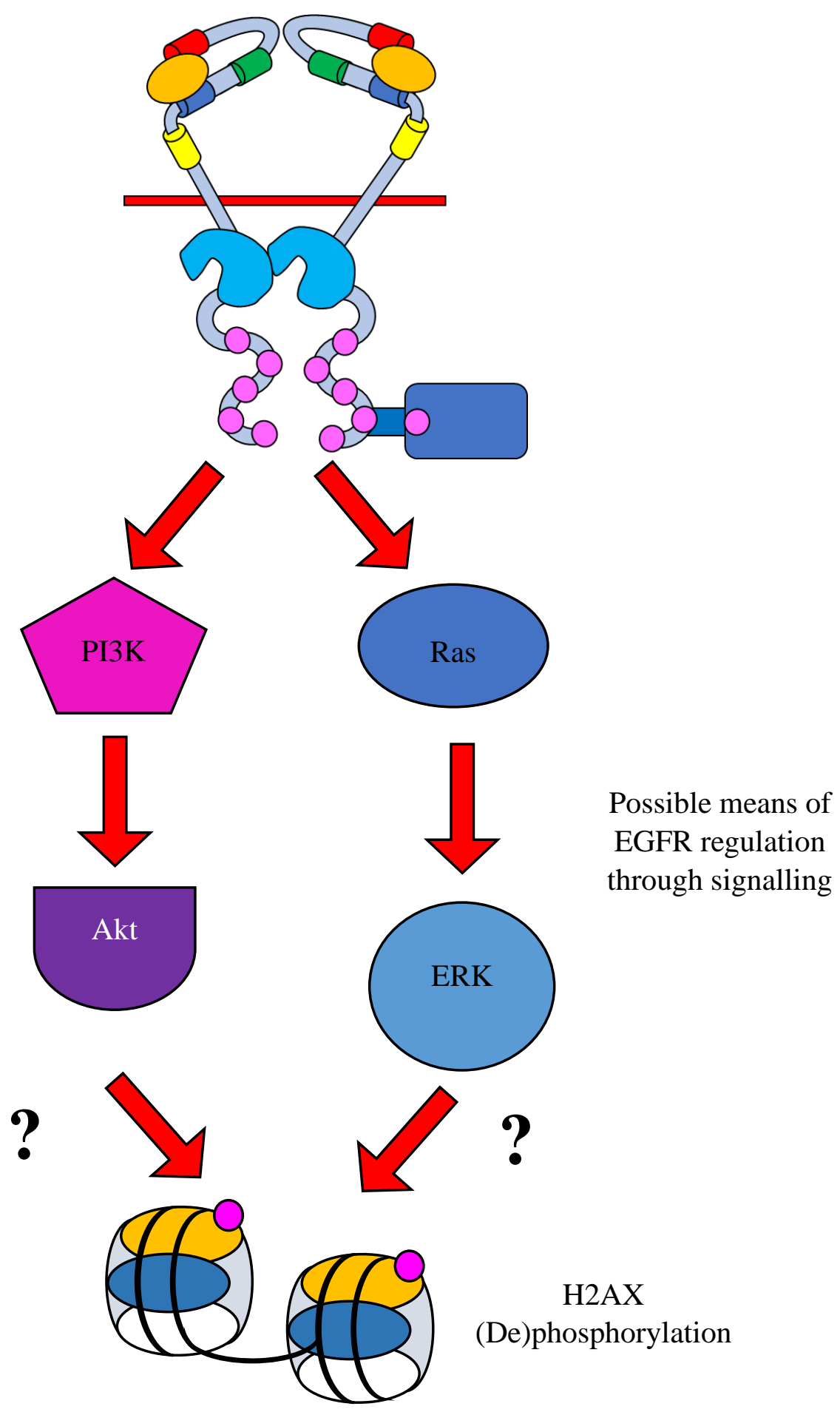

Figure 7. EGFR mediated H2AX phosphorylation. EGFR has different signalling complexes that may alter the ability of a cell to undergo the DNA damage response. An examination of how EGFR alters the phosphorylation of $\gamma \mathrm{H} 2 \mathrm{AX}$, a marker of DSBs, and thus influences the DNA damage response at the site can elucidate some of the signalling mechanisms by which this process is controlled. A primary examination of the PI3K and Ras signalling pathways will provide the foundational framework of how this can be done considering 1). PI3K-Akt signalling regulates cell growth 2). Ras-Raf-Erk signalling has already been shown to influence the prevalence of posttranslational modifications of histones by EGFR. 


\subsection{RESULTS}

The objectives of this thesis were to examine the effects of EGFR activation on the DNA damage response and the protein-protein interactions that make these effects possible. This was completed through the use of immunofluorescence microscopy, the MaMTH assay, and statistical analysis.
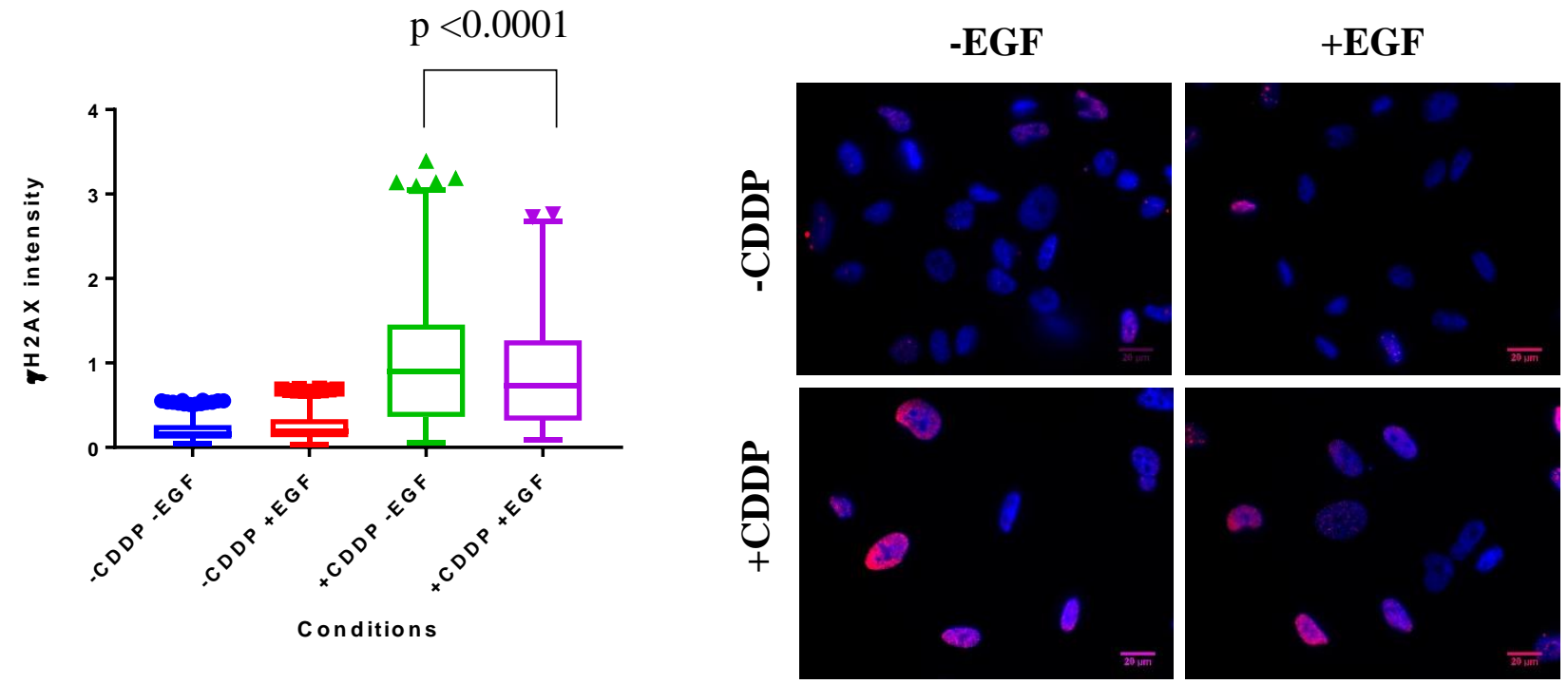

Figure 8. Acute stimulation with EGF decrease the detection of $\gamma \mathrm{H} 2 \mathrm{AX}$ in cisplatin damaged MDA-MB-231 cells. MDA -MB-231 breast cancer cells exposed to cisplatin had a statistically significant difference in $\gamma \mathrm{H} 2 \mathrm{AX}$ expression when compared to the condition with both cisplatin and acute EGF stimulation ( $\mathrm{n}=5, \mathrm{k}=489$ and 587, $\mathrm{p}<0.0001$ ). The effect of acute EGF stimulation was not observed in the condition where there was no cisplatin present, remaining similar to the basal (-CDDP -EGF) condition. In the blue is the DAPI (nucleus) and in the red is the $\gamma \mathrm{H} 2 \mathrm{AX}$. The marker of double stranded breaks used is $\gamma \mathrm{H} 2 \mathrm{AX}$, thus the term $\gamma \mathrm{H} 2 \mathrm{AX}$ is used throughout to define the damage accumulated in the cells as a result of cisplatin (CDDP) treatment).

The experiments were conducted in $0.1 \%$ serum media, in order to limit the activation of key signalling pathways by serum that would be also triggered by acute EGF stimulation. This experimental design allowed resolution of the effects of acute EGF stimulation from chronic regulation of $\mathrm{H} 2 \mathrm{AX}$ phosphorylation by plasma member receptors. It should also be noted that the MDA-MB-231 cells have a G13D KRAS mutation, which causes the constitutive activation of downstream signalling pathways (Raf-Ras-Erk and in some cases PI3K-Akt) (Kim et al., 2015). 
However, this is compensated for through both the normalization of the data, and our negative controls.

To determine the effect of acute EGF stimulation of the DNA damage and repair response, I examined the effect of acute (10 min) stimulation with EGF on the cellular levels of $\gamma \mathrm{H} 2 \mathrm{AX}$. To induce the accumulation of DNA in these cells, prior to EGF stimulation, cells were treated with cisplatin for $16 \mathrm{~h}$, also performed in media supplemented only with $0.1 \%$ FBS. In Figure 8 the results show that stimulation with EGF decreases the levels of $\gamma \mathrm{H} 2 \mathrm{AX}$ in cisplatin-treated MDAMB-231 cells compared to cells treated with cisplatin but not acutely treated with EGF ( $p<0.0001)$. This suggests the existence of a mechanism subsequent to EGFR activation, and activation of downstream effectors affiliated with EGFR, which regulates the DNA damage response or repair. As discussed in the introduction, some of the key signals activated by EGFR are PI3K-Akt and Ras-Raf-Erk; however, the contribution of each of these signalling pathways to regulation of $\gamma \mathrm{H} 2 \mathrm{AX}$ levels upon EGF stimulation is not known.

To determine how PI3K-Akt or Ras-Erk pathways may contribute to regulation of $\gamma \mathrm{H} 2 \mathrm{AX}$, both constitutively and in the EGF-stimulated state, I next examined the regulation of $\gamma \mathrm{H} 2 \mathrm{AX}$ levels in cells treated with inhibitors of PI3K (to inhibit the PI3K-Akt pathway) or MEK1 (to inhibit the Ras-Erk pathway). 


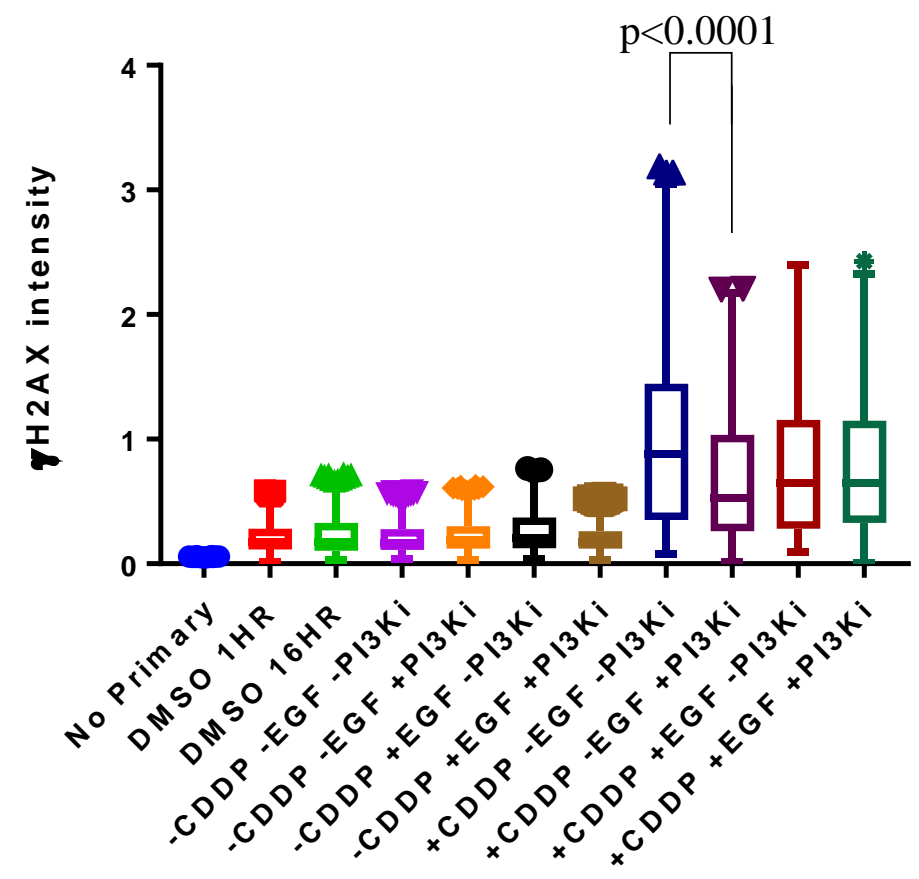

Conditions

Figure 9. PI3K pathway inhibition reverses the DNA damage response in cisplatin exposed cells. MDA 231 breast cancer cells exposed to cisplatin had a statistically significant difference in $\gamma \mathrm{H} 2 \mathrm{AX}$ intensity when compared to the condition with both cisplatin and acute EGF stimulation ( $\mathrm{k}=382$ and $342, \mathrm{p}<0.0001)$. As well, in conditions where PI3K inhibitor GDC0941 was added to cisplatin damaged cells there was a decrease in the detection of $\gamma \mathrm{H} 2 \mathrm{AX}$ $(\mathrm{k}=305, \mathrm{p}<0.0001)$. Comparing this condition to the EGF stimulated cisplatin damaged cells there is no statistical significance, this is also seen when the two are added together. However, in the condition where both EGF and PI3Ki is present in cisplatin damaged cells, there is a statistically significant difference to the cisplatin positive control $(\mathrm{k}=327, \mathrm{p}<0.0001)$.

For these experiments, cells were again treated with cisplatin for $16 \mathrm{~h}$ to induce DNA damage, or left untreated (control). Following this cisplatin treatment, some cells were also treated with PI3K inhibitor for $1 \mathrm{~h}$ in the continued presence of cisplatin, and subsequently some samples were also treated with EGF for $10 \mathrm{~min}$. This experimental design allowed for study of the role of PI3K signalling in both the constitutive DNA damage response (i.e. in non-EGF treated cells), as well as the EGF-stimulated DNA damage response. The cisplatin only condition was the positive control (representing DNA damaged cells without additional perturbations) and was used to 
normalize all conditions, giving it a mean value of 1 . When comparing the previously described positive control condition to those which are additionally treated with either EGF, the PI3K inhibitor (GDC0941, PI3Ki henceforth), or a combination of both certain trends and statistically significantly different measurements were observed. I will first present the data showing each cell as an individual measurement, highlighting the median and variance of individual cell measurements (Figure 9). I will then discuss the reproducibility of these measurements between independent experiments as well as other analyses of this data. This methodology for presenting the data will be repeated in the subsequent cases for inhibition of ERK.

Firstly, consistent with the results shown in Figure 8, acute stimulation (10 minutes) of EGFR by EGF in cisplatin-treated cells led to a decrease in the detection of $\gamma \mathrm{H} 2 \mathrm{AX}$ levels compared to cells treated with cisplatin alone, suggesting the importance of EGFR in the DNA damage response (Figure 9). Furthermore, cells treated with PI3Ki in the last hour of a 16h cisplatin treatment regimen exhibited a reduction in $\gamma \mathrm{H} 2 \mathrm{AX}$ compared to cells with cisplatin alone (Figure 9). Additionally, cisplatin-treated cells treated with a combination of both EGF and PI3Ki led to a similar level of $\gamma \mathrm{H} 2 \mathrm{AX}$ as cells treated with cisplatin alongside EGF or PI3Ki alone, and this combination treatment also results in a lower level of $\gamma \mathrm{H} 2 \mathrm{AX}$ than the cisplatin-only positive control. However, there is no statistically significant difference between $\gamma \mathrm{H} 2 \mathrm{AX}$ levels in cisplatin treated cells treated with PI3Ki and cisplatin-treated cells subjected to EGF stimulation. This lack of additivity of these effects suggests that the effects of EGF stimulation and PI3Ki on $\gamma \mathrm{H} 2 \mathrm{AX}$ levels in cisplatin-treated cells may share some targets or regulatory components.

This data presented in Figure 9 represents the pooling of all individual cells across all experiments performed examining the effect of PI3K inhibition. To further examine the reproducibility of the regulation of $\gamma \mathrm{H} 2 \mathrm{AX}$ levels in cisplatin treated cells by EGF or PI3Ki 
treatment, the medians of the $\gamma \mathrm{H} 2 \mathrm{AX}$ measurements in each condition in each individual experiment and the standard error of the mean was plotted to examine the variation between individual experiments. For this analysis, the $\gamma \mathrm{H} 2 \mathrm{AX}$ levels in each condition in each experiment was normalized to the mean $\gamma \mathrm{H} 2 \mathrm{AX}$ level of the cisplatin-only (positive control) condition. 


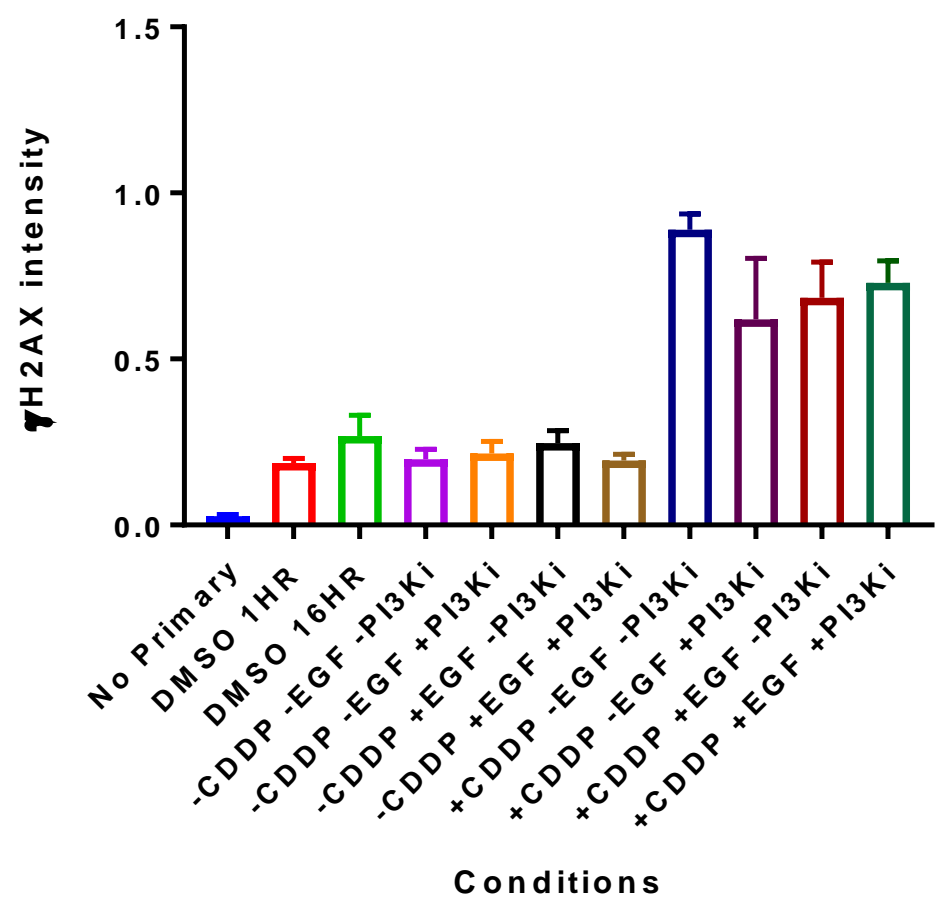

Figure 10. Variation in individual experiments alters the intensity levels of $\gamma \mathrm{H} 2 \mathrm{AX}$ as seen by the medians and standard error of the mean. The previously described data was replotted to represent the median of each condition as well as the standard error of the mean. It was determined that the previously described effect of EGF on decreasing the expression levels of $\gamma \mathrm{H} 2 \mathrm{AX}$ was no longer significant. As well, when comparing with ANOVA any condition exposed to cisplatin with any other cisplatin added condition, no comparison was significant. The data, as presented, suggests that as a whole the expression levels simplified to the mean values does not show a statistically-significant effect of EGF stimulation or PI3Ki treatment on $\gamma \mathrm{H} 2 \mathrm{AX}$ levels in cisplatin damaged cells.

Statistical analysis of the data as represented in Figure 10 shows the variability between the experimental conditions between repetitions, which indicates that the differences observed between certain conditions was not statistically significantly different. Comparing the cisplatin alone condition to the cisplatin treated cells with EGF there is no statistically significant difference $(\mathrm{p}=0.6791)$. A lack of statistical significance can also be seen when comparing the cisplatin treated condition with the cisplatin treated cells with PI3Ki $(\mathrm{p}=0.3148)$. This suggests that the response from experiment to experiment is variable, in the response seen to the additives such as EGF and PI3Ki. However, the effect of cisplatin alone in comparison to cells with no additives is still statistically significant $(\mathrm{p}<0.0001)$, implying the variance may lie with either EGF or PI3Ki. 


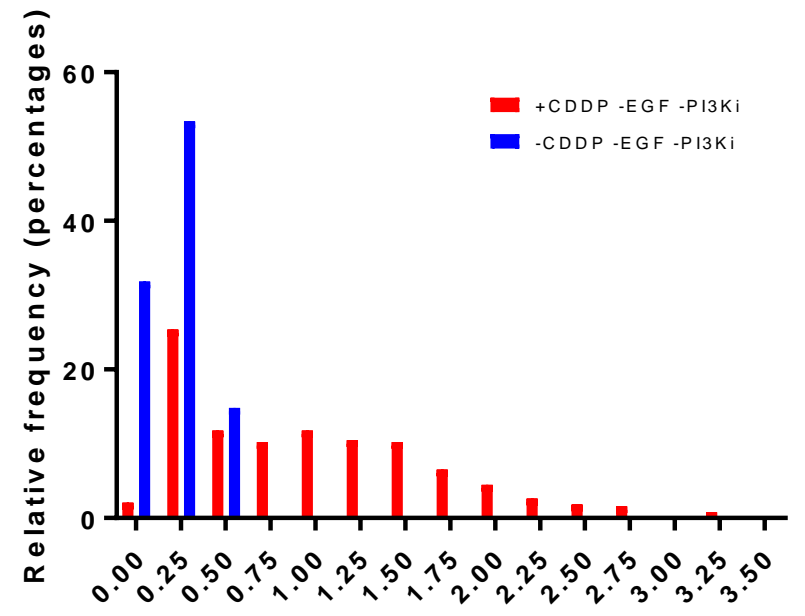

Bin Center

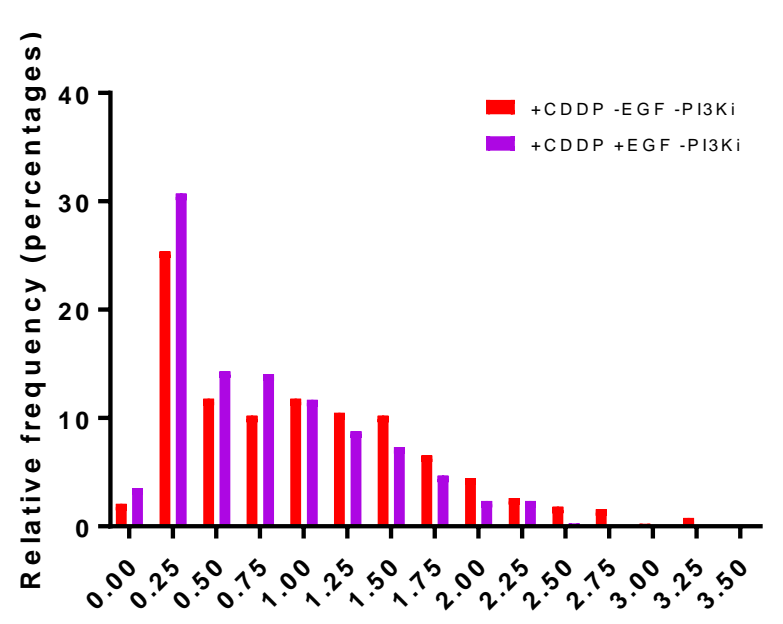

Bin Center

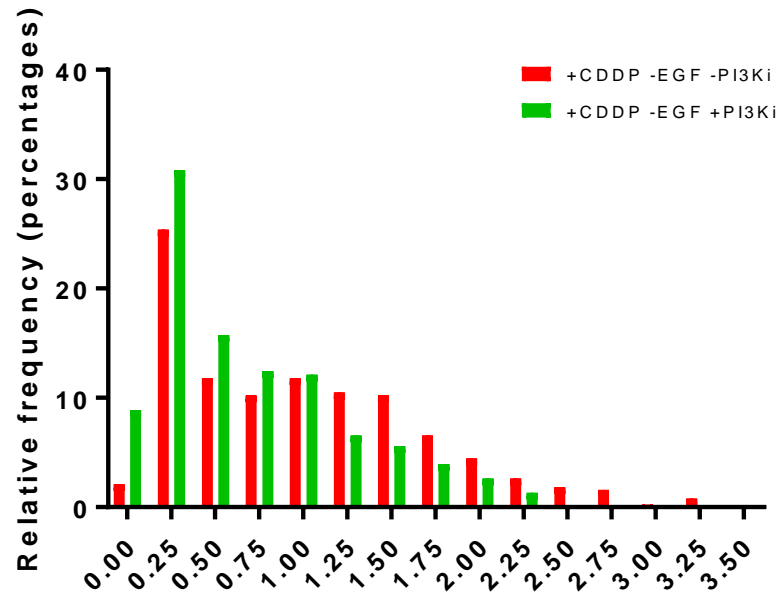

Bin Center

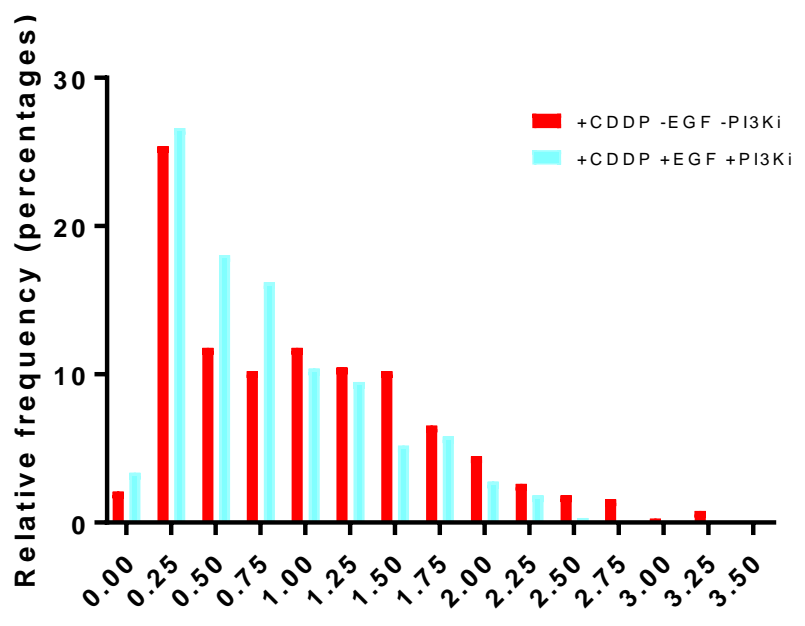

Bin Center

Figure 11. PI3K pathway inhibition alters the distribution of the cells with $\gamma \mathbf{H} 2 \mathrm{AX}$ intensity. MDA 231 breast cancer cells exposed to cisplatin had a statistically significant difference in $\gamma \mathrm{H} 2 \mathrm{AX}$ intensity when compared to the condition with both cisplatin and acute EGF stimulation $(\mathrm{k}=382$ and 342, $\mathrm{p}<0.0001)$. As well, in conditions where PI3K inhibitor GDC0941 was added to cisplatin damaged cells there was a decrease in the detection of $\gamma \mathrm{H} 2 \mathrm{AX}(\mathrm{k}=305$, $\mathrm{p}<0.0001$ ). Comparing this condition to the EGF stimulated cisplatin damaged cells there is no statistical significance, this is also seen when the two are added together. However, in the condition where both EGF and PI3Ki is present in cisplatin damaged cells, there is a statistically significant difference to the cisplatin positive control $(\mathrm{k}=327, \mathrm{p}<0.0001)$.

I next sought to understand how EGF or PI3Ki may be altering the levels of $\gamma \mathrm{H} 2 \mathrm{AX}$ in a cell population. From the results shown in Figure 9, in some cases EGF and PI3Ki reduce the levels of $\gamma \mathrm{H} 2 \mathrm{AX}$ in cisplatin-treated cells. This could be due to either (i) EGF or PI3Ki eliciting a 
global reduction in $\gamma \mathrm{H} 2 \mathrm{AX}$ levels in cisplatin-treated DNA-damaged cells, or (ii) this could reflect that these treatments reduce the number of cells that are above a threshold for $\gamma \mathrm{H} 2 \mathrm{AX}$ to be considered 'damaged', while most cells that exhibit $\gamma \mathrm{H} 2 \mathrm{AX}$ staining do so at high levels. To distinguish between these possibilities, I examined the frequency distribution of $\gamma \mathrm{H} 2 \mathrm{AX}$ levels in cells treated with cisplatin in combination with other agents. Comparing the frequency distribution of the $\gamma \mathrm{H} 2 \mathrm{AX}$ intensity, it can be seen that the addition of cisplatin shifts the distribution of $\gamma \mathrm{H} 2 \mathrm{AX}$ levels towards much higher value bin compared to cells not treated with cisplatin (Figure 11), as expected for cells exhibiting DNA damage. From this analysis, there is a large change to the distribution of the values when cisplatin is added, as the $\gamma \mathrm{H} 2 \mathrm{AX}$ expression values reach over 3.0, whilst in the no additive condition all values are below 0.6 with most falling in the $0.0-0.2$ range. This reflects the effect of cisplatin to induce the accumulation of DNA damage in a large proportion of cells. In addition, this frequency distribution reveals that normalized $\gamma \mathrm{H} 2 \mathrm{AX}$ levels of $\sim<0.6$ likely represent $\gamma \mathrm{H} 2 \mathrm{AX}$ in cells with minimal or no accumulated DNA damage, as this is the range of $\gamma \mathrm{H} 2 \mathrm{AX}$ level values detected in non-cisplatin-treated cells.

I next compared the distribution of $\gamma \mathrm{H} 2 \mathrm{AX}$ levels in cisplatin-treated cells to cells treated with cisplatin alongside EGF alone, PI3Ki alone or EGF+ PI3Ki alone. In each of these panels, it can be seen in the condition with cisplatin alone that there is a larger range of where $\gamma \mathrm{H} 2 \mathrm{AX}$ expression is detected, in all other conditions there is similar intensities for bins under 2.25, however only in the condition with cisplatin alone do we observe continued $\gamma \mathrm{H} 2 \mathrm{AX}$ expression in ranges exceeding 2.25. This suggests that although there is still detectable levels of $\gamma \mathrm{H} 2 \mathrm{AX}$ expression, and thus DNA double strand breaks in these conditions, stimulation with EGF and/or the introduction of PI3Ki leads to a broad reduction of $\gamma \mathrm{H} 2 \mathrm{AX}$ levels in cells across the distribution of the $\gamma \mathrm{H} 2 \mathrm{AX}$ level range, rather than a selective enhancement of cells with no or limited $\gamma \mathrm{H} 2 \mathrm{AX}$ 
staining (likely reflecting undamaged cells). This suggests that the pathways involved in the DNA damage response as regulated by EGF stimulation and/or PI3K inhibition perturb the ability of cells to induce formation $\gamma \mathrm{H} 2 \mathrm{AX}$, and therefore influencing the ability of the cell to sustain higher levels of $\gamma \mathrm{H} 2 \mathrm{AX}$ upon damage.

To additionally represent the data and show the relevance of the distribution of the values, the $95 \%$ percentile value from the pooled data across the PI3K experiments for our negative control condition (-CDDP -EGF -PI3Ki) was used was used to set a threshold to score cells in a binary manner as having $\gamma \mathrm{H} 2 \mathrm{AX}$ reactivity ( $\gamma \mathrm{H} 2 \mathrm{AX}$ levels above this value) or not having $\gamma \mathrm{H} 2 \mathrm{AX}$ reactivity ( $\gamma \mathrm{H} 2 \mathrm{AX}$ levels below this value). The value was 0.5012 , this value was selected as it had been observed that the negative control was routinely lower in $\gamma \mathrm{H} 2 \mathrm{AX}$ expression, and the 95\% percentile ensures that any values that may enter the range of DNA damage expression are likely reflective of outliers. This shows that the addition of EGF causes approximately a modest decrease of about $10 \%$ in the number of cells that are expressing $\gamma \mathrm{H} 2 \mathrm{AX}$-positive score. Additionally, when comparing the other cisplatin damaged conditions, we can see that inhibition of PI3K causes approximately a 13\% decrease, however the triple positive condition only corresponds to a 5\% decrease, suggesting no synergistic effect between EGF addition and PI3K inhibition (Figure 12). 


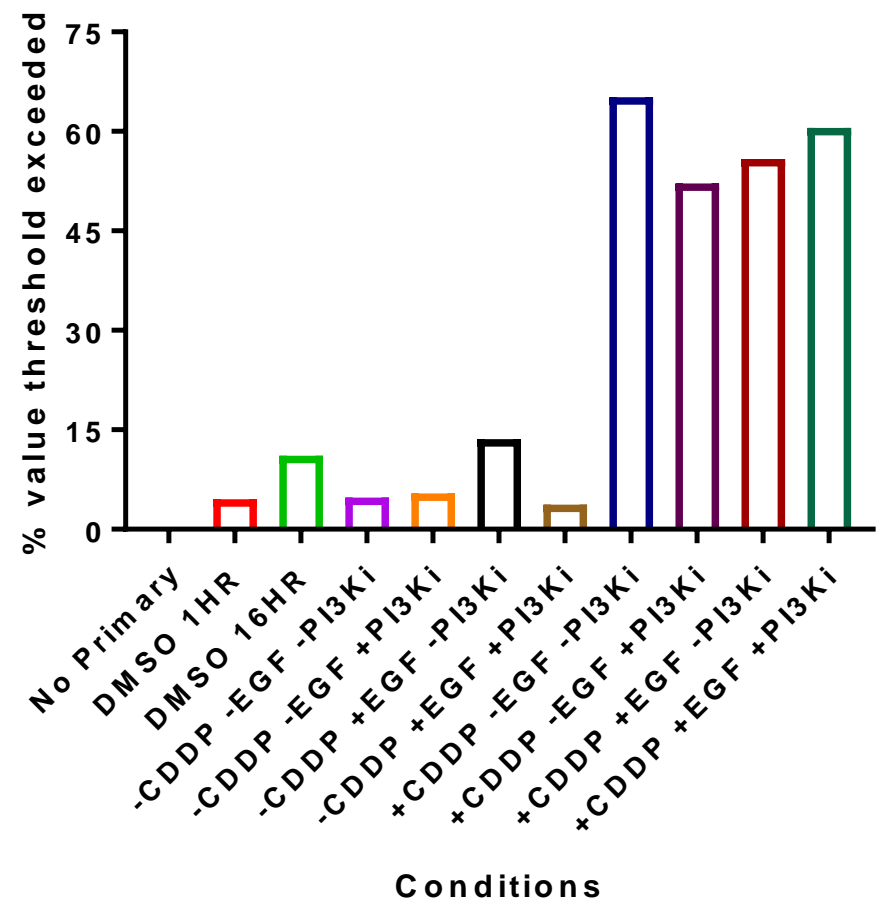

Figure 12. Exposure to cisplatin induces an increase in the percentage of MDA-MB-231 cells with DNA damage. The $95 \%$ percentile of the negative control condition, 0.5012, was used to set a threshold of DNA damage. All values across the PI3Ki set of experiments were then compared to our threshold, when values were equal to or greater than the set threshold, they were assigned a value of 1 , otherwise 0 . The sum of each condition was then divided by the total number of values in said condition to determined the percentage of values that exceed our threshold. Our positive control condition expressed the largest percent value for threshold exceeded, 65.1832, the other cisplatin damaged conditions had values of 52.1311, 55.848, and 60.5505.

Considering the addition of EGF and PI3Ki together to the cisplatin treated cells did not have such a pronounced decrease in $\gamma \mathrm{H} 2 \mathrm{AX}$ levels as the additives did alone, it is possible that the treatments are using some common pathway(s) to influence the change in $\gamma \mathrm{H} 2 \mathrm{AX}$ levels. Furthermore, the observed decrease may not be additive as a result of a limiting factor in the common pathway that is influenced both by EGF stimulation and PI3K inhibition; when both are added to the media their downstream effectors may compete for the use of cellular resources and thus alter the effect they have on the levels of $\gamma \mathrm{H} 2 \mathrm{AX}$. 


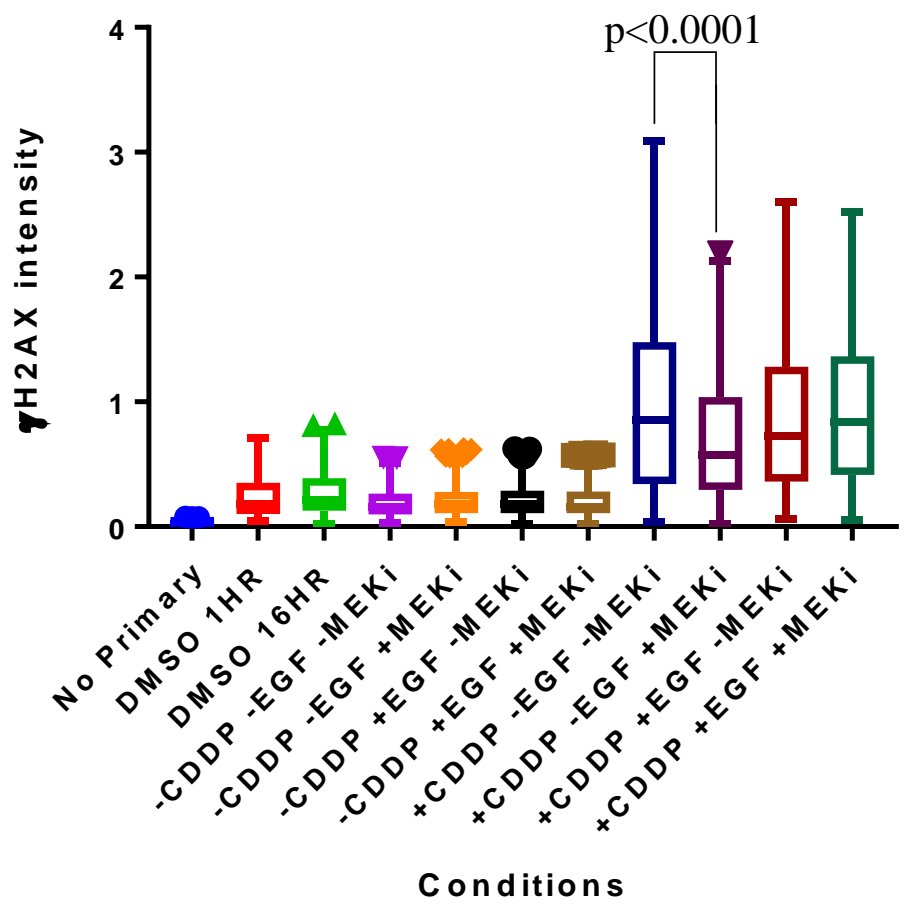

Figure 13. ERK pathway inhibition reverses the DNA damage response in acutely EGF stimulated cisplatin damaged cells. MDA 231 breast cancer cells exposed to cisplatin had a different trend in $\gamma \mathrm{H} 2 \mathrm{AX}$ expression when compared to the condition with both cisplatin and acute EGF stimulation $(\mathrm{k}=204$ and 212, $\mathrm{p}=0.0770)$. As well, in conditions where MEK inhibitor PD98059 was added to cisplatin damaged cells there was a decrease in the detection of $\gamma \mathrm{H} 2 \mathrm{AX}(\mathrm{k}=252, \mathrm{p}<0.0001)$. Comparing this condition to the EGF stimulated cisplatin damaged cells there is a statistically significant difference $(\mathrm{p}<0.0001)$, this is also seen when the two are added together. However, in the condition where both EGF and MEKi is present in cisplatin damaged cells, there is a no significant difference.

To examine the role of the Ras-Raf-Erk signalling pathway in controlling the DNA damage response, cells were again treated with cisplatin for $16 \mathrm{~h}$ to induce DNA damage or left untreated (control). Following this cisplatin treatment, some cells were also treated with MEK inhibitor for $1 \mathrm{~h}$ in the continued presence of cisplatin, and subsequently some also were also treated with EGF for $10 \mathrm{~min}$. This experimental design allowed study of the role of MEK signalling in both the constitutive active DNA damage response (i.e. in non-EGF treated cells), as well as the EGFstimulated DNA damage response. The cisplatin positive only condition was the positive control (representing DNA damaged cells without additional perturbations) and was used to normalize all conditions, giving it a mean value of 1 . When comparing the previously described positive control 
condition to those which are additionally treated with either EGF, the MEK inhibitor (PD98059, MEKi henceforth), or a combination of both certain trends and statistically significant findings are observed.

In Figure 8 and Figure 9, acute stimulation of EGFR by EGF in cisplatin treated cells leads to a decrease in the detection of $\gamma \mathrm{H} 2 \mathrm{AX}$ levels, as well in Figure 13 when compared to cells treated with cisplatin alone $(\mathrm{p}=0.0770)$. Furthermore, the addition of MEKi to the cisplatin treated cells for the last hour of a $16 \mathrm{~h}$ cisplatin treatment regimen exhibited a reduction in $\gamma \mathrm{H} 2 \mathrm{AX}$ compared to cells with cisplatin alone $(\mathrm{p}<0.0001)$. However, cisplatin treated cells with a combination of both EGF and the MEKi does not lead to a similar conclusion, as this combination results in an expression level of $\gamma \mathrm{H} 2 \mathrm{AX}$ similar to the cisplatin-only positive control condition ( $\mathrm{p}=0.9998)$. The cisplatin conditions with the addition of either EGF or the MEKi, are different in values, yet independently are able to decrease $\gamma \mathrm{H} 2 \mathrm{AX}$ expression, suggesting an antagonistic relationship between the pathway involved in EGF stimulated EGFR and ERK.

This data presented in Figure 13 represents the pooling of all individual cells across all experiments performed examining the effect of ERK inhibition. To further examine the reproducibility of the regulation of $\gamma \mathrm{H} 2 \mathrm{AX}$ levels in cisplatin treated cells by EGF or MEKi treatment, the means of the $\gamma \mathrm{H} 2 \mathrm{AX}$ measurements in each condition in each individual experiment and the standard error of the mean was plotted to examine the variation between individual experiments. For this analysis, the $\gamma \mathrm{H} 2 \mathrm{AX}$ levels in each condition in each experiment was normalized to the mean $\gamma \mathrm{H} 2 \mathrm{AX}$ level of the cisplatin-only (positive control) condition. 


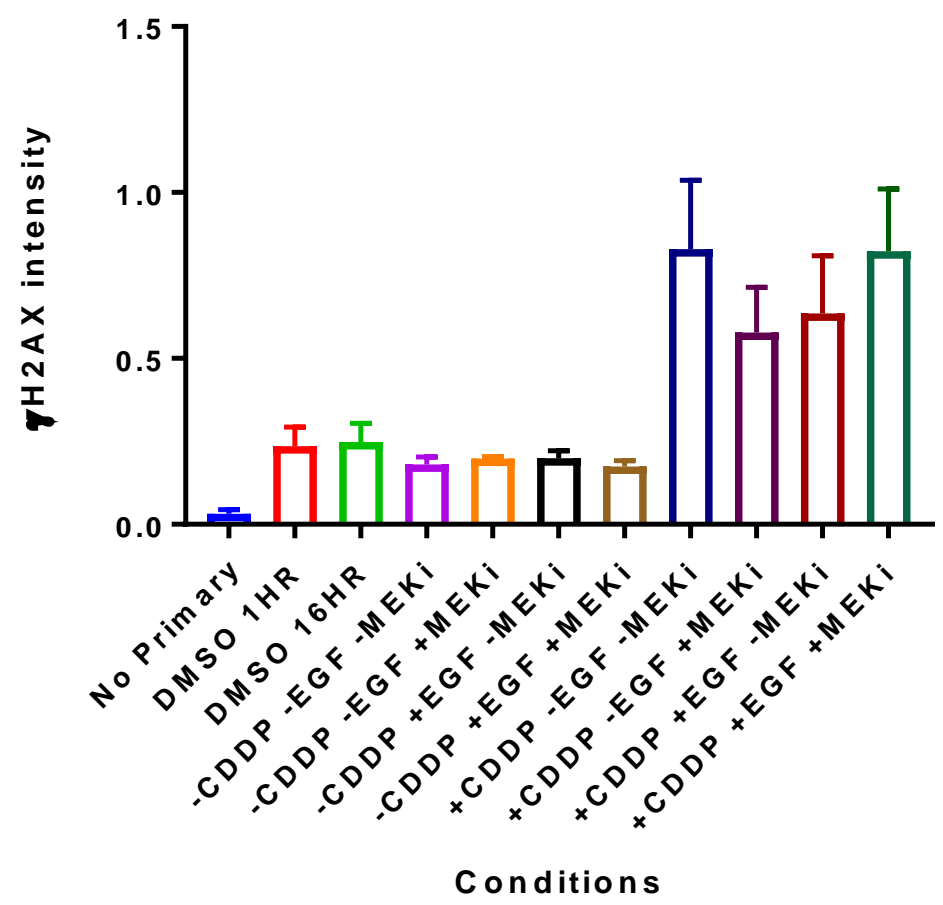

Figure 14. Variation in individual experiments alters the expression levels of $\gamma \mathrm{H} 2 \mathrm{AX}$ as seen by the medians and standard error of the mean. The previously described data was replotted to represent the median of each condition as well as the standard error of the mean. It was determined that the previously described effect of EGF on decreasing the expression levels of $\gamma \mathrm{H} 2 \mathrm{AX}$ was no longer significant. As well, when comparing with ANOVA any condition exposed to cisplatin with any other cisplatin added condition, no comparison was significant.

Statistical analysis of the data as represented in Figure 14 shows the variability between the experimental conditions between repetitions. Comparing the cisplatin alone condition to the cisplatin-treated cells with EGF there is no statistically significant difference $(\mathrm{p}=0.9628)$. A lack of statistical significance can also be seen when comparing the cisplatin treated condition with the cisplatin treated cells with MEKi $(\mathrm{p}=0.8505)$. This suggests that the response from experiment to experiment is variable, in the response seen to the additives such as EGF and MEKi. However, the effect of cisplatin alone in comparison to cells with no additives is still statistically significant $(\mathrm{p}=0.0001)$, implying the variance may lie with either EGF or MEKi. 

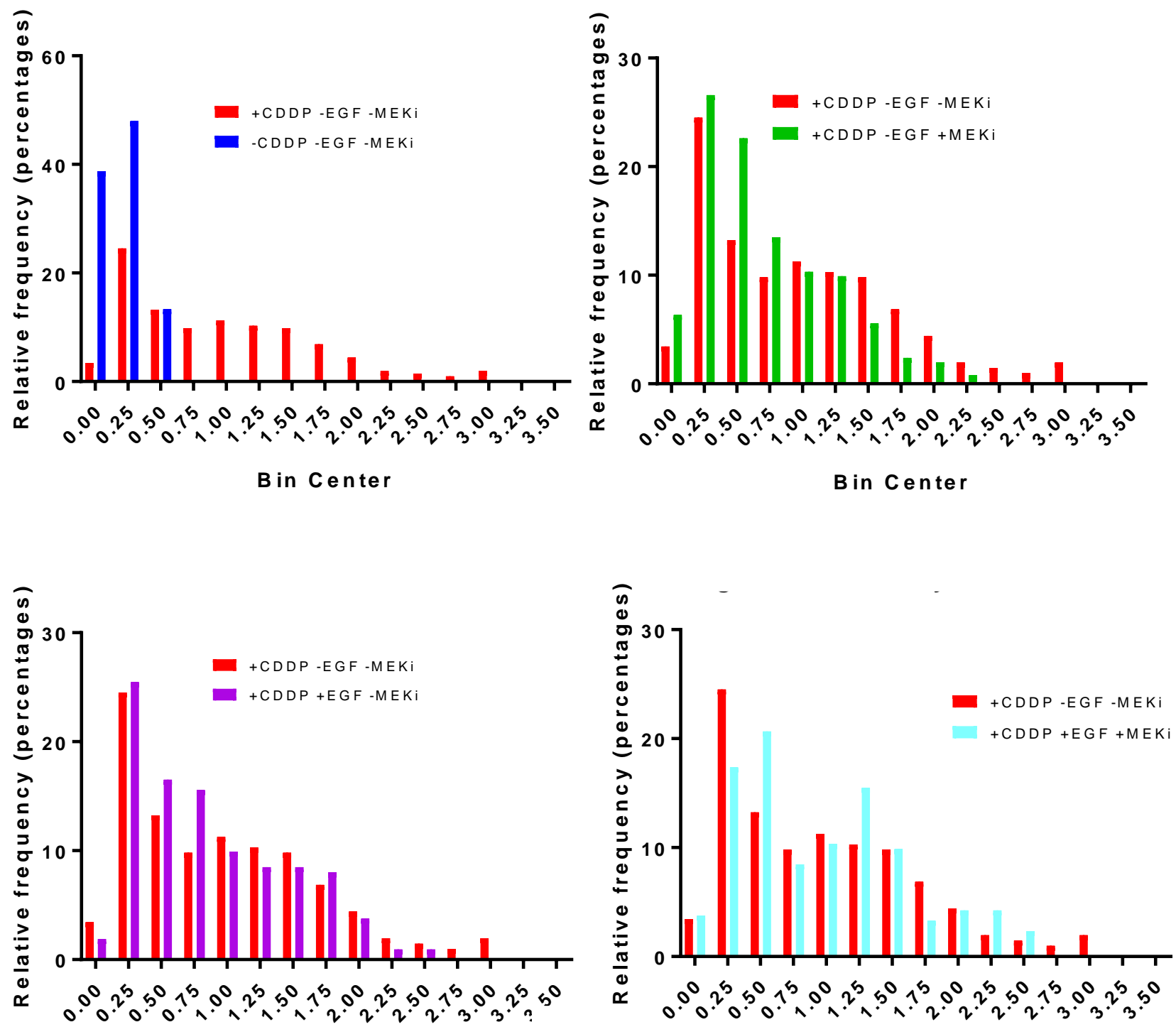

Bin Center

Bin Center

Figure 15. ERK pathway inhibition reverses the DNA damage response in acutely EGF stimulated cisplatin damaged cells. MDA 231 breast cancer cells exposed to cisplatin had a different trend in $\gamma \mathrm{H} 2 \mathrm{AX}$ expression when compared to the condition with both cisplatin and acute EGF stimulation ( $\mathrm{k}=204$ and 212, $\mathrm{p}=0.0770)$. As well, in conditions where ERK inhibitor PD98059 was added to cisplatin damaged cells there was a decrease in the detection of $\gamma \mathrm{H} 2 \mathrm{AX}(\mathrm{k}=252, \mathrm{p}<0.0001)$. Comparing this condition to the EGF stimulated cisplatin damaged cells there is a statistically significant difference $(\mathrm{p}<0.0001)$, this is also seen when the two are added together. However, in the condition where both EGF and MEKi is present in cisplatin damaged cells, there is a no significant difference.

I next sought to understand how EGF or MEKi may be altering the levels of $\gamma \mathrm{H} 2 \mathrm{AX}$ in a cell population. From the results shown in Figure 13, in some cases EGF and MEKi reduce the levels of $\gamma \mathrm{H} 2 \mathrm{AX}$ in cisplatin-treated cells. This could be due to EGF or MEKi eliciting a global 
reduction in $\gamma \mathrm{H} 2 \mathrm{AX}$ levels in cisplatin-treated cells, or this could reflect that these treatments reduce the number of cells that are above a threshold for $\gamma \mathrm{H} 2 \mathrm{AX}$ to be considered 'damaged', while most cells that exhibit $\gamma \mathrm{H} 2 \mathrm{AX}$ staining do so at high levels. To distinguish between these possibilities, I examined the frequency distribution of $\gamma \mathrm{H} 2 \mathrm{AX}$ levels in cells treated with cisplatin in combination with other agents. Comparing the frequency distribution of the $\gamma \mathrm{H} 2 \mathrm{AX}$ intensity, it can be seen that the addition of cisplatin shifts the distribution of $\gamma \mathrm{H} 2 \mathrm{AX}$ levels towards much higher value bin compared to cells not treated with cisplatin (Figure 15). From this analysis, there is a large change the distribution of the values when cisplatin is added, where $\gamma \mathrm{H} 2 \mathrm{AX}$ intensity values reach 3.0. In the no additive condition all values are below 0.75 with most falling in the 0.0-0.2 range. This reflects the effect of cisplatin to induce the accumulation of DNA damage in a large proportion of cells. In addition, this frequency distribution reveals that normalized $\gamma \mathrm{H} 2 \mathrm{AX}$ levels of $\sim<0.75$ likely represent $\gamma \mathrm{H} 2 \mathrm{AX}$ in cells with minimal or no accumulated DNA damage, as this is the range of $\gamma \mathrm{H} 2 \mathrm{AX}$ level values detected in control (non-cisplatin-treated) cells.

I next compared the distribution of $\gamma \mathrm{H} 2 \mathrm{AX}$ levels in cisplatin-treated cells to cells treated with cisplatin alongside EGF, MEKi, or EGF + MEKi. In each of these panels, it can be seen in the condition with cisplatin alone that there is a larger range of where $\gamma \mathrm{H} 2 \mathrm{AX}$ expression is detected, in all other conditions there is similar intensities for bins under 2.50 , however only in the condition with cisplatin alone do we observe continued $\gamma \mathrm{H} 2 \mathrm{AX}$ expression in ranges exceeding 2.50. This suggests that although there is still detectable levels of $\gamma \mathrm{H} 2 \mathrm{AX}$ expression, and thus DNA double strand breaks in these conditions, stimulation with EGF and/or the introduction of MEKi leads to a broad reduction of $\gamma \mathrm{H} 2 \mathrm{AX}$ levels in cells across the distribution of the $\gamma \mathrm{H} 2 \mathrm{AX}$ level range, rather than a selective enhancement of cells with no or limited $\gamma \mathrm{H} 2 \mathrm{AX}$ staining (likely reflecting undamaged cells), consistent with the results presented in Figure 11 that similarly 
examined the effects of EGF stimulation or treatment with PI3Ki. This suggests that the pathways involved in the DNA damage response as regulated by EGF stimulation and/or ERK inhibition perturb the ability of cells to express higher levels of $\gamma \mathrm{H} 2 \mathrm{AX}$, and therefore influencing the ability of the cell to display the DNA damaged phenotype.

To additionally represent the data and show the relevance of the distribution of the values, the $95 \%$ percentile value from the pooled data across the ERK experiments for our negative control condition (-CDDP -EGF -MEKi) was used was used to set a threshold to score cells in a binary manner as having $\gamma \mathrm{H} 2 \mathrm{AX}$ reactivity ( $\gamma \mathrm{H} 2 \mathrm{AX}$ levels above this value) or not having $\gamma \mathrm{H} 2 \mathrm{AX}$ reactivity $(\gamma \mathrm{H} 2 \mathrm{AX}$ levels below this value). The value was 0.4455 , this value was selected as it had been observed that the negative control was routinely lower in $\gamma \mathrm{H} 2 \mathrm{AX}$ expression, and the 95\% confidence interval ensures that any values that may enter the range of DNA damage expression are likely reflective of outliers. None of the treatments exhibited changes in the percentage of cells that displayed a damaged phenotype as determined by this threshold. 


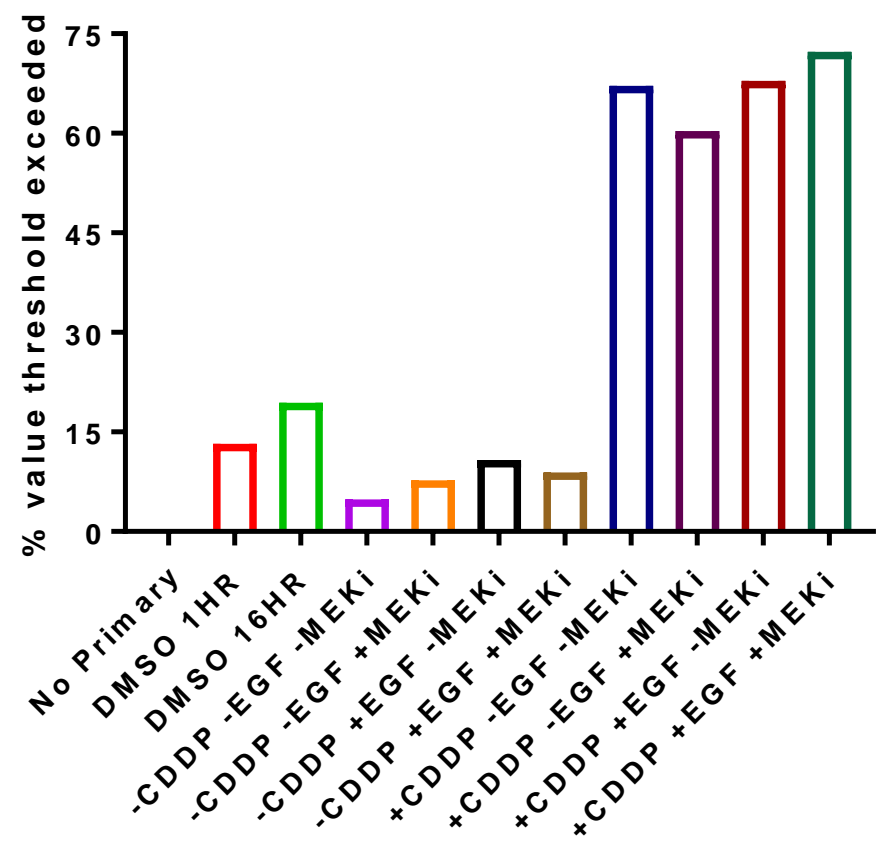

Conditions

Figure 16. Exposure to cisplatin induces an increase in the percentage of MDA-MB-231 cells with DNA damage. The $95 \%$ percentile of the negative control condition, 0.4455 , was used to set a threshold of DNA damage. All values across the MEKi set of experiments were then compared to our threshold, when values were equal to or greater than the set threshold, they were assigned a value of 1 , otherwise 0 . The sum of each condition was then divided by the total number of values in said condition to determined the percentage of values that exceed our threshold. Our positive control condition for threshold exceeded was 67.16, the other cisplatin damaged conditions had values of 60.32, 67.92, and 72.3 .

Considering the addition of EGF and MEKi together to the cisplatin treated cells resulted in an increase in $\gamma \mathrm{H} 2 \mathrm{AX}$ levels higher than either additive individually, it is possible that the treatments are using a common pathway to influence the change in $\gamma \mathrm{H} 2 \mathrm{AX}$ levels and may have an antagonistic effect on one another. This increase may be the result of a common signalling pathways used when both are added to the media; their downstream effectors may compete for the use of cellular resources and thus alter the effect they have on the levels of $\gamma \mathrm{H} 2 \mathrm{AX}$. 


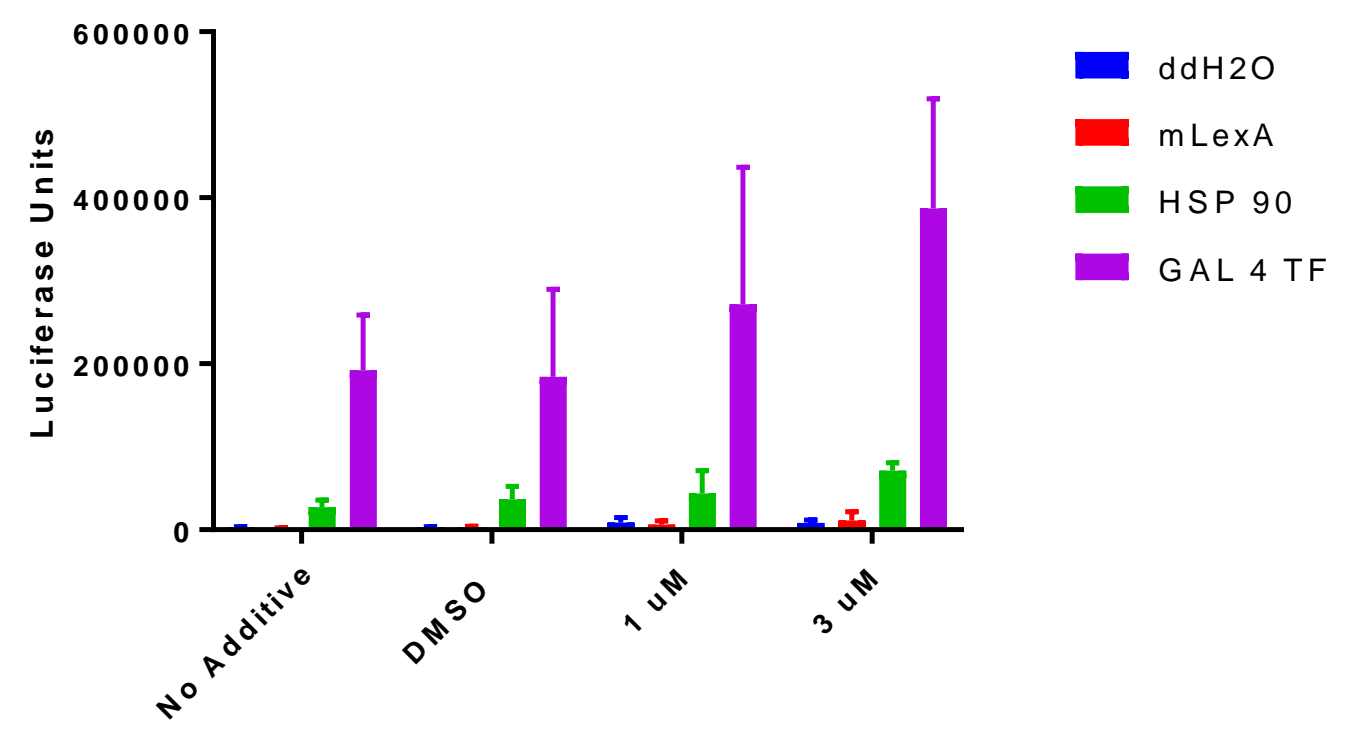

Conditions

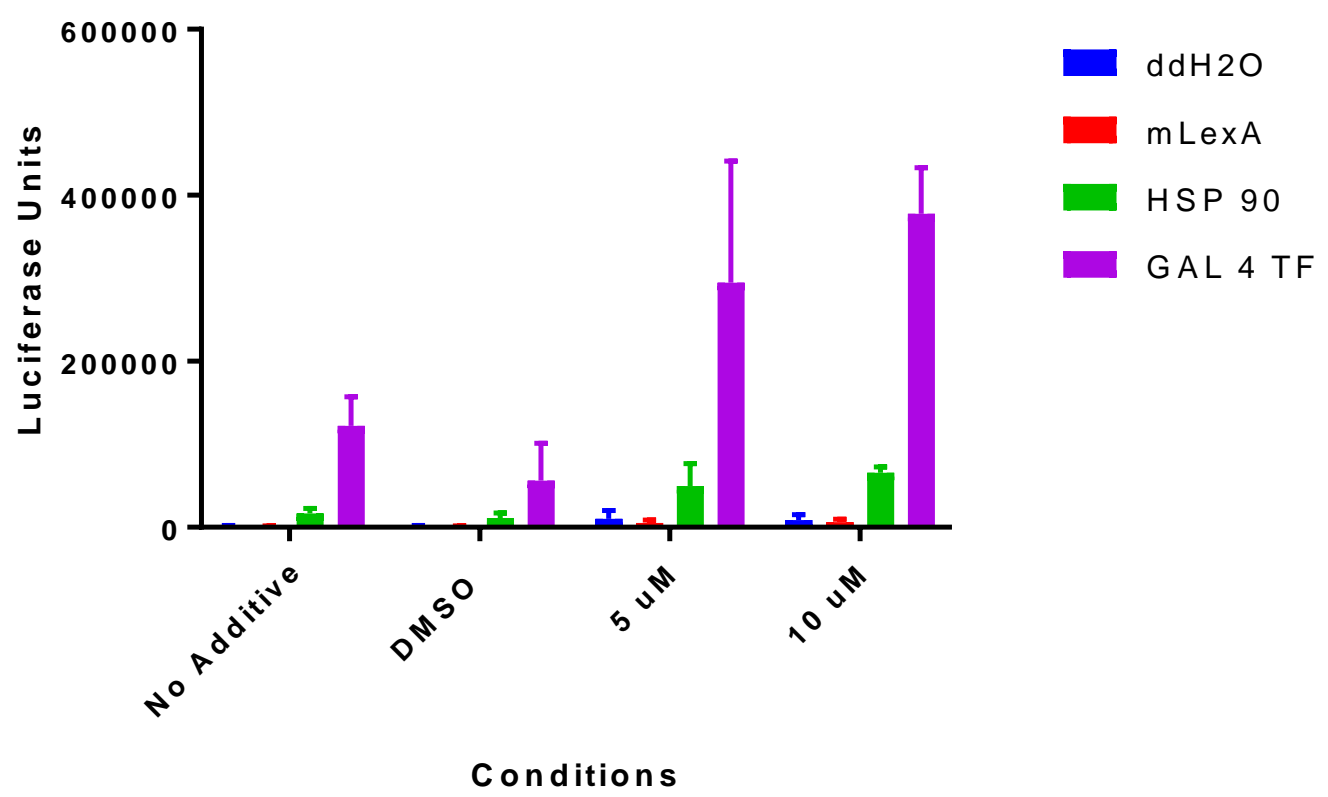

Figure 17. Examination of PitStop2 influence of protein-protein interactions in HEK 293 cells. Additional screenings were completed using the clathrin coated pit inhibitor, PitStop2. The top figure shows the low concertation plate, containing two controls, Blank and Dimethyl Sulfoxide, as well as $1 \mu \mathrm{M}$ and $3 \mu \mathrm{M}$ of PitStop2, the bottom figure has the same controls but uses 5 and $10 \mu \mathrm{M}$ of the clathrin coated pit inhibitor PitStop2. 
EGFR is a key regulator in many signalling complexes, as it acts as a mediator between extracellular signals, ligands, and intracellular signal transduction. The work I have completed has shown that EGFR to an extent may control the expression of $\gamma \mathrm{H} 2 \mathrm{AX}$. Furthermore, it appears that EGF stimulation influences the ability to regulate $\gamma \mathrm{H} 2 \mathrm{AX}$ through the Ras-Raf-Erk signalling pathway, and that the PI3K-Akt may also regulate $\gamma \mathrm{H} 2 \mathrm{AX}$, but not in the context of EGFR signaling. Both of these signalling pathways require the formation of nanodomains at the plasma membrane; either Ras nanoclusters or clathrin nanodomains. This lead to an examination using MaMTH of the EGFR interations that are required for clathrin-dependent signals such as PI3KAkt and control of H2AX phosphorylation (e.g. by Ras-Raf-Erk) and other specific cellular outcomes.

To use MaMTH, one needs to compare EGFR interactions in control cells with cells in which clathrin is perturbed. One could use siRNA gene silencing, but there are resource considerations to using siRNA for a large-scale experiment such as MaMTH. The clathrin inhibitor PitStop2 is thus very useful to perturb clathrin for study of clathrin-dependent interactions with MaMTH. However, PitStop2 has been noted to have a few critical limitations and off-target effects that could in principle limit its usefulness for MaMTH to study clathrin-dependent interactions. Of particular importance is the effect of PitStop2 to potentially block nuclear import by affecting the nuclear pore complex (Liashkovich et al., 2015). Hence, to establish whether this strategy of examining the effect of PitStop2 can be effective for a screen to study clathrin-dependent EGFR interactions, I needed to establish if PitStop2 affected expression of the luciferase reporter assay in this system.

To determine if PitStop2 had off-target effects that preclude use of PitStop2 to study clathrin-dependent interactions of EGFR, I prepared several HEK 293T cells stably expressing the 
EGFR MaMTH construct and luciferase reporter gene by transfection with various prey constructs, followed by exposure to the clathrin coated pit inhibitor, PitStop2, for a period of 16 hours. The cells treated with dimethyl sulfoxide (DMSO) acted as the vehicle control. Some cells were treated with ddH2O instead of transfection reagent (Blank).

In Figure 17 there are two types of positive control baits for luciferase signal this experiment. The first positive control bait is the free Gal 4 transcription factor (TF), which is expressed in such a way to induce luciferase expression without requiring any interactions with EGFR. It was observed that the positive control Gal 4TF reached levels exceeding the 100,000 Luciferase units threshold consistently across all treatment conditions, as expected. The second type of control bait was a well-established known interactor of EGFR, HSP90, which requires interaction with EGFR and cleavage of Gal4TF from the cell surface. This control also provided substantial signal over background - both the blank (not transfected with bait plasmid) and the LexA "bait" (a protein that does not interact with EGFR). For both Gal4TF control and Hsp90, PitStop2 treatment did not impair the ability of the MaMTH assay to detect EGFR-dependent interactions (based on Hsp90 result) nor did it disrupt the efficiency of the core luciferase assay on which MaMTH is based (based on the Gal4TF result). In comparison, the other plasmids (negative controls, LexA) had substantially lower expression of luciferase, suggesting the MaMTH assay worked as anticipated. 


\subsection{DISCUSSION}

The experiments that I conducted as part of my graduate studies research suggest that EGFR and some of the signalling pathways that it can cative may influence the DNA damage response. Acute stimulation with EGF decreased the level of $\gamma \mathrm{H} 2 \mathrm{AX}$ levels in cisplatin-treated cells. As $\gamma \mathrm{H} 2 \mathrm{AX}$ is an indicator of double stranded breaks, this suggests that EGFR may regulate the DNA damage response. Inhibition of PI3K-Akt signalling by treatment with (PI3Ki) in cisplatin-treated cells decreased the levels of $\gamma \mathrm{H} 2 \mathrm{AX}$. As well, Ras-Raf-Erk pathway inhibition decreased $\gamma \mathrm{H} 2 \mathrm{AX}$ expression. However, there may be a reversal in the effect of EGF on levels of $\gamma \mathrm{H} 2 \mathrm{AX}$ when MEKi is present. This suggests that both the PI3K-Akt and Ras-Raf-Erk pathway may influence the ability of EGFR to regulate the DNA damage response, and that the influence that EGFR has on $\gamma \mathrm{H} 2 \mathrm{AX}$ levels may be due to the activation of the Ras-MEK1-Erk signaling pathway by the receptor. Furthermore, the work completed on the MaMTH assay has been optimized for the purposes of examining potential protein-protein interactions of EGFR that require clathrin.

\subsection{Acute EGF stimulation decreased $\gamma \mathrm{H} 2 \mathrm{AX}$ levels in cisplatin exposed cells}

EGFR is activated in the presence of ligand, such as EGF. When bound to ligand EGFR undergoes a conformational change allowing for the recruitment of scaffolding proteins and the transduction of signals. In cells that were exposed to the chemotherapeutic agent, cisplatin, there is a large increase in $\gamma \mathrm{H} 2 \mathrm{AX}$ levels $(\mathrm{p}<0.0001)$. In all experiments, $\gamma \mathrm{H} 2 \mathrm{AX}$ levels were used to quantify the DNA damage accumulated in the cells by cisplatin, as $\gamma \mathrm{H} 2 \mathrm{AX}$ expression is a marker

of double stranded breaks (Giglia-Mari et al., 2011; Jackson, 2002; Jackson and Bartek, 2009; Sáez, 2018; Xu et al., 2016). Phosphorylation of H2AX can also be detected in cases where single 
strand breaks (SSBs) have occurred, and throughout the cellular processes such as mitosis or apoptosis (Borrego-Soto et al., 2015).

I observed that exposing cisplatin-treated cells to EGF for 10 min resulted in a decrease of $\gamma \mathrm{H} 2 \mathrm{AX}$ levels when compared to the positive control (+CDDP -EGF) condition $(\mathrm{p}<0.0001)$. This is a novel regulation of $\gamma \mathrm{H} 2 \mathrm{AX}$ levels by EGFR signalling that to our knowledge has not been reported previously. This suggests two possible broad mechanisms: 1) EGF stimulation may elicit a signal that masks DNA damage, such as by selective dephosphorylation of $\gamma \mathrm{H} 2 \mathrm{AX}$, or 2) a highly accelerated DNA damage response mechanism triggered by EGFR activation. Considering the acuteness of the EGF stimulation, and that the process of repairing DNA damage may take substantially longer than $10 \mathrm{~min}$, it is more likely that the response observed is masking the DNA damage instead of a repair mechanism that has been triggered by EGFR activation. This initial observation lead to an examination of some of the better characterized signalling pathways that are regulated by EGFR, such as the PI3K-Akt and Ras-Raf-Erk signalling pathways.

The MDA-MB-231cells that were used in this experiment have a G13D KRAS mutation which leads to constitutively activated Ras protein (Kim et al., 2015). As well, the experiments are exposed to $0.1 \%$ serum media to minimize the presence of growth factors and other ligands that would otherwise robustly activate many of the signals activated by EGFR. Although this condition does not completely remove the presence of such receptor ligands, it limits activation of EGFR and can therefore be used to sustain the cells. This was used to establish our baseline of $\gamma \mathrm{H} 2 \mathrm{AX}$ levels in these cells as seen in the negative control (-CDDP -EGF) condition. Our continued probing of the signalling pathways activated by EGFR aimed to determine whether the initial observation that signals derived from EGFR could impact $\gamma \mathrm{H} 2 \mathrm{AX}$ levels was the result of exposure 
to the EGF ligand to trigger signals, or whether the "baseline" levels of signalling pathways influenced the DNA damage response.

\subsection{PI3K inhibition decreased $\gamma \mathrm{H} 2 \mathrm{AX}$ expression in cisplatin exposed cells}

GDC0941 is pan-PI3K class I inhibitor, which has been studied in the clinic, and shown to reduce phosphorylation of downstream signalling components such as Akt (Ehrhardt et al., 2015; Sarker et al., 2015). These studies suggest that GDC0941 is an effective treatment option, either alone or in combination with other cancer therapies (Ehrhardt et al., 2015; Sarker et al., 2015). Work completed by Ehrhardt et al. has shown that GDC0941 is an effective chemotherapeutic to treat medulloblastomas (Ehrhardt et al., 2015)The work completed, as well as some of the first clinical trials of GDC0941 has shown its efficacy in causing cancer cell death, limiting cellular mobility, and limiting cell growth; as well as determining that deregulation of PI3K and PTEN are suitable biomarkers for GDC0941 treatment (Ehrhardt et al., 2015; Sarker et al., 2015).

Comparing our cisplatin damaged cells to those that were exposed to both cisplatin and our PI3K inhibitor a statistically significant decrease is observed when examining the behaviour of individual cells pooled from multiple experiments $(\mathrm{p}<0.0001)$. This effect was comparable to the acutely EGF stimulated cisplatin damaged cells, as there was no statistically significant difference between cisplatin+EGF and cisplatin+PI3Ki treated cells. This suggests that both the PI3K pathway and EGF stimulation are able to regulate the DNA damage response by controlling $\gamma \mathrm{H} 2 \mathrm{AX}$ levels. Additionally, when cisplatin damaged cells are exposed to both the PI3K inhibitor and EGF we are still able to observe a decrease in $\gamma \mathrm{H} 2 \mathrm{AX}$ expression in comparison to the positive control $(p<0.0001)$ however the effect of the two agents are not additive, let alone synergistic. This 
suggests that the mechanism by which EGFR is regulating the DNA damage response is separate from PI3K-AKt, as we do not see the PI3Ki inhibitor reversing the effect seen by acute EGF stimulation.

Considering that the inhibition of the PI3K-Akt signalling pathway resulted in a decreased level of $\gamma \mathrm{H} 2 \mathrm{AX}$, we speculate that the unperturbed PI3K would enhance $\gamma \mathrm{H} 2 \mathrm{AX}$ levels, in the absence of acute EGF stimulation. It is possible that the $\gamma \mathrm{H} 2 \mathrm{AX}$ levels are higher in the cisplatin damaged cells where PI3K is still active due to downstream signals being able to trigger phosphorylation of H2AX. In the absence of EGF our cisplatin treated cells have enhanced levels of $\gamma \mathrm{H} 2 \mathrm{AX}$, but when EGF is added we see that these levels are decreased. It is possible that the introduction of EGF to the cisplatin treated cells, causes an influx of ligand effected signalling pathways to be activated which may trigger dephosphorylation of $\gamma \mathrm{H} 2 \mathrm{AX}$ or alternatively, the decreased fluorescence could be the result of recruitment of DNA damage response complexes to $\gamma \mathrm{H} 2 \mathrm{AX}$, leading to marking of the $\gamma \mathrm{H} 2 \mathrm{AX}$ antibody used to detect this signal.

Understanding the mechanism by which cisplatin-treated cells respond to certain ligand and signalling pathways would provide novel insight into the ability of cancer cells to avoid cell cycle arrest or programmed cell death. More specifically, in cancers with EGFR overexpression, these underlying mechanisms could be manipulated to more effectively prevent cell growth and trigger cell cycle arrest and apoptosis. An examination of the medians and standard error of the means of individual experiments is useful to also study the reproducibility of the effect of PI3Ki treatment from one independent experiment to the other. This analysis reveals a similar trend, where it can be observed that there may be a decrease in $\mathrm{H} 2 \mathrm{AX}$ phosphorylation in the presence of EGF or the PI3K inhibitor GDC0941. The comparison of the medians of positive control and the cisplatin treated cells with EGF revealed a $\mathrm{p}=0.6791$, indicating that this did not meet our 
threshold of $\mathrm{p}<0.05$ that we used to establish that treatments yielded a statistically significant difference in $\gamma \mathrm{H} 2 \mathrm{AX}$ levels. This is likely the result of the variation from experiment to experiment. The data presented with all individual points is a representation of the variation of all data points as a whole, while the standard error of the mean is biased and does not accurately represent the variation in individual experiments.

The matter of reproducibility would need to be further examined to ensure that this fluctuation between individual repetitions of these are not due to a fundamental issue with the design of the assay. This can be addressed by completing additional assays to determine what differences exist in individual cells or a population of cells. Although we assume homogeneity in a population of cells it is possible that aspects of individual cells such as what stage of the cell cycle they are present in hinder the ability of certain components of our assay to be effective. As mentioned prior certain markers of DNA damage are more common during the G2/M transition in comparison to other stages, additionally it is possible that cells which had higher levels of $\gamma \mathrm{H} 2 \mathrm{AX}$ could have undergone apoptosis and lifted off the coverslips, preventing them from being properly fixed during the experimental process and thus removing them from the population of cells examined.

In order to determine how the $\gamma \mathrm{H} 2 \mathrm{AX}$ expression is altered between conditions we examined the frequency distribution of the values as normalized by the positive control. In the first histogram there is stark contrast between the negative and positive control, the negative control values do not exceed 0.6 whilst the positive control has a much larger range reaching $\gamma \mathrm{H} 2 \mathrm{AX}$ expression 5-fold higher. EGF stimulation or PI3Ki treatment reduces $\gamma \mathrm{H} 2 \mathrm{AX}$ across all bins exceeding our threshold values, rather than selectively increasing the proportion of undamaged (or below $\gamma \mathrm{H} 2 \mathrm{AX}$ threshold) cells. This suggests that additives such as EGF and the inhibition of PI3K 
are altering the distribution of $\gamma \mathrm{H} 2 \mathrm{AX}$ expression in cisplatin damaged cells, resulting in fewer cells having higher ranges of damage while not having a substantial effect on those cells which already have little to no $\gamma \mathrm{H} 2 \mathrm{AX}$ expression. To further analyze how the distribution of cisplatin damaged cells is influenced by EGF and PI3K inhibition we created a threshold to categorize cells that are have DNA double strand breaks and those that do not.

The $95^{\text {th }}$ percentile of the negative control condition was used to establish the threshold to determine whether or not a cell was positive for $\gamma \mathrm{H} 2 \mathrm{AX}$ expression, as there was little overlap with the positive control and ensured that any values present were likely outliers. The value, 0.5012, was used to separate all cells by giving them a value of 1 or 0 , dependent on whether their expression levels were greater than/equal to or less than 0.5012 respectively. The sum of each condition was then taken and divided by the number of values in order to determine the percentage of cells in that condition can be characterized as having $\gamma \mathrm{H} 2 \mathrm{AX}$ expression. This process allowed us to determine the change in the percent cells damaged as a result of EGF addition, PI3K inhibition, or a combination of both. In comparison to the positive control condition we determined that EGF causes modest reduction in the percentage of $\gamma \mathrm{H} 2 \mathrm{AX}$-positive cells, as did PI3K inhibition. The thresholding data suggests that the introduction of EGF to the cisplatin-treated cells is not altering the presence of DNA damage but is instead reducing the level of $\gamma \mathrm{H} 2 \mathrm{AX}$ that is present in the damaged cells. 


\subsection{MEK inhibition antagonizes acute EGF stimulations effect on $\gamma \mathrm{H} 2 \mathrm{AX}$ expression in cisplatin exposed cells}

Inhibiting the ERK signalling pathway, with the addition of PD98059, we are able to observe a decrease in $\gamma \mathrm{H} 2 \mathrm{AX}$ levels when compared to our cisplatin damaged cells $(\mathrm{p}<0.0001)$. This suggests a mechanism by which the ERK signalling pathway is regulating the DNA damage response. However, we see a reversal of the EGF-stimulated effect upon addition of the MEK1 inhibitor. This suggests a pathway where the MEK1-inhibited cells, when stimulated with EGF, are no longer able to decrease the levels of $\gamma \mathrm{H} 2 \mathrm{AX}$ present. This could be due to the creation of signalling complex at the plasma membrane forming and altering the transduction of signals from the receptor into the cell, or alternatively a negative feedback loop activated by EGF that alters the efficacy of the ERK signalling pathway responsible for our observed phenomena. We can speculate that since the addition of MEK1i to the cisplatin-treated cells blocks the ability of EGF sitmulation to alter the level of $\gamma \mathrm{H} 2 \mathrm{AX}$, it is likely that the effect of EGFR on control of $\gamma \mathrm{H} 2 \mathrm{AX}$ requires the Ras-MEK-Erk pathway. Considering the complexity of the EGFR signalling network, and the inhibition of MEKon the ability to influence the DNA damage it is possible that activation of phosphatases, such as PP2A, is influencing this response. Many of the signal transduction pathways that are regulated by Ras-Raf-Erk result in nuclear translocation of proteins and effect the status of the DNA (McCubrey et al., 2012).

MEK inhibition could result in slower cell cycle progression and protein production. When EGF is added, this process once again becomes active, this could result in increased activity in the nucleus and changes in the recruitment of DNA damage response proteins to the site of double stranded breaks. 
An examination of the variance between independent experiments (mean of the meadians of individual cell measurements) is useful to also study the reproducibility of the effect of MEKi treatment from one independent experiment to the other. This analysis reveals a similar trend, where it can be observed that there may be a decrease in the presence of EGF or the ERK inhibitor PD98059, but that these effects may not be statistically significantly different, reflecting some variation in the experimental outcomes between experiments.

In order to determine how the $\gamma \mathrm{H} 2 \mathrm{AX}$ expression is altered between conditions we examined the frequency distribution of the values as normalized by the positive control. In the first histogram there is stark contrast between the negative and positive control, the negative control values do not exceed 0.6 whilst the positive control has a much larger range reaching $\gamma \mathrm{H} 2 \mathrm{AX}$ expression 5-fold higher. Using this basis of comparison, we observed that all other conditions had similar distribution to that of our positive control, however in all cases there was a greater proportion of values in the lower end of the bin spectrum, while the positive control continued further into the bin range. This suggests that additives such as EGF and the inhibition of ERK are altering the distribution of $\gamma \mathrm{H} 2 \mathrm{AX}$ expression in cisplatin damaged cells, resulting in fewer cells having higher ranges of damage while not having a substantial effect on those cells which already have little to no $\gamma \mathrm{H} 2 \mathrm{AX}$ expression. To further analyze how the distribution of cisplatin damaged cells is influenced by EGF and ERK inhibition we created a threshold to categorize cells that are have DNA double strand breaks and those that do not.

The $95^{\text {th }}$ percentile of the negative control condition was used to establish the threshold to determine whether or not a cell was positive for $\gamma \mathrm{H} 2 \mathrm{AX}$ expression, as there was little overlap with the positive control and ensured that any values present were likely outliers. The value, 0.4455 , was used to separate all cells by giving them a value of 1 or 0 , dependent on whether their 
expression levels were greater than/equal to or less than 0.4455 respectfully. The sum of each condition was then taken and divided by the number of values in order to determine the percentage of cells in that condition can be characterized as having $\gamma \mathrm{H} 2 \mathrm{AX}$ expression. This process allowed for us to determine the change in the percent cells damaged as a result of EGF addition, ERK inhibition, or a combination of both. In comparison to the positive control condition we determined that EGF causes modest reduction in the percentage of $\gamma \mathrm{H} 2 \mathrm{AX}$-positive cells, however ERK inhibition did not. The thresholding data suggests that the introduction of EGF to the cisplatintreated cells is not altering the presence of DNA damage, but is instead reducing the level of $\gamma \mathrm{H} 2 \mathrm{AX}$ that is present in the damaged cells.

An examination of our signalling pathways of interest has led to the several possible mechanisms by which EGF can alter the level of $\gamma \mathrm{H} 2 \mathrm{AX}$ in cisplatin treated cells, Figure 18. If this is being completed by dephosphorylation processes it is likely that EGF is acting on phosphatases that alter the phosphorylation of $\gamma \mathrm{H} 2 \mathrm{AX}$. Considering the role $\gamma \mathrm{H} 2 \mathrm{AX}$ plays in recruiting proteins to the site of DNA damage, it is possible that dephosphorylation will inhibit the ability of the cell to undergo DNA repair. There is the possibility that the DNA damage response can occur through alternative mechanisms which do not rely on $\gamma \mathrm{H} 2 \mathrm{AX}$, however there is also the possibility that cell will either 1) continue through the cell cycle with damaged DNA, preventing accurate replication cycles from occurring or 2) the cells will undergo apoptosis. This can be studied through the use of metabolism assays to determine the use of nutrients by the cells as well as determining what proportion of cells die due to the inability to fix their DNA. 


\subsection{Protein-protein interactions can be examined by the MaMTH assay in clathrin perturbed cells}

The Stagljar laboratory has been using the MaMTH assay in the past to examine the proteinprotein interactions between EGFR and various proteins that influence signalling complexes and signal transduction through the cell (Saraon et al., 2017). An examination of the proteins dependent on the presence of clathrin for the purpose of signal transduction can be used to elucidate the importance of molecular domains unique to the cell surface and their influence on signal internalization. Work completed in our laboratory has already shown the importance of clathrin in some signalling pathways, such as the necessity of clathrin to act as a scaffold for EGFR at the plasma membrane (Garay et al., 2015b).

Using an assay such as MaMTH will allow for further extraction of information related to dynamic signalling modules at the plasma membrane. The work completed on the MaMTH assay has shown that we are now able to move forward and analyze the protein-protein interactions occurring with EGFR that are dependent on the presence of clathrin and the formation of clathrin coated pits. The work has shown that the cells are able to survive for extended periods of time with the clathrin inhibitor PitStop2 being present for 16 hours, without impairment of the nuclear pore complex or influencing the ability of luciferase to translocate to the nucleus (Liashkovich et al., 2015). The system has now been optimized, as has been seen by Gal 4 TF reaching an acceptable range, and it has been seen that the possible side effects of PitStop2 being added has had no effect on the ability of the assay to work. Additional work would need to be done to ensure the system is optimized and reflective of the physiological conditions that can be readily found in cells. The methodology behind the MaMTH assay results in the overexpression of proteins, as well as 
needing to account for interactions that may not happen in close enough proximity to the EGFR tagged protein at the plasma membrane. An alternative method to complete this could be BioID.

The BioID assay uses engineered ligase to trigger catalysis in close proximity to the protein of interest, this results in biotinylation of the proteins in close proximity (Brückner et al., 2009; Roux et al., 2013). The proteins that have been biotinylated can then be further examined to determine the type of interaction present (Brückner et al., 2009; Roux et al., 2013). By completing an assay similar to that of BioID we could cross reference the protein-protein interactions that we conclude from MaMTH to ensure to increase our confidence in the results. 


\subsection{CONCLUSIONS}
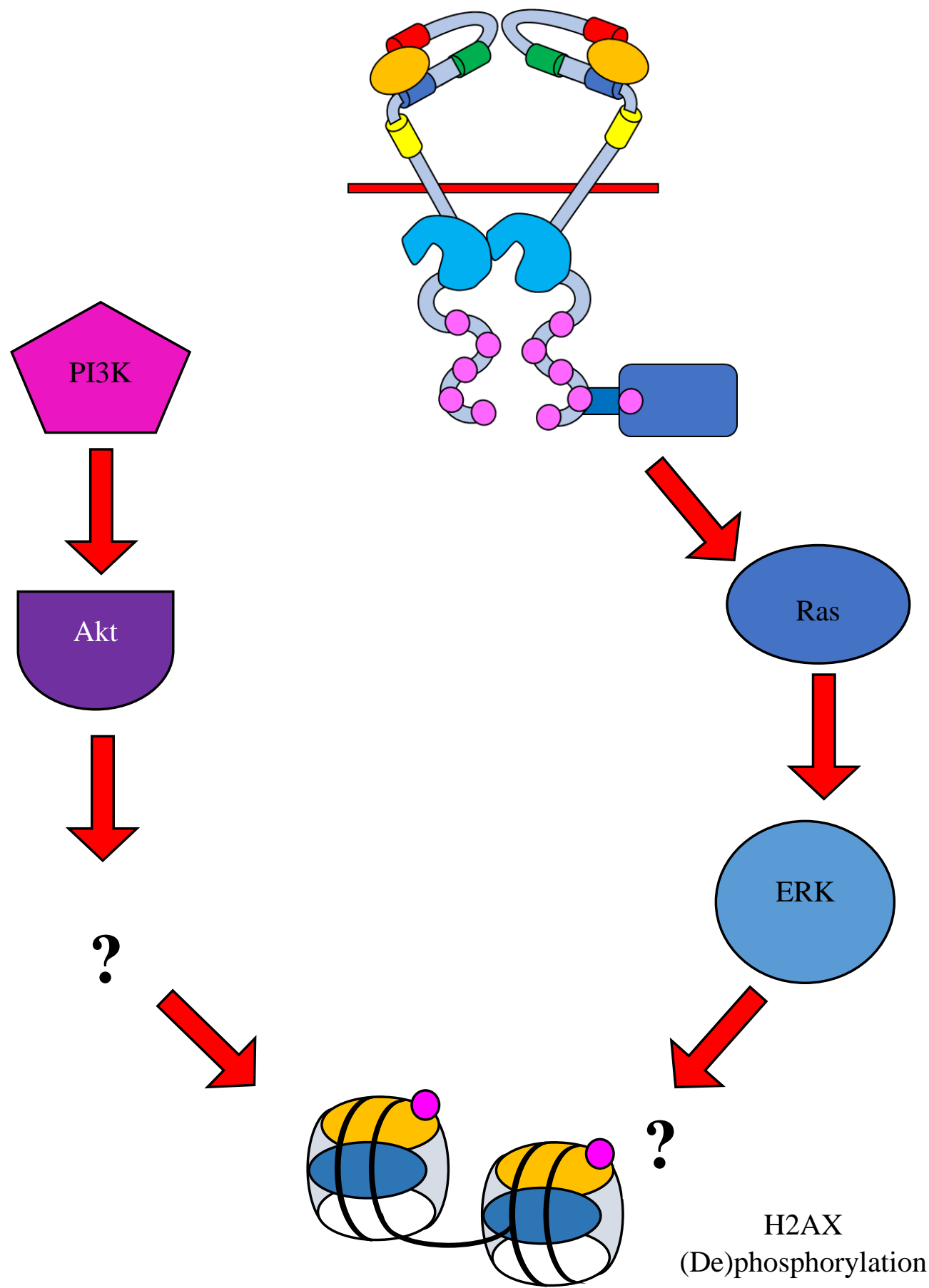

Figure 18. EGFR mediates H2AX phosphorylation through the Ras/Raf/Erk signalling pathway. The inhibition of the Ras/Raf/Erk signalling pathway regulates the detection of $\gamma \mathrm{H} 2 \mathrm{AX}$. The PI3K/Akt signalling pathway has shown to have some matter of regulation, but needs to be further probed. The Ras/Raf/Erk signalling pathway may control this change in $\mathrm{H} 2 \mathrm{AX}$ phosphorylation either by triggering a phosphatase or a dephosphatase. 
After examining the results, the following findings have been concluded; acute EGF stimulation decreases detection of $\gamma \mathrm{H} 2 \mathrm{AX}$, inhibition of the PI3K-Akt signalling pathway decreases $\gamma \mathrm{H} 2 \mathrm{AX}$ expression both in the absence of acute EGF, and inhibition of the Ras-Raf-Erk signalling pathway revserses the effect of EGF stimulation on $\gamma \mathrm{H} 2 \mathrm{AX}$ levels. This suggests that then effect of EGF stimulation to reduce $\gamma \mathrm{H} 2 \mathrm{AX}$ levels may be mediated by the Ras-MEK1-Erk signaling pathway downstream of EGFR.

It was determined that the addition of EGF for short periods of time (10 minutes) was sufficient to decrease $\gamma \mathrm{H} 2 \mathrm{AX}$ expression levels in cisplatin damaged cells. This provides insight into the mechanism that influences the DNA damage response in cells. A reduction in the $\gamma \mathrm{H} 2 \mathrm{AX}$ expression levels, a marker for DNA double strand breaks, suggests that activated EGFR is able to either trigger repair or mask the damage that has occurred. This observation then lead to the examination of a few of the signalling pathways that are well characterized in order to determine their influence on this phenomenon.

Inhibition of the PI3K-Akt pathway, by GDC0941, identified a possible influence in the DNA damage response of cisplatin damaged cells. It was determined that inhibition of the PI3KAkt signalling pathway was able to decrease $\gamma \mathrm{H} 2 \mathrm{AX}$ expression independent of EGF stimulation. This effect was not synergistic with EGF as there was no statistically significant difference in the condition with both agents present.

Inhibition of the Ras-Raf-Erk pathway, by PD98059, elucidated a possible role for the RasRaf-Erk signalling pathway to mediate the effects of EGFR activation on regulation of $\gamma \mathrm{H} 2 \mathrm{AX}$ levels. 
The findings suggest that although PI3K-Akt inhibition is able to reduce the levels of $\gamma \mathrm{H} 2 \mathrm{AX}$, this may reveal a function of PI3K-Akt signaling that is independent of EGF stimulated EGFR, as there was no reversal in the effect when both the inhibitor and EGF were present. Our model, Figure 18, shows that the pathway may have an additional component downstream of Akt which will alter the ability of H2AX to either be phosphorylated or dephosphorylated, without EGF stimulation being required. In contrast, the inhibition of MEK resulted in the reversal of the decreased $\gamma \mathrm{H} 2 \mathrm{AX}$ levels as seen by the addition of EGF. This suggests that the EGFR DNA damage response is regulated by the Ras/Raf/Erk signalling pathway, as inhibition of MEK reversed the decrease. Further probing into this pathway could elucidate how this is occurring. 


\subsection{FUTURE DIRECTIONS}

Building on the work that has been completed a further analysis of the signalling pathways and the protein-protein interactions could be completed to further elucidate the mechanisms underlying EGFR and the DNA damage response. The data accumulated thus far has shown that an inhibition of the Ras-Raf-Erk signalling pathway may alter the ability of EGFR to regulate the DNA damage response. This suggests that these pathways play a role in regulating the DNA damage response. However, additional experiments should be conducted to resolve the source of the interexpertimental variability. It is possible that EGF can elicit control of the DNA damage response only under specific conditions, including certain levels of cell-cell contact and/or specific composition of serum used for cell culture. Each of these paramaters could have been to some extend exhibited variability between experiments, thus perhaps leading to some of the variability in the effects of EGF and other agents on $\mathrm{H} 2 \mathrm{AX}$ phosphorylation. Future experiments that may systematically probe how parameters such as cell confluence and specific serum factors may alter the ability of EGFR to control H2AX phosphorylation can be conducted.

In addition, future experiments could also consider how the perturbation of clathrin may impact Ras localization at the plasma membrane. The Ras nanodomains have already been well characterized, by examining these nanodomains and the signalling complexes. However, whether and how the adaptors such as Grb2 and Shc1 as well as the Ras-GEF SOS that associate with EGFR at the plasma membrane and are require to trigger Ras activation may be controlled by clathrin remains to be determined. This can be examined using the MaMTH assay to detected interactions between EGFR, Shc1, Grb2 and SOS, and examine the effect of inhibition of clathrin via pitstop2 treatment. This may reveal how components of the signalling pathway responsible for regulation of the DNA damage response may be influenced by clathrin. 
To expand the work being done, we could return to the MaMTH assay to determine which of the many protein-protein interactions engaged by ligand-bound (activated) EGFR are controlled by clathrin. This would involve the use of clathrin inhibitors such as PitStop2 and Dynasore, both of which have been used extensively in our lab and have also been test run with the MaMTH assay, showing they can be used for extended periods of time without any drastic changes in cell morphology or viability. This would allow for an in-depth examination of the individual components that are required for the signalling response we have seen thus far.

Furthermore, the data has shown that inhibition of Akt does not alter the ability of EGF stimulated EGFR to decrease the presence of $\gamma \mathrm{H} 2 \mathrm{AX}$. This suggests that this pathway does contribute to the ability of EGFR to regulate the DNA damage response. It would nonetheless be interesting to examine the protein-protein interactions at the surface in the clathrin inhibited state to determine which interactions at the plasma membrane may play a role in the regulation of Akt signaling. The experiments completed have shown that it is possible to use PitStop2 for periods of up to 16 hours without any mass cell death, suggesting that such experiments would be possible without the use of more invasive methods such as siRNA.

As well, future experiments can examine more pathways that are involved in the DNA damage response, by determining which protein-protein interactions at the plasma membrane are perturbed by the inhibition of clathrin through a MaMTH assay. The proteins that are shown to have changed in interaction intensity can then be used to cross reference literature to see what other pathways are being affected by pitstop2 and therefore under the control of clathrin structures at the plasma membrane. We can then look into inhibiting these pathways and observing how they alter the detection of markers of DNA damage. 
Finally, we should complete follow-up experiments to 1). Show an alternate means of DNA damage creation and 2). Use another marker of DNA damage to show the effects are not specific only to $\gamma \mathrm{H} 2 \mathrm{AX}$. This could be completed through the use of reagents such as hydrogen peroxide $\left(\mathrm{H}_{2} \mathrm{O}_{2}\right)$ or other reactive oxidative species. As we were specifically observing the presence of double strand breaks, it would be beneficial to examine more possible sources in order to show a broader effect. An alternate marker of DNA damage would also help with this process as $\gamma \mathrm{H} 2 \mathrm{AX}$ is specific to double strand breaks and one location, using another marker would resolve whether the effects of EGFR signaling at to elicit H2AX dephosphorylation or to enhance the repair of DNA damage. 


\subsection{MATERIALS AND METHODS}

A variety of methods were used across the two laboratories at both the Ryerson University MaRS facility and the Štagljar group at the University of Toronto. The work completed varies from both the MaMTH assay and the bacterial culture work to working with breast cancer cells at Ryerson University. As a result all of the outlined protocols as presented below reflect the work completed.

\subsection{Cell culture of MDA-MB-231 cell line}

MDA-MB-231 cells (American Type Cell Culture) were grown in T75 flasks (Starstedt). Cells were passaged once confluent; the media was disposed of from the flask. The flask was then washed with $10 \mathrm{~mL}$ of phosphate buffered saline $1 \times(\mathrm{PBS})$ (Sigma Aldrich). The flask was shaken several times and the $1 \times$ PBS was disposed of in a waste beaker. $1 \mathrm{~mL}$ of $0.25 \%$ trypsin-EDTA $1 \times$ (Gibco) was then added to the flask and the flask was shaken several times in order to dislodge the cells. After observation under the light microscope it was seen that a sufficient number of cells had become round and were dislodged. A remaining 9mL of growth media, RPMI 1640 medium with $10 \%$ fetal bovine serum (FBS) and 1\% penicillin/streptomycin (Gibco) was added to the flask. The liquid in the flask was pipetted up and down along the walls of the flask several times and then transferred to a new flask. Depending on the date of experimentation and if seeding was occurring at the same time, the volume added to the new flask varied from $1.0 \mathrm{~mL}$ of cells and $9.0 \mathrm{~mL}$ of new growth media to $5.0 \mathrm{~mL}$ of cells and $5.0 \mathrm{~mL}$ of media. 


\subsection{Cell culture of HEK 293 cell line}

HEK 293 cells (University of Toronto) were grown in 10cm dishes (Starstedt). To passage once confluent; first the liquid was disposed of from the dish. The dish was then washed with 10mL of phosphate buffered saline $1 \times(\mathrm{PBS})$ (Sigma Aldrich). The dish was shaken several times and the $1 \times$ PBS was disposed of in a waste beaker. $1 \mathrm{~mL}$ of TrypLE (Gibco) was then added to the dish and the dish was shaken several times in order to dislodge the cells. After observation under the light microscope it was seen that a sufficient number of cells had become round and were dislodged. A remaining 9mL of growth media, DMEM F12 medium with $10 \%$ fetal bovine serum (FBS) and $1 \%$ penicillin/streptomycin (Gibco) was added to the dish. The liquid in the dish was pipetted up and down along the walls of the dish several times and then transferred to a new dish. Depending on the date of experimentation and if seeding was occurring at the same time, the volume added to the new dish varied from $1.0 \mathrm{~mL}$ of cells and $9.0 \mathrm{~mL}$ of new growth media to $5.0 \mathrm{~mL}$ of cells and $5.0 \mathrm{~mL}$ of media.

\subsection{Mammalian Membrane Two Hybrid Assay}

The HEK 293T cells from the Stagljar were used for this process, they were also provided from the lab. At $100 \%$ confluency the cells were treated with TrypLE (Gibco), then $1 \mathrm{~mL}$ of the cells was transferred to a $15 \mathrm{~mL}$ Falcon tube with $10 \mathrm{~mL}$ of $10 \%$ FBS media (Gibco). This mixture was vortexed and the cells were poured into a plastic reserve. A multi-channel pipette was then used to transfer $100 \mathrm{uL}$ to each well in a 96 well plate. After 24 hours, the cells were transfected with PEI solution. This process was done by creating two mixtures Mix A) required $2 \mathrm{uL}$ of PBS (Sigma Aldrich) and 0.4uL of the DNA plasmid per well and Mix B) required 2uL of PBS and 
$0.12 \mathrm{uL}$ of polyethylenimine (PEI) reagent (Invitrogen) per well $(1 \mathrm{mg} / \mathrm{mL})$. After Mix A and B are combined and pipetted up and down several times, they are left at room temperature for a period of 10 minutes, then $4 \mathrm{uL}$ of the combined solution is added to each well. $4-5$ hours after the transfection reagent has been added, the media is removed from the wells of the 96 well plate and replaced with new media mixtures containing tetracycline (T7660 Sigma Aldrich), PitStop2 (ab120687 abcam), and a combination of these additives. After a period of 16 hours, the luciferon (Milipore Sigma) (20nM) reagent is prepared, and left for 20-30 minutes in the dark to ensure homogeneity. 5uL of sample is taken from each well and transferred to a new "white plate" for the purpose of reading the bioluminescence produced from luciferase. Using the plate reader injector function $20 \mathrm{uL}$ of the luciferon mix was added to each well and the bioluminsence recorded in an excel spreadsheet that could then be used for further analysis.

\subsection{MDA-MB-231 Cell Seeding}

Coverslips for epifluorescence microscopy (VWR) were treated with $70 \%$ ethanol (Caledon) and flamed to sterilize. The MDA-MB-231 breast cancer cells were transferred to a 12 well plate (Grenier Bio-One) on the first day. To each well a total of $1 \mathrm{~mL}$ of the solution containing both cells and 10\% FBS growth media were added (Gibco). The amount of cell solution and growth media added varied as a result of the confluency of the cells prior to seeding, with an experiment day two confluency of $70-80 \%$ being optimal. At seeding the proportion of cells to media, if the flask was $100 \%$ confluent, is $4.2 \mathrm{~mL}$ of cells and $9.8 \mathrm{~mL}$ of media. 


\subsection{Cisplatin treatment of MDA-MB-231 cells}

On day 2, the wells are examined to determine the confluency of the cells. Optimally ranging from 70-80\% confluent. The cisplatin (\#ab141398 abcam) was prepared in the fume hood, the investigator was required to place a disposable gown on, as well as double gloving in order to ensure that there is no risk of contact with the powder form. Any tips, as well as all material used was disposed of separately or disinfected. The cisplatin was dissolved in dimethyl sulfoxide (DMSO) (\#DMS666 Bioshop) and made at a concentration of 150mM in a microcentrifuge tube. Once dissolved the cisplatin could be transported out of the fume hood and brought to the tissue culture room. The $150 \mathrm{mM}$ cisplatin stock would be diluted 1:5 (30mM) in 0.1\% FBS media, and further serially diluted 1:1000 $(30 \mathrm{uM})$ in an appropriate amount of media to cover the required wells. Once the solution was prepared the wells were aspirated of the $10 \%$ FBS media, and washed once with DPBS. Afterwards the cisplatin was added to the appropriate wells, and the 12 well plates were returned to the incubator for 15 hours.

\subsection{PI3K and ERK Inhibitor Treatment of MDA-MB-231 cells with, GDC 0941 and PD98059}

The wells were labelled according to the conditions that were to be used, cisplatin (\#ab141398 abcam), dimethyl sulfoxide (DMSO), (\#DMS666 Bioshop), GDC0941 (\#ab141352 abcam), or PD98059 (\#9900 Cell Signalling Technology), and later epidermal growth factor (\#PHG0311 Gibco). On day 3, the previously described inhibitors were added to the respective wells, the inhibitor solutions were created by adding the appropriate volume of inhibitor to a coinciding volume of $0.1 \%$ FBS media. The GDC0941 and PD98059 solution was created as a 1:1000 dilution (10 and $20 \mathrm{uM}$ respectfully), first completed in a 1:10 through the addition of the 
stock to $0.1 \%$ FBS media in a microcentrifuge tube and then from this a 1:100 dilution as a determined amount of the new diluted stock was added drop wise directly to the wells. For solution mixes with multiple inhibitors; the inhibitors were added together to the same volume, DMSO was added in a dilution that matched that of the highest concentration of inhibitor present. After the inhibitors were added, the 12 well plate was returned to the incubator for a period of 50 minutes. Upon the expiry of the 50 minute period, epidermal growth factor was added to appropriate wells dropwise at a concentration of $20 \mathrm{ng} / \mathrm{uL}$ for a period of 10 minutes.

\subsection{Immunofluorescence Microscopy}

After the incubation period had ended the plates were put on ice and the media was aspirated and replaced with $1 \mathrm{~mL} /$ well of $4 \%$ paraformaldehyde for a period of 30 minutes in the dark (15710 Electron Microscopy Sciences) Next, the 4\% paraformaldehyde solution was aspirated from the wells and replaced with $1 \mathrm{~mL} /$ well of $100 \mathrm{mM}$ glycine and then $100 \mathrm{mM}$ glycine $+\mathrm{TX}-100$ for periods of 10 minutes each respectively. The wells were then washed twice with PBS + and 3\% bovine serum albumin was put in the wells having the plates incubate for 15 minutes (\#ALB005.100 BioShop). The coverslips (VWR) were then flipped onto the cover of the well plate which had been covered in Parafilm and $200 \mu \mathrm{L}$ of the primary antibody spotted onto it. The primary antibody solution had been prepared by adding in a 1:200 dilution the Phospho-Histone H2A.X (Ser139) (20E3) Rabbit mAb (\#9718 Cell Signalling Technology) to the respective volume of cold $1 \%$ bovine serum albumin (BSA) that was stored in in the $4^{\circ} \mathrm{C}$ refrigerator. The $1 \%$ BSA was prepared by adding $0.3 \mathrm{~g}$ of cold albumin to $30 \mathrm{~mL}$ of PBS+. The coverslips were then put in the dark for 1 hour. After the 1 hour time period expired the coverslips were returned to the respective well and washed with the PBS+ (once quickly, twice for 5 minutes on the shake table, 
and once quickly again). The secondary antibody solution was created by adding donkey antirabbit IgG (H+L) secondary antibody, Alexa Fluor 647 (\#711-605-650 Jackson Immuno Research) in a $1: 400$ dilution to $1 \% \mathrm{BSA} .750 \mu \mathrm{L}$ of the secondary antibody solution was then added to each of the wells. The 12 well plate was then placed in the dark for 1 hour. After the 1 hour time period the cells were washed PBS+ (once quickly, twice for 5 minutes on the shake table, and once quickly again). $1 \mathrm{~mL}$ of the DAPI solution was added (Roche Diagnostics) which was created as a 1:15000 dilution with PBS+ was added to each well and left for 5 minutes in the dark. The wells were then washed 5 times quickly with PBS+. The coverslips were then removed from the wells and mounted to the slides (VWR) using a single drop of DAKO fluorescent mounting media (DAKO).

\subsection{Imaging by fluorescence microscopy}

Wide-field epifluorescence was performed on an Olympus IX83 inverted microscope with a $\times 60$ objective, coupled to a Hamamatsu ORCA-Flash4.0 digital camera (Olympus Canada, Richmond Hill, Canada). The exposure time and brightness settings were determined by first using the cisplatin positive control condition. Once the exposure and brightness settings were determined they remained unchanged for the rest of the images in the individual experiments. For each experiment, approximately 10 images/condition were taken.

\subsection{Image Analysis}

ImageJ was used to accumulate the data for each of the images. Both the DAPI and CY5 channel were opened in the software. On the toolbar, the "Freehand" tool was selected, in the DAPI channel the individual nuclei were manually delineated and recorded as regions of interest. 
Once all of the nuclei were recorded, the CY5 channel was entered and the region of interests applied. Once again using the "Freehand" tool, an area of background was selected. In both the nucleus and background regions of interest, the mean fluorescence intensity corresponding to the H2AX phosphorylation stain was recorded. For each individual cell measurement, each individual value had the background subtracted from the individual mean fluorescent intensity recorded from the nucleus (corrected value). Then, for each "corrected value" was normalized to the mean of the "corrected value" measured in the cisplatin-only treated positive control (normalized corrected value. This data was then transferred to the GraphPad program (Prism) to complete statistical analysis. For data with more than two experimental conditions, the statistical analysis used was one way ANOVA (both parametric and non-parametric) with Tukey post-test. 


\section{REFERENCES}

Abulaiti, A., Fikaris, A.J., Tsygankova, O.M., and Meinkoth, J.L. (2006). Ras induces

chromosome instability and abrogation of the DNA damage response. Cancer Res. 66, 1050510512.

Ballou, L.M., and Lin, R.Z. (2008). Rapamycin and mTOR kinase inhibitors. J. Chem. Biol. 1, $27-36$.

Batzer, A.G., Rotin, D., Ureña, J.M., Skolnik, E.Y., and Schlessinger, J. (1994). Hierarchy of binding sites for Grb2 and Shc on the epidermal growth factor receptor. Mol. Cell. Biol. 14, $5192-5201$.

Borrego-Soto, G., Ortiz-López, R., and Rojas-Martínez, A. (2015). Ionizing radiation-induced DNA injury and damage detection in patients with breast cancer. Genet. Mol. Biol. 38, 420-432.

Burgess, A.W. (2008). EGFR family: Structure physiology signalling and therapeutic targets ${ }^{\dagger}$. Growth Factors 26, 263-274.

Chappie, J.S., Mears, J.A., Fang, S., Leonard, M., Schmid, S.L., Milligan, R.A., Hinshaw, J.E., and Dyda, F. (2011). A pseudoatomic model of the dynamin polymer identifies a hydrolysisdependent powerstroke. Cell 147, 209-222.

Chou, R.-H., Wang, Y.-N., Hsieh, Y.-H., Li, L.-Y., Xia, W., Chang, W.-C., Chang, L.-C., Cheng, C.-C., Lai, C.-C., Hsu, J.L., et al. (2014). EGFR modulates DNA synthesis and repair through Tyr phosphorylation of histone H4. Dev. Cell 30, 224-237.

Conner, S.D., and Schmid, S.L. (2003). Regulated portals of entry into the cell. Nature 422, 3744. 
Cutter, A.R., and Hayes, J.J. (2015). A brief review of nucleosome structure. FEBS Lett. 589, 2914-2922.

Dasari, S., and Tchounwou, P.B. (2014). Cisplatin in cancer therapy: molecular mechanisms of action. Eur. J. Pharmacol. 740, 364-378.

Davis, A.J., and Chen, D.J. (2013). DNA double strand break repair via non-homologous endjoining. Transl. Cancer Res. 2, 130-143.

Delos Santos, R.C., Garay, C., and Antonescu, C.N. (2015). Charming neighborhoods on the cell surface: Plasma membrane microdomains regulate receptor tyrosine kinase signaling. Cell. Signal. 27, 1963-1976.

Delos Santos, R.C., Bautista, S., Lucarelli, S., Bone, L.N., Dayam, R.M., Abousawan, J., Botelho, R.J., and Antonescu, C.N. (2017). Selective regulation of clathrin-mediated epidermal growth factor receptor signaling and endocytosis by phospholipase $\mathrm{C}$ and calcium. Mol. Biol. Cell 28, 2802-2818.

Douglass Wright, W., Shah, S.S., and Heyer, W.-D. (2018). Homologous recombination and the repair of DNA double-strand breaks. J. Biol. Chem.

Dutta, D., Williamson, C.D., Cole, N.B., and Donaldson, J.G. (2012). Pitstop 2 is a potent inhibitor of clathrin-independent endocytosis. PLoS One 7, e45799.

Ehrhardt, M., Craveiro, R.B., Holst, M.I., Pietsch, T., and Dilloo, D. (2015). The PI3K inhibitor GDC-0941 displays promising in vitro and in vivo efficacy for targeted medulloblastoma therapy. Oncotarget 6.

Eichel, K., Jullié, D., and von Zastrow, M. (2016). $\beta$-Arrestin drives MAP kinase signalling from 
clathrin-coated structures after GPCR dissociation. Nat. Cell Biol. 18, 303-310.

Eichel, K., Jullié, D., Barsi-Rhyne, B., Latorraca, N.R., Masureel, M., Sibarita, J.-B., Dror, R.O., and von Zastrow, M. (2018). Catalytic activation of $\beta$-arrestin by GPCRs. Nature 557, 381-386.

Er, E.E., Mendoza, M.C., Mackey, A.M., Rameh, L.E., and Blenis, J. (2013). AKT facilitates EGFR trafficking and degradation by phosphorylating and activating PIKfyve. Sci. Signal. 6 , ra45.

Di Fiore, P.P., and von Zastrow, M. (2014). Endocytosis, signaling, and beyond. Cold Spring Harb. Perspect. Biol. 6.

Freed, D.M., Bessman, N.J., Kiyatkin, A., Salazar-Cavazos, E., Byrne, P.O., Moore, J.O., Valley, C.C., Ferguson, K.M., Leahy, D.J., Lidke, D.S., et al. (2017). EGFR Ligands Differentially Stabilize Receptor Dimers to Specify Signaling Kinetics. Cell 171, 683-695.e18.

Funk, J.O. (2005). Cell Cycle Checkpoint Genes and Cancer. In Encyclopedia of Life Sciences, (Chichester, UK: John Wiley \& Sons, Ltd), pp. 1-6.

Funk, J.O. (2006). Cell Cycle Checkpoint Genes and Cancer. In Encyclopedia of Life Sciences, (Chichester, UK: John Wiley \& Sons, Ltd), p.

Garay, C., Judge, G., Lucarelli, S., Bautista, S., Pandey, R., Singh, T., and Antonescu, C.N. (2015a). Epidermal growth factor-stimulated Akt phosphorylation requires clathrin or ErbB2 but not receptor endocytosis. Mol. Biol. Cell 26, 3504-3519.

Garay, C., Judge, G., Lucarelli, S., Bautista, S., Pandey, R., Singh, T., and Antonescu, C.N. (2015b). Epidermal growth factor-stimulated Akt phosphorylation requires clathrin or ErbB2 but not receptor endocytosis. Mol. Biol. Cell 26, 3504-3519. 
Giglia-Mari, G., Zotter, A., and Vermeulen, W. (2011). DNA damage response. Cold Spring Harb. Perspect. Biol. 3, a000745.

Goh, L.K., and Sorkin, A. (2013). Endocytosis of receptor tyrosine kinases. Cold Spring Harb. Perspect. Biol. 5, a017459.

Goh, L.K., Huang, F., Kim, W., Gygi, S., and Sorkin, A. (2010). Multiple mechanisms collectively regulate clathrin-mediated endocytosis of the epidermal growth factor receptor. J. Cell Biol. 189, 871-883.

Hall, M.D., Telma, K.A., Chang, K.E., Lee, T.D., Madigan, J.P., Lloyd, J.R., Goldlust, I.S., Hoeschele, J.D., and Gottesman, M.M. (2014). Say no to DMSO: Dimethylsulfoxide inactivates cisplatin, carboplatin, and other platinum complexes. Cancer Res. 74, 3913-3922.

Hanahan, D., and Weinberg, R.A. (2011). Hallmarks of cancer: The next generation. Cell 144, $646-674$.

Huang, Z., Wang, Y., Nayak, P.S., Dammann, C.E., and Sanchez-Esteban, J. (2012). Stretchinduced fetal type II cell differentiation is mediated via ErbB1-ErbB4 interactions. J. Biol. Chem. 287, 18091-18102.

Huse, M., and Kuriyan, J. (2002). The conformational plasticity of protein kinases. Cell 109, $275-282$.

Irannejad, R., Tsvetanova, N.G., Lobingier, B.T., and von Zastrow, M. (2015). Effects of endocytosis on receptor-mediated signaling. Curr. Opin. Cell Biol. 35, 137-143.

Jackson, S.P. (2002). Sensing and repairing DNA double-strand breaks. Carcinogenesis 23, 687696. 
Jackson, S.P., and Bartek, J. (2009). The DNA-damage response in human biology and disease. Nature 461, 1071-1078.

Kholodenko, B.N., Demin, O. V, Moehren, G., and Hoek, J.B. (1999). Quantification of short term signaling by the epidermal growth factor receptor. J. Biol. Chem. 274, 30169-30181.

Kim, R.-K., Suh, Y., Yoo, K.-C., Cui, Y.-H., Kim, H., Kim, M.-J., Gyu Kim, I., and Lee, S.-J. (2015). Activation of KRAS promotes the mesenchymal features of basal-type breast cancer. Exp. Mol. Med. 47, e137.

Lemmon, M.A., and Schlessinger, J. (2010). Cell signaling by receptor tyrosine kinases. Cell $141,1117-1134$.

Leyton-Puig, D., Isogai, T., Argenzio, E., van den Broek, B., Klarenbeek, J., Janssen, H., Jalink, K., and Innocenti, M. (2017). Flat clathrin lattices are dynamic actin-controlled hubs for clathrinmediated endocytosis and signalling of specific receptors. Nat. Commun. 8, 16068.

Li, L., Zhao, G.-D., Shi, Z., Qi, L.-L., Zhou, L.-Y., and Fu, Z.-X. (2016). The Ras/Raf/MEK/ERK signaling pathway and its role in the occurrence and development of HCC. Oncol. Lett. 12, 3045-3050.

Liang, J., and Slingerland, J.M. (2003). Multiple Roles of the PI3K/PKB (Akt) Pathway in Cell Cycle Progression. Cell Cycle 24, 339-345.

Liashkovich, I., Pasrednik, D., Prystopiuk, V., Rosso, G., Oberleithner, H., and Shahin, V. (2015). Clathrin inhibitor Pitstop-2 disrupts the nuclear pore complex permeability barrier. Sci. Rep. 5, 9994.

LoPiccolo, J., Blumenthal, G.M., Bernstein, W.B., and Dennis, P.A. (2008). Targeting the 
PI3K/Akt/mTOR pathway: effective combinations and clinical considerations. Drug Resist. Updat. $11,32-50$.

Lu, S.M., and Fairn, G.D. (2018). Mesoscale organization of domains in the plasma membrane beyond the lipid raft. Crit. Rev. Biochem. Mol. Biol. 53, 192-207.

Lucarelli, S., Pandey, R., Judge, G., and Antonescu, C.N. (2016a). Similar requirement for clathrin in EGF- and HGF- stimulated Akt phosphorylation. Commun. Integr. Biol. 9, e1175696.

Lucarelli, S., Pandey, R., Judge, G., and Antonescu, C.N. (2016b). Similar requirement for clathrin in EGF- and HGF- stimulated Akt phosphorylation. Commun. Integr. Biol. 9, e1175696.

Lucarelli, S., Delos Santos, R.C., and Antonescu, C.N. (2017). Measurement of Epidermal Growth Factor Receptor-Derived Signals Within Plasma Membrane Clathrin Structures. In Methods in Molecular Biology (Clifton, N.J.), pp. 191-225.

Luria, S.E., and Delbruck, M. (1943). MUTATIONS OF BACTERIA FROM VIRUS SENSITIVITY TO VIRUS RESISTANCE'-’.

Matallanas, D., Arozarena, I., Berciano, M.T., Aaronson, D.S., Pellicer, A., Lafarga, M., and Crespo, P. (2003). Differences on the inhibitory specificities of H-Ras, K-Ras, and N-Ras (N17) dominant negative mutants are related to their membrane microlocalization. J. Biol. Chem. 278, $4572-4581$.

Mattoon, D.R., Lamothe, B., Lax, I., and Schlessinger, J. (2004). The docking protein Gab1 is the primary mediator of EGF-stimulated activation of the PI-3K/Akt cell survival pathway. BMC Biol. 2, 24.

McCubrey, J.A., Steelman, L.S., Chappell, W.H., Abrams, S.L., Wong, E.W.T., Chang, F., 
Lehmann, B., Terrian, D.M., Milella, M., Tafuri, A., et al. (2007). Roles of the Raf/MEK/ERK pathway in cell growth, malignant transformation and drug resistance. Biochim. Biophys. Acta $1773,1263-1284$.

McCubrey, J.A., Steelman, L.S., Chappell, W.H., Abrams, S.L., Montalto, G., Cervello, M., Nicoletti, F., Fagone, P., Malaponte, G., Mazzarino, M.C., et al. (2012). Mutations and deregulation of Ras/Raf/MEK/ERK and PI3K/PTEN/Akt/mTOR cascades which alter therapy response. Oncotarget 3, 954-987.

McCulloch, S.D., and Kunkel, T.A. (2008). The fidelity of DNA synthesis by eukaryotic replicative and translesion synthesis polymerases. Cell Res. 18, 148-161.

McMahon, H.T., and Boucrot, E. (2011). Molecular mechanism and physiological functions of clathrin-mediated endocytosis. Nat. Rev. Mol. Cell Biol. 12, 517-533.

McPherson, P.S., Ritter, B., and Wendland, B. (2013). Clathrin-Mediated Endocytosis.

Mendoza, M.C., Er, E.E., and Blenis, J. (2011). The Ras-ERK and PI3K-mTOR pathways: crosstalk and compensation. Trends Biochem. Sci. 36, 320-328.

Mettlen, M., Chen, P.-H., Srinivasan, S., Danuser, G., and Schmid, S.L. (2018). Regulation of Clathrin-Mediated Endocytosis. Annu. Rev. Biochem. 87, 871-896.

Miaczynska, M., and Bar-Sagi, D. (2010). Signaling endosomes: seeing is believing. Curr. Opin. Cell Biol. 22, 535-540.

Miettinen, P.J., Berger, J.E., Meneses, J., Phung, Y., Pedersen, R.A., Werb, Z., and Derynck, R. (1995). Epithelial immaturity and multiorgan failure in mice lacking epidermal growth factor receptor. Nature 376, 337-341. 
Oda, K., Matsuoka, Y., Funahashi, A., and Kitano, H. (2005). A comprehensive pathway map of epidermal growth factor receptor signaling. Mol. Syst. Biol. 1, 2005.0010.

Olivier, M., Hollstein, M., and Hainaut, P. (2010). TP53 mutations in human cancers: origins, consequences, and clinical use. Cold Spring Harb. Perspect. Biol. 2, a001008.

Pálfy, M., Reményi, A., and Korcsmáros, T. (2012). Endosomal crosstalk: meeting points for signaling pathways. Trends Cell Biol. 22, 447-456.

Platta, H.W., and Stenmark, H. (2011). Endocytosis and signaling. Curr. Opin. Cell Biol. 23, 393-403.

Porta, C., Paglino, C., and Mosca, A. (2014). Targeting PI3K/Akt/mTOR Signaling in Cancer. Front. Oncol. 4, 64.

Ramachandran, R., and Schmid, S.L. (2018). The dynamin superfamily. Curr. Biol. 28, R411R416.

Rosselli-Murai, L.K., Yates, J.A., Yoshida, S., Bourg, J., Ho, K.K.Y., White, M., Prisby, J., Tan, X., Altemus, M., Bao, L., et al. (2018). Loss of PTEN promotes formation of signaling-capable clathrin-coated pits. J. Cell Sci. 131, jcs208926.

Sáez, G.T. (2018). DNA Injury and Repair Systems. Int. J. Mol. Sci. 19.

Sambrook, J., and Russell, D.W. (2005). Identification of associated proteins by coimmunoprecipitation. Nat. Methods 2, 475-476.

Saraon, P., Grozavu, I., Lim, S.H., Snider, J., Yao, Z., and Stagljar, I. (2017). Detecting Membrane Protein-protein Interactions Using the Mammalian Membrane Two-hybrid (MaMTH) Assay. In Current Protocols in Chemical Biology, (Hoboken, NJ, USA: John Wiley \& Sons, 
Inc.), pp. $38-54$.

Sarker, D., Ang, J.E., Baird, R., Kristeleit, R., Shah, K., Moreno, V., Clarke, P.A., Raynaud, F.I., Levy, G., Ware, J.A., et al. (2015). First-in-human Phase I study of Pictilisib (GDC-0941), a potent pan-class I phosphatidylinositol-3-kinase (PI3K) inhibitor, in patients with advanced solid tumors. Clin. Cancer Res. 21, 77.

Scaltriti, M., and Baselga, J. (2006). The epidermal growth factor receptor pathway: a model for targeted therapy. Clin. Cancer Res. 12, 5268-5272.

Schlessinger, J. (2000). Cell signaling by receptor tyrosine kinases. Cell 103, 211-225.

Schmid, S.L. (2017). Reciprocal regulation of signaling and endocytosis: Implications for the evolving cancer cell. J. Cell Biol. 216, 2623-2632.

Schmid, E.M., and McMahon, H.T. (2007). Integrating molecular and network biology to decode endocytosis. Nature 448, 883-888.

Sorkin, A., and Goh, L.K. (2009). Endocytosis and intracellular trafficking of ErbBs. Exp. Cell Res. 315, 683-696.

Sugiyama, M.G., Fairn, G.D., and Antonescu, C.N. (2019). Akt-ing Up Just About Everywhere: Compartment-Specific Akt Activation and Function in Receptor Tyrosine Kinase Signaling. Front. Cell Dev. Biol. 7, 70.

Todd, R., Hinds, P.W., Munger, K., Rustgi, A.K., Opitz, O.G., Suliman, Y., and Wong, D.T. (2002). Cell cycle dysregulation in oral cancer. Crit. Rev. Oral Biol. Med. 13, 51-61.

Villaseñor, R., Kalaidzidis, Y., and Zerial, M. (2016). Signal processing by the endosomal system. Curr. Opin. Cell Biol. 39, 53-60. 
von Kleist, L., Stahlschmidt, W., Bulut, H., Gromova, K., Puchkov, D., Robertson, M.J., MacGregor, K.A., Tomilin, N., Pechstein, A., Chau, N., et al. (2011). Role of the Clathrin Terminal Domain in Regulating Coated Pit Dynamics Revealed by Small Molecule Inhibition. Cell 146, 471-484.

Wang, D., and Lippard, S.J. (2005). Cellular processing of platinum anticancer drugs. Nat. Rev. Drug Discov. 4, 307-320.

Wang, K., Yamamoto, H., Chin, J.R., Werb, Z., and Vu, T.H. (2004). Epidermal growth factor receptor-deficient mice have delayed primary endochondral ossification because of defective osteoclast recruitment. J. Biol. Chem. 279, 53848-53856.

Watcharasit, P., Bijur, G.N., Zmijewski, J.W., Song, L., Zmijewska, A., Chen, X., Johnson, G.V.W., and Jope, R.S. (2002). Direct, activating interaction between glycogen synthase kinase3beta and p53 after DNA damage. Proc. Natl. Acad. Sci. U. S. A. 99, 7951-7955.

Willox, A.K., Sahraoui, Y.M.E., and Royle, S.J. (2014). Non-specificity of Pitstop 2 in clathrinmediated endocytosis. Biol. Open 3, 326-331.

Xu, Y., Li, N., Xiang, R., and Sun, P. (2014). Emerging roles of the p38 MAPK and PI3K/AKT/mTOR pathways in oncogene-induced senescence. Trends Biochem. Sci. 39, 268276.

Xu, Z., Shao, J., Li, L., Peng, X., Chen, M., Li, G., Yan, H., Yang, B., Luo, P., and He, Q. (2016). All-trans retinoic acid synergizes with topotecan to suppress AML cells via promoting RAR $\alpha$-mediated DNA damage. BMC Cancer 16, 2.

Yao, Z., Darowski, K., St-Denis, N., Wong, V., Offensperger, F., Villedieu, A., Amin, S., Malty, 
R., Aoki, H., Guo, H., et al. (2017). A Global Analysis of the Receptor Tyrosine Kinase-Protein Phosphatase Interactome. Mol. Cell 65, 347-360.

Zhang, X., Gureasko, J., Shen, K., Cole, P.A., and Kuriyan, J. (2006). An allosteric mechanism for activation of the kinase domain of epidermal growth factor receptor. Cell 125, 1137-1149.

Zheng, Y., Zhang, C., Croucher, D.R., Soliman, M.A., St-Denis, N., Pasculescu, A., Taylor, L., Tate, S.A., Hardy, W.R., Colwill, K., et al. (2013). Temporal regulation of EGF signalling networks by the scaffold protein Shc1. Nature 499, 166-171. 